Florida International University

FIU Digital Commons

FIU Electronic Theses and Dissertations

University Graduate School

$11-9-2017$

\title{
An Exploration of Black National Pan-Hellenic Council (NPHC) Sorority Membership as it Relates to Academic Achievement and Civic Engagement
}

Canela Eatman

Florida International University, Canela.Eatman@fiu.edu

DOI: 10.25148 /etd.FIDC004044

Follow this and additional works at: https://digitalcommons.fiu.edu/etd

Part of the Higher Education Commons

\section{Recommended Citation}

Eatman, Canela, "An Exploration of Black National Pan-Hellenic Council (NPHC) Sorority Membership as it Relates to Academic Achievement and Civic Engagement" (2017). FIU Electronic Theses and Dissertations. 3518.

https://digitalcommons.fiu.edu/etd/3518 


\section{FLORIDA INTERNATIONAL UNIVERSITY}

Miami, Florida

\section{AN EXPLORATION OF BLACK NATIONAL PAN-HELLENIC COUNCIL (NPHC) SORORITY MEMBERSHIP AS IT RELATES TO ACADEMIC ACHIEVEMENT AND CIVIC ENGAGEMENT}

A proposal submitted in partial fulfillment of the requirements for the degree of

DOCTOR OF EDUCATION

in

HIGHER EDUCATION ADMINISTRATION

by

Canela Una Acosta Eatman

2017 
To: $\quad$ Dean Michael R. Heithaus

College of Arts, Sciences and Education

This dissertation, written by Canela Una Acosta Eatman, and titled An Exploration of Black, National Pan-Hellenic Council (NPHC) Sorority Membership as it Relates to Academic Achievement and Civic Engagement having been approved in respect to style and intellectual content, is referred to you for judgment.

We have read this dissertation and recommend that it be approved.

Glenda D. Musoba

Dawn E. Addy

Thomas G. Reio

Tonette S. Rocco, Major Professor

Date of Defense: November 9, 2017

The dissertation of Canela Una Acosta Eatman is approved.

Dean Michael R. Heithaus College of Arts, Sciences and Education

Andrés G. Gil

Vice President Research and Economic Development and Dean of the University Graduate School

Florida International University, 2017 
(C) Copyright 2017 by Canela Una Acosta Eatman

All rights reserved. 


\section{DEDICATION}

To Mami, Carmen Rose Acosta, thank you for being you. Knowing when I was spent and when to push me. While you gave ample tough love, under it were prayers for my well-being and maintaining discernment. You are part of the reason I am able to continue my pursuits in education. The other part is Wheta, my abuela, Felicita Torres. I cannot thank you enough. Though your physical is no longer here, I talk to you often. I rely on the lessons you taught me though your formal education ceased at the third grade. I can still hear you, cogelo suave, y así va a terminar. Mami and Wheta, gave me the tools necessary to get through this process and I thank you both, for your endless support, from the bottom of my heart.

This is also dedicated to the most thorough borough, BK! Brooklyn! There is a strength that I pull from my birth place daily, but especially in adversity. And this doctorate process beckoned some rather adverse times, but Brooklyn prepared me with a myriad of lessons in resilience. Having been born in Brooklyn Hospital, attending Brooklyn Technical high school (go Engineers), and the public schools I attended in between, there is a pride that was instilled both in the classroom and the hallways. The countless musicians and rappers from my birthplace that spoke of their failed tries, followed by amazing triumphs, they never neglected to big up Brooklyn! So, who am I to break tradition... Brooklyn, we did it! 


\section{ACKNOWLEDGMENTS}

First and foremost, I thank God and the Ancestors for keeping me and letting me know that this work I am doing is greater than me. They reminded me, the shoulders that I stand on are resilient and I am too.

I must express my deepest gratitude to my committee members, Dr. Glenda D. Musoba, Dr. Dawn E. Addy, Dr. Thomas G. Reio, and Dr. Tonette S. Rocco. I am particularly grateful to my chair Dr. Rocco for her unique guidance, support, and, most

importantly, for never giving up on me. She has been a continual motivating factor in my educational journey.

I will take a bit of a cue from Issa Rae and would also like to acknowledge all the Black students in the various doctorate programs at FIU, Chaundra Whitehead, Keisha Hill-Grey, Judy Bernier, and Greg Salters, who supported me in this process because they knew the odds were not in my favor but they wanted to see me win!

And I must also acknowledge the less melinated but just as important FIU doc candidate, Lori Ann Gionti for taking time to go through my proposal line-by-line. It was so extremely helpful to my growth and understanding, thank you!

I'd be remiss if I didn't acknowledge all the HBCUs that have added to my edification, Norfolk State, Morgan State, and my Home by the Sea, the thought sent from heaven above, Hampton University. Thee Hampton University has given me the foundation to believe that it's possible, to dream no small dream, and to know that, vision 
without action is dreaming but action without vision is drudgery, thank you Dr. William Harvey. It's time for some [more] action!

This part, this part right here, it can only be properly done by endearingly renaming it, Big Ups \& Shout Outs. And so, moving forward, that is in fact what these are, and in no particular order, I must acknowledge my big sister Chris, from telling me to go to class in high school when I didn't feel like it to that needed signature, forever, grateful and love ya!

My $\Delta \mathrm{Z} \& \mathrm{Z} \Gamma$ Sorors and Frat, Jah, Tamika, Dai, Will, Orlando, Rodney, Shak, and the whole IS 2.0 for checking on me and reminding me to live a little. Feeding the spirit is what they did and I'm forever grateful. Bush, my funny little SiStar \& Zelta, thank you! Rho Alpha Sorors, specifically Kelsi, Rana, Saidah, and Treasure, thank you! I must give the solo dolo shout to my, LS, Elena, this is for both of us. Thank you for paving the way! Pi Pi \& Lambda Tau Sorors and Frat, big ups to Addy (your corner of my degree awaits - lol), Bethy, Missy, Nina, Nadege, Markie-Mark, and Renee, the good times, the challenges, and the hospital visits. Big ups to y'all for never wavering in support! The countless members of NPHC, and why I know this dissertation was even a thing, because I lived their care and kindness day in and day out. Shout outs to Coach Cailah for getting my spirit and body back in the gym, Kimeka for the energy and prayers to get me to this very point in the journey and beyond, Cristina for always keeping it a buck and sticking around for vent and salsa sessions, Shica for the laughs and thoughtfulness, Karmia and Dingle for loving me as I am, Yumi for simply being that Brooklyn breath of fresh air, Zakiya and Ashlyn for being plain old fun when I probably 
wouldn't, Keion for checking on me and getting us to the Million Man March and back in the middle of Hampton homecoming because - important, Shaundau for being a consummate supporter, Corinne for the prayers and laughs - but those prayers - they got me through. Ryan for allowing me room and space to think, Malik for the fried fish that fed my tummy and spirit every homecoming, but for also just checking on me, Neil, my Frat that helped me move when I couldn't figure out the logistics and last but not least my immediate supervisor, Justin who gave me the needed time off to handle business, Dr. Hall, we're waiting on you!

Colossal big ups to church family at Pembroke Park Church of Christ, particularly Chanell and Raheim, the assistance and push to find a church home especially since I move pretty often, was needed, thank you! The Facebook funnies are always welcome, Chanell. Raheim, unselfishly giving your time and energy during my surgery recovery, always grateful—love you.

Massive big up to my Primas \& Primos of $\Sigma \Lambda \Gamma$ and $\Sigma \Lambda \mathrm{B}$, particularly Shirley and Byron, we may not always see eye-to-eye but growth is always the outcome, gracias por todito!

Big ups to the whole TTF massive! Track Team Forever, Brooklyn Tech Track! Taneka, Jo-Jo, Janelle, Sei, Tyn-Tyn, Princess, Sabrina, Florcie, Jennifer, Tasha, and Nakia, love you to life, ladies! And of course Tracee, Kelly, Fran, January, and Amy of Hampton University's Women's Track Team, thank you for laughs and encouragement, over the years. 
Morgan State staff definitely held me down during the last leg of this journey. Big ups to Chad, my fellow RD, for being an ear, the jokes, and the tag-team on workshopsyou're up next! And the Director of Residence Life, Dr. Gwynn, thank you for understanding. You knew what time it was and you let me do what was needed. Thanks, fellas!

I always heard people say get off Facebook, you're on Twitter too much, you need not post of Instagram, and texting should be kept to a minimum, and to that I say, acknowledged and untrue. The prayers via inbox and on my wall, propelled me to continue. The groups I was thrown into by Facebook friends, connected me with other supporters I never knew existed. And the private groups, oh, the private groups. Corinne and Rikesha, my Hamptonian homies, we've cried on video chat, laughed, dance, sang hymnals, and written chapters-you can't tell me Facebook isn't God's work. My girls, Yashica and Kimeka, group dynamics are amazing. Knowing that at 3:32am one of us is probably up to support the other, is enough to keep me sane. Randomly meeting the homie, Court and keeping up with her via Twitter and Instagram because her posts are hilarious as well as inspiring. Niki, my Junior year neighbor in Queen St Hall, helping me stay focused while I became a Zeta and your words of encouragement on social media and in person. Thank you, ladies.

Like Bleek said in It's Alright_- everything left out, you can blame it on the brain, not the heart, I'm playing my part, stretched out, just about the best out... and to complete 
my thought, I'll pull from Jay Z—Je t'adore, that means I love you, of course I love you... I love all y'all —For real!!

Last but surely not least, as Black women rarely do, I want to acknowledge myself during this process. From being homeless, to laying family members to rest, to three surgeries in this year alone, numerous employment mismatches, ignoring those that scoffed at my idea of becoming a doctor and the others that guffawed as the calendar pages turned and I had yet to attain my Ed. D, through all of that, I must acknowledge self. I am thankful for my resilience, resolve, and faith. Look Mami, WE made it! I's a doctor now! 


\author{
ABSTRACT OF THE DISSERTATION \\ AN EXPLORATION OF BLACK NATIONAL PAN-HELLENIC COUNCIL (NPHC) \\ SORORITY MEMBERSHIP AS IT RELATES TO ACADEMIC ACHIEVEMENT AND \\ CIVIC ENGAGEMENT \\ by \\ Canela Una Acosta Eatman
}

Florida International University, 2017

Miami, Florida

Professor Tonette S. Rocco, Major Professor

The purpose of the study was to explore the experience of 13 Black, National PanHellenic Council (NPHC) sorority members as they relate to their academic achievement and civic engagement. Participants were female, upperclassmen students at four different Historically Black Colleges and Universities (HBCUs), half private and the other public. Criterion, purposive, and snowball sampling were used to secure participants.

Using the Community of Practice as a theoretical framework, which is comprised of five stages, participants' experiences were described, analyzed, and interpreted to inform the study. Data were collected through individual phone interviews, using a semistructured interview protocol, and were analyzed using inductive analysis.

Four themes emerged from the inductive analysis and those themes derived subthemes: (a) Support- (1) academic support, (2) financial support, and (3) engaging and 
influence; (b) Academic Intention- (1) understanding academic achievement before sorority membership, and (2) understanding academic achievement after sorority membership; (c) Service- (a) civic engagement, (b) volunteering, and (c) filling a need; lastly, (d) Social Awareness- (a) personal service goals, (b) personal social responsibility, and (c) understanding civic engagement agents.

The study provided implications for practitioners in higher education, such as the need to understand the historical significance, to advise these groups in a comprehensive manner, to conduct further research on the experiences of graduate chapter members caused by life experiences, and to identify sorority interests prior to membership for optimal outcomes. The study findings have implications for future support, research, and resources offered in helping these women navigate both student life and sorority membership. It is recommended that future researchers continue to examine the experiences of Black, NPHC sorority women, in order to inform higher education practitioners to better assist with their growth and development. 


\section{TABLE OF CONTENTS}

CHAPTER

PAGE

I. INTRODUCTION 1

Background of the Problem 3

Problem Statement $\quad 15$

$\begin{array}{ll}\text { Purpose of the Study } & 18\end{array}$

$\begin{array}{ll}\text { Research Questions } & 19\end{array}$

Theoretical Framework 19

Significance of the Study $\quad 21$

Delimitations $\quad 23$

Definition of Terms $\quad 23$

$\begin{array}{ll}\text { Summary } & 26\end{array}$

II. REVIEW OF THE LITERATURE 27

Black Students and College $\quad 27$

A Brief History of Collegiate Fraternal Organizations 28

National Pan-Hellenic Council Background $\quad 29$

Academic Achievement $\quad 34$

Civic Engagement 49

$\begin{array}{ll}\text { Summary } & 63\end{array}$

$\begin{array}{lll}\text { III. METHODS } & 64\end{array}$

$\begin{array}{ll}\text { Purpose of the Study } & 64\end{array}$

$\begin{array}{ll}\text { Research Questions } & 65\end{array}$

Phenomenological Research Design $\quad 65$

Researcher's Autobiography $\quad 66$

$\begin{array}{ll}\text { Assumptions } & 69\end{array}$

$\begin{array}{lr}\text { Journaling Process } & 70\end{array}$

$\begin{array}{ll}\text { Sampling } & 70\end{array}$

$\begin{array}{ll}\text { Data Collection } & 72\end{array}$

Data Analysis $\quad 73$

Data Management $\quad 74$

$\begin{array}{ll}\text { Ethical Considerations } & 74\end{array}$

$\begin{array}{ll}\text { Integrity Measures } & 75\end{array}$

$\begin{array}{ll}\text { Summary } & 76\end{array}$

$\begin{array}{ll}\text { IV. FINDINGS } & 77\end{array}$

$\begin{array}{ll}\text { Support } & 77\end{array}$

$\begin{array}{ll}\text { Academic Intention } & 83\end{array}$ 
$\begin{array}{lr}\text { Service } & 89\end{array}$

Social Awareness $\quad 95$

$\begin{array}{ll}\text { Summary } & 101\end{array}$

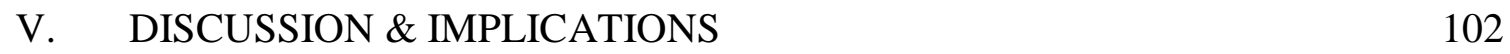

Response to the Research Questions 102

Relationship to Theoretical Framework 106

Implications for Student Affairs Practitioners 109

Recommendations for Future Research 111

$\begin{array}{ll}\text { Limitations of the Study } & 113\end{array}$

$\begin{array}{ll}\text { Summary } & 114\end{array}$

$\begin{array}{ll}\text { REFERENCES } & 115\end{array}$

$\begin{array}{ll}\text { APPENDICES } & 135\end{array}$

$\begin{array}{ll}\text { VITA } & 140\end{array}$ 


\section{CHAPTER I \\ INTRODUCTION}

The purpose of the present study was to explore the experiences of Black, NPHC sorority members, as they relate to understanding their academic achievement and civic engagement. The research was viewed through the lens of the community of practice (CoP) theory, where knowledge is created, shared, organized, revised, and passed on amongst various members with a common interest in a social setting (Wenger, 1998b). It is important to acknowledge a significant difference between CoP (Wenger, 1998b) and its use, as opposed to Wenger's other theories — CoP (Lave \& Wenger, 1991) and Seven Principles of Cultivating CoP (Wenger, McDermott \& Snyder, 2002). Lave and Wenger (1991) studied the behavior of novices in groups such as an apprenticeship, as they become established members. While Lave and Wenger (1991) addresses the social learning aspect of NPHC sororities, focus is not placed on the members' understanding of their practices, which is a focal point of my study. Seven Principles of Cultivating CoP (Wenger et al., 2002) centers on the actions and perceptions of volunteers, some of which leave, merely because they can. While that may be true for some CoPs, the nature of NPHC sororities is such that they are not volunteers, but willing participants who have paid hundreds of dollars and participated in extensive courses of study and passed tests, in preparation for commitment to full-fledged membership (Kimbrough, 2003). The NPHC sorority chapters are usually smaller than predominantly White sororities. Recognizing this fact, NPHC sororities realize the need for active participation from all members (Kimbrough, 2003; Ross, 2000). Community of practice is most fitting for the 
analysis of the study because it focuses on members' understanding of their experience, a muted voice in the breadth of the literature. Wenger's CoP (1998b) states:

Communities of practice develop around things that matter to people. As a result, their practices reflect the members' understanding of what is important. Apparently, external constraints or directives can influence understanding, but even then, members develop practices that are their response to these external forces. Even when a community's actions conform to an external mandate, it is the community-not the mandate - that produces the practice (p. 2).

While both Community of Practice (Lave et al., 1991) and Seven Principles of Cultivating Community of Practice (Wenger et al., 2002) place emphasis on CoP, they do not give the community a voice. The focus of the theories mentioned above is not the members' understanding of a community of practice. The community and focus of the study Black, sorority women because their voices are omitted in the literature.

The chapter begins with the background to the study, the problem statement, the purpose of the study, the research questions, and the theoretical framework. The significance of the study, definitions of terms, and organization of the study are also included in the chapter. 


\section{Background of the Problem}

America's racial segregation and exclusion of Black people was an accepted norm in spaces which include (but not limited to) bathrooms, restaurants, sports, schools, (of various levels) and organizations. Those that attempted to defy the status quo, were met with hostility. Paul Robeson, an exemplary student and football player at Rutgers in New Jersey, was excluded when competing with Southern schools as these institutions were often vehement about the practice of racial segregation (Thelin, 2004). The practice of excluding Black students on sports teams also deprived them of social experiences granted to White students and yielded social segregation. The type of segregation was also apparent in organizations like the Freemasons in the eighteenth century, and naturally extended to the White Greek-system of fraternities and sororities in the nineteenth century (Kimbrough, 2003). Black students encountered discrimination in institutions of higher education, as it was a nationally accepted practice (Thelin, 2004). A nation operating on the premise of lawful bigotry beckoned a safe space for Black students, and engendered Black fraternalism (Trotter, 2004).

As a result of the discrimination faced by Blacks in America, these groups played several valuable roles. These roles included serving as a replacement for the cultural identity that was stripped from them as slaves, sustaining social change movements, providing a platform for Black civic engagement, and supporting the Black power movements of the twentieth century (Kimbrough, 2003; Trotter, 2004). The Black fraternalism of the eighteenth century led to the beginnings of Black Greek letter organizations. 
For over 100 years, Black Greek letter organizations have been an integral part of the experiences of Black students in higher education (Kimbrough, 2003; Ross, 2000). Many educated and renowned Black Americans are members of these organizations, including Martin Luther King, Jr., Rosa Parks, and Maya Angelou (Parks, 2014). Black Greek organizations are so prominent that in 1988, filmmaker Spike Lee directed a controversial movie on Black Greek life, School Daze. It was a depiction of Black Greek life on the campus of a historically Black college. Lee incorporated aspects of scholarship, camaraderie, networking, hazing, and most pertinent to the study, questioning the need for these organizations at the collegiate level. It received mixed reviews because of the portrayal of Black Greeks, Non-Greeks, and student affairs practitioners (Lucas, 1988). While the movie premiered over 20 years ago, scholarship, camaraderie, and networking are still prevalent in Black Greek life today.

Black Greek life is formally known as the National Pan-Hellenic Council. The Council is an umbrella organization that houses the historically Black sororities and fraternities. The first NPHC Sorority, Alpha Kappa Alpha was founded in 1908, followed by Delta Sigma Theta in 1913 and Zeta Phi Beta in 1920, and concluded with the fourth, Sigma Gamma Rho, established in 1922. All of these sororities were founded at Howard University, except Sigma Gamma Rho, which was established at Butler University (Ross, 2000). The NPHC culture is to state the Sorority's name in its entirety to emphasize the legacy, history, and pay respect. However, in this dissertation, for brevity and clarity they are used as AKA, DST, ZPhiB, and SGRho, respectively. 
The NPHC mission and stated purpose are to "[maintain] unanimity of thought and action as far as possible in the conduct of Greek-Lettered collegiate... sororities, and to consider problems of mutual interest to its membered organizations" (NPHC, 2012; Ross, 2000). The NPHC contributes to the mission and stated purpose by providing peer groups for academic support and achievement, retention, and a continued "safe place" (Collins, 2000, p.100). The safe place is a mechanism designed to be a haven for Black women. It is intended to be exclusionary, by solely allowing Black females a place to interact, examine issues of concern and address social injustices.

At the turn of the twentieth century, there were challenges to the traditional roles of women, and the odds of Black women earning a degree were overwhelmingly small (Ross, 2000). The sororities' mission was (and is) to endorse the struggle faced by Blacks, encourage leadership roles, uphold standards of scholarship, and encourage individual excellence (Brown, Parks, \& Phillips, 2005). The NPHC sororities have been a catalyst for positivity within the Black community for over a century. However, the negative issues and attitudes represented in Lee's film (Maslin, 1988) do not overshadow the benefits of these organizations which has allowed them to remain prevalent in Black Greek life today (Hill, 2012). As collegiate and community pillars, NPHC sororities have maintained the mission of academic achievement and overall success (Kimbrough, 2003; National Pan-Hellenic Council, 2014; Ross, 2000). These organizations have positively affected the lives of members and others benefiting from services and programs, as a consequence of their respective organizational missions and steady growth in the number of entire chapters per organization worldwide (Kimbrough, 2003). 
Sororities in NPHC have been closely related to academic achievement and civic engagement since their inception (Ross, 2000). While there are many factors like economic power, institutional power, and the power to enforce, mentioned in Pharr's $(1996,1997)$ theories of internalized oppression, those theories focus on the notion that the oppressed internalize the views of the dominant group, causing self-hatred, selfabuse, and despair. However, the study is not focused on societal influence but the voices of Black, NPHC sorority members and their understanding academic achievement and civic engagement. All four Sororities require that aspirants be full-time students and maintain a minimum GPA of 2.5 according to NPHC headquarters (NPHC, 2012). However, chapters reserve the right to require a higher GPA and often exercise that right (the University of North Carolina at Charlotte, 2011). Members are also expected to remain active in the chapter and nationally (NPHC, 2012). Founding members and early initiates participated in creating loan funds for members who needed financial assistance for school. They established national projects such as Vocational Guidance to place focus on education (Alpha Kappa Alpha Sorority, Inc., 2014) and conducted book drives for military men (Delta Sigma Theta Sorority, Inc., 2015). More recently, members have launched the African Village Development, which is intended to address the education crisis at different levels; the Zeta National Education Foundation that works cooperatively with universities to provide scholarships for students (Zeta National Educational Foundation, Inc., 2014); and conduct educational programs, workshops, symposia and forums for the public (Sigma Gamma Rho Sorority National Education Fund, Inc., 2015). 
Just like NPHC's relationship with academic achievement, civic engagement has been at the forefront since the inception the NPHC. Civic engagement is evident in AKA's promotion of race consciousness, DST participated in a Women's Suffrage March, ZPhiB established the Zeta Housing Project of 1943 which was implemented to identify and register housing vacancies for World War II workers (Johnson, 2015). The SGRhos had civic engagement firsts such as Joyce Williams Warren - First Black Arkansas Judge and Ruth Whitehead Whaley - First Black Woman in U.S. to practice law (Johnson, 2014). The early civic engagement of NPHC sorority members set a precedent for a recent event (Johnson, 2015). Loretta Lynch, a member of DST, became the first African American women to become the U.S. attorney general. However, as a result of partisan bickering, her nomination process was delayed for more than 150 days. Throughout all of those days, NPHC sororities made their presence known, and their voices heard. The Sorors of DST sat in hearings wearing Sorority colors, members of AKA advocated for her vote on the House floor, while U. S. Representatives as well as members of SGRho and ZPhiB took to social media and participated in press conferences on Lynch's behalf. These women remained steadfast in their civic engagement until the Senate confirmed Loretta Lynch as the $83^{\text {rd }}$ U.S. Attorney General (Johnson, 2015). 
Harper, Byars, and Jelke (2005) noted the benefits of NPHC organizations at Historically Black Colleges and Universities (HBCU) because of their strong network, which includes socially supportive environments and academic adjustment. However, they found literature concerning the effects of membership in sororities and college retention to be limited. The literature primarily addressed delayed college adjustment. At most institutions of higher education, joining an NPHC Sorority is not permitted until students have attended at least one semester at the school or have sophomore credits. Intentional membership intake postponement, delays possible effects on student adjustment. However, Harper et al., (2005) argued that membership positively affects personal development and academic success of members as well as Black, non-members.

\section{Academic Achievement}

While there was once a consensus on what measures should be included in an academic achievement assessment, that consensus no longer exists among educators (Ginsberg, Shapiro \& Brown, 2004; Ward, Stoker \& Murray-Ward, 1996). Exams and assessments such as Collegiate Assessment of Academic Proficiency (CAAP) and the National Assessment of Educational Progress (NAEP; NAEP, 2013) are generally used to evaluate academic achievements. Both of these assessments are standardized. Grade point average (GPA) is another standard way of assessing academic achievement (McGrath \& Braunstein, 1997; Tross, Harper, Osher, \& Kneidinger, 2000). However, GPA is not an ideal measure of academic achievement because it is a linear combination of several assigned course grades, which encompasses instructor grading practices, and course taking strategies (Lei, Bassiri, \& Schultz, 2001). Another measure of academic 
achievement is the student's ability to profit from instruction in an area of study (Crow \& Crow, 1969). Academic achievement is reflected by the student's demonstration of skill and knowledge. For the purpose of the study, academic achievement is defined as the act of consciously pursuing a degree (Bok, 2006). Conscious pursuit includes being socially aware, that is, cognizant of current events and their relevance from a historical standpoint. It is germane to academic achievement and necessary for the study because the student's engagement in the classroom relates to concept application in the student's community (Dewey, 1916; Wenger, 1998b).

Studies that measure academic achievement are sparse. However, research on the relationship between Greek life and academic achievement exist, but often lack particular data on Black members. Baier and Whipple (1990) conducted a study with a sample size of 904 men and women at a Predominantly White Institution (PWI) and found that there was no significant difference in the grades of sorority or non-Greeks. Another study found that the grades of sorority members was statistically not different when compared to the GPAs of non-sorority members (Grubb, 2006). Still, it was unclear whether any of the sorority women were members of NPHC sororities (Pascarella, Edison, Whitt, Nora, Hagedorn, \& Terenzini, 1996). None of these studies specifically addressed NPHC sororities and academic achievement. 
The literature on academic achievement and NPHC sororities is scant (Parks \& Spencer, 2013) even though NPHC has stood for academic achievement for over 100 years (Armfield, Bradley, Clarke, \& Parks, 2011). Pascarella and Terenzini (1991) concluded that the empirical research is insufficient to support claims for or against participating in NPHC to enhance academic achievement or civic engagement. The NPHC sorority population is overlooked (Kimbrough, 2003). For example, a study highlighted the positive effects of sorority membership on academic achievement, but failed to address NPHC sorority involvement specifically (Whipple, 1998). More recently, the Center for the Study of the College Fraternity (CSCF; 2010) compiled an annotated bibliography organized by the years 1950-1970, 1980-1985, 1986-1990, 19901995 and 1996- 2010 about fraternity and sorority involvement. The annotated bibliography contained over 500 published documents, of which only 20 mentioned Black members. The paucity is consistent throughout the literature on fraternal organizations thus, leading to a significant gap in the literature on people of color.

\section{Civic Engagement}

The definition of civic engagement varies among authors (Jacoby, 2009). Some define civic engagement as individual volunteerism (Wilson, 2000), while others define it as an active collaboration to improve the well-being of those in their community, through an approach that is harmonious with the campus mission (Bringle, Hatcher, \& Holland, 2007). The present study, civic engagement is defined as the involvement of students through discussion and action on major social issues, both inside and outside the university (Dewey, 1916). The stages of development within CoP occur over time and 
are potential, coalescing, active, dispersed, as well as memorable (Wenger, 1998b). Potential is discovering commonalities within the group. In the case of NPHC sororities and civic engagement, they begin to explore community (outside) social issues and strengths within the group to assist in combating those issues. They then move to coalescing, which identifies members' potential. Some members are good at organizing protests; others are better at writing to prominent government officials, while some may have a knack for fundraising. The group consists of both neophytes and prophytes, which make way for active. Active entails engaging in joint activities where prophytes have the opportunity to demonstrate the practices of the past to the neophytes. The neophytes can then add to the practice. The exchange may go back and forth, between neophytes and prophytes as well as within the respective groups in order to adapt it to any changing circumstance. As the semester comes to an end, their engagement may shift but still sustained because of organizational missions. However, a newer member may continue to fight against social injustice within the sorority, since elected officials can change by the semester. The behavior is known as dispersed. The semester may be over but the knowledge gained can be used to dismantle other issues of injustice, whether in a school setting or in life. The final stage is called memorable.

It is important to acknowledge that civic engagement is not to be confused with service-learning or community service, which fails to engage the student intentionally and with the community (American Psychological Association, 2015). Civic engagement has a broad range of activities, which is neither inclusive of community service agencies nor professors but can include voter registration, getting students to sign petitions, and 
staging sit-ins. These events occur within the Active stage of CoP. Civic engagement responds to the day-to-day social injustices without the influence of outside perspectives. Most recently, a member of DST heard a member of a predominantly White sorority, Delta Zeta, use a racial slur during an event intended to unify organizations on the campus of Temple University (Brandt \& Bohnel, 2015). The incident was reported to University officials. Once members of NPHC felt that the necessary steps were not taken to address and reprimand the student, a demonstration was organized. The NPHC members held hands on stage while Julia Crusor, a member of DST, read a statement to the audience addressing bigotry. National Pan-Hellenic Council's acts of civic engagement not only excluded university officials — because of their lack of responsiveness to the injustice, but also excluded outside agencies to support their civic engagement efforts. They took matters into their own hands.

Acts like these serve as examples of civic engagement by NPHC sorority women, to be researched for the study and not service-learning. Service learning is often determined by university administration to foster a public relations opportunity within a predetermined window of time, rather than an ongoing engagement for the purpose of resolving community issues (Boyer, 1994). Application of knowledge as it pertains to the needs of the surrounding community is central to civic engagement (Ross, 2000; NPHC, 2012). Bringle and Steinberg (2010) found that civic engagement boosted students' knowledge of contemporary social issues, in addition to their communication and listening skills. 
The literature on civic engagement and NPHC sororities is limited and implicit (Chong \& Rogers, 2005; Porter \& Parks, 2011). One study found that the civic behavior of predominately White Greek council members and NPHC organizations paralleled their missions (Asel, Seifert, \& Pascarella, 2009). However, the researchers failed to properly cite NPHC organizations within the study or have a substantial sample, as there were less than 25 NPHC participants in a sample size of 3,153 students. The lack of literature does not mirror the amount of time and effort these organizations have put forth in the area of civic engagement since their inception but does reflect a lack of scholarship focused on the NPHC. One area of civic engagement was the issue of Black voting rights. Barriers to Black voting included enslavement, anti-literacy laws, violence and intimidation, grandfather clauses, gerrymandering, literacy requirements, property requirements, threats of eviction or loss of jobs, and poll taxes. In addition, the voter suppression of today includes deadlines and penalties for tardy voter registration, purging of voter rolls because of "ethnic" names, limited early voting, felony disenfranchisement, all of which disproportionately affect Black voter turnout. Members of NPHC sororities fought against all these injustices; more specifically, the founders of DST marched on March 3, 1913, along with other groups for women's suffrage (Bernard, 2013). In addition to political affairs, NPHC sororities engage in civic matters concerning the health of members and other Black women. The initiative SororsCaring was established using social media to bring diabetes awareness and prevention through workshops, utilizing the collaboration of NPHC sororities and American Public Health Association (Johnson, 2006). As a result of the lifelong commitment of NPHC sorority members, they continue 
to influence their communities long after earning a degree by joining a graduate chapter of an NPHC sorority (Kimbrough, 2003; Ross, 2000). The innovative project SororsCaring serves as a conduit, providing direct access to medical care, to a disproportionately affected population — Black women in the US from adolescents to senior citizens (American Diabetes Association, 2014; Office on Women's Health Department of Health and Human Services, 2010). Those involved in civic engagement as seasoned citizens have often found their knowledge to be insufficient as young adults while still in college, and have sought enlightenment from graduate members on issues of civic responsibility (Boggs, Rocco, \& Spangler, 1995). The passing of knowledge within NPHC sorority chapters parallel a similar flow of knowledge, from neophytes to prophytes. As neophytes learn more about civic responsibility through exchanges, they become seasoned prophytes, through the community of practice (Wenger, 1998b).

Though research on NPHC sororities and civic engagement are sparse, there are studies concerning sororities and community service, which have a positive relationship with civic engagement. Social justice involvement is an indicator of future actions in civic engagement (Wade, 2000). The NPHC sororities are usually involved in hands-on community service projects with a focus on social justice (Kimbrough, 2003). Mathiasen (2005) suggested that community service allows sorority members to place importance on the care of others and a sense of responsibility for their welfare. All of which are indicators of civic engagement. 
On December 15, 2014, Sorority Sisters premiered on VH1 (Carter, 2015). The premiere prompted member unification across sorority lines to boycott a social injustice in the form of a reality television show, Sorority Sisters (Carter, 2015). The NPHC sororities utilized social activism and empowerment, which are civic engagement outcomes (Sax, 2004). The show is a hyper-stereotypical depiction of Black, NPHC women (NPHC, 2014). The NPHC sorority members saw it as a social injustice because it not only degraded organizations established as a vehicle for positive social change, but demeaned Black womanhood and sisterhood through shocking images and messages about self-worth, sexuality, and gender roles (NPHC, 2014). In less than a month's time, members of every NPHC sorority mobilized through social media outlets, email, and parcel post to pressure advertisers to pull their commercials aired during Sorority Sisters (Ho, 2015). The intense mobilization resulted in the cancellation of Sorority Sisters despite having three more episodes left to air for the season (Carter, 2015).

\section{Problem Statement}

On April 27, 2015, Loretta Lynch, a member of DST, was sworn in as the U.S. Attorney general but the preparation for that moment took many years of academic achievement and civic engagement from her, in addition to other NPHC sorority members (Johnson, 2015; Rhodan, 2015). As sorority members graduate and move toward the prospect of graduate level membership, an examination of Black, sorority membership is needed to understand their academic achievement and civic engagement experiences (Kimbrough, 2005). Academic achievement and civic engagement practices are introduced to NPHC sorority neophytes by way of the new member process and 
continue to evolve, as the member remains involved in the organization (Wenger, 1998;

Ross, 2000). The preparation instills the concept of African communalism (Scott, 2003), the idea of "we, us, our" as opposed to "me, my, I," to counteract gender and racial injustices that have plagued members since birth (Brown et al., 2005; Ross, 2000). The African-centered perspective, as it pertains to NPHC sorority members, is the interdependence amongst the new members, the new members and their prophytes, and the sorority members within the community, creating a community of practice. The community of practice engages sorority members in ways that can develop their intellect through academic achievement and challenges their dedication to the community through civic engagement.

As with civic engagement, academic achievement among NPHC sorority members can be explored using the stages of development in $\mathrm{CoP}$, delineated below. The stages of CoP are potential, coalescing, active, dispersed, as well as memorable (Wenger, 1998b). During the potential stage, members in the sorority begin learning the academic strengths and challenges within the group as grades are monitored throughout the school year (Kimbrough, 2003). Coalescing occurs when members identify the academic strengths and challenges among each other. For example, a math major may sit in on the class of another member who is having trouble with math to see how they can help the struggling member. Once the math major identifies the issue, they actively engage in a plan to achieve academically. By letting another member know about their academic challenges they are immersing themselves in the active stage of CoP. After that, both skilled and challenged members may not engage as often at the end of semester, but they 
may still follow up to see if academic achievement is still in pursuit. The behavior is called dispersed. Lastly, members may have finished with the semester of academic challenges in a specific class, but the tools gained during the particular semester may be applicable in other situations. For example, those same study tips and organizational skills learned can be used in other classes or life. The final stage is called memorable (Wenger, 1998b).

The NPHC sororities are proponents in and for the Black community (Brown et al., 2005). These organizations have monumentally affected Black history in America (Bonner, 2006). Since their inception, these organizations have been at the forefront of various civil rights movements by putting education first (Kimbrough, 2003). During the Great Depression, the women of AKA sponsored the Mississippi Health Project, the brain child of AKA member, Dr. Ida L. Jackson (Ross, 2000). Together, the Sorority and project offered rural residents books and education. They also started summer school for rural teachers, which offered self-improvement courses. More recently ZPhiB responded to the relentless incidents of police brutality faced by Black people in America (Zeta Phi Beta Sorority, Inc., 2014b). On December 22, 2014, the president of ZPhiB released a national civic engagement program titled "Get Engaged" by utilizing dedicated sorority members to foster citizen participation and strengthen relationships among elected officials, law enforcement, educators, and the community. The NPHC sororities have, and continue to be, vehicles for social action and education but have yet to be studied explicitly. 


\section{Purpose of the Study}

The purpose of the study was to explore the experiences of Black, NPHC sorority members, as they relate to understanding their academic achievement and civic engagement. These organizations are historically different when compared to mainstream Greeks and require uniquely tailored support, but are not understood because of the lack of empirical research within higher education (Fries-Britt \& Griffin, 2007). Empirical research can provide support to historically marginalized people (Black women) in institutions of higher education (Davies, Lubelska, \& Quinn, 1994; Strayhorn \& McCall, 2012). In the study, responsible citizens are the value in CoP, and the value is enhanced by legitimizing participation (Wenger, 1998b). While legitimization may appear to require outside agencies to legitimize the participation in NPHC sororities, it is actually "an opportunity to talk about how their participation in these groups contributes to the organization [NPHC] as a whole" (Wenger, 1998b, p. 7). In other words, the voices of members are to be heard "by creating an environment in which the value of [what] the communities bring is acknowledged" (Wenger, 1998b, p. 7). The study may initiate discourse and reflection on the part of NPHC Headquarters, Greek Life advisors, NPHC sorority members, and student affairs practitioners to create supportive environments for sorority members. The discourse among the parties mentioned above, combined with data from the study may affect the way in which NPHC sororities are advised. 


\section{Research Questions}

The primary research question is, from the points of view of Black NPHC sorority members, how do they see academic achievement and civic engagement? The subsidiary research questions are:

1) What are the perceptions, attitudes, and lived experiences of NPHC sorority members regarding academic achievement?

2) What are the perceptions, attitudes, and lived experiences of NPHC sorority members regarding civic engagement?

3) How do Black NPHC sorority members understand the influence of membership on their academic achievement and civic engagement?

4) How does an NPHC sorority act as a Community of Practice to foster a spirit of academic achievement and civic engagement in members?

\section{Theoretical Framework}

Wenger's CoP involves groups of people (communities) who utilize social learning by regularly meeting and exchanging ideas to improve something of mutual concern in an organization (Wenger, 1998b). The active participants regularly collaborate for an extended period to determine strategies and share solutions (Lave et al., 1991; Wenger, 1998b). A CoP defines itself by utilizing three components: mutual engagement, joint enterprise, and shared repertoire (Wenger, 1998b). Within a social context, mutual engagement occurs first by establishing norms in the community. The community interacts using the established standards as guidelines. The community also determines their purpose for engaging as a collective, also known as a joint enterprise. 
Community members often renegotiate the joint enterprise as pertinent information about the domain is learned (Brown \& Duguid, 1991). Finally, the community produces a shared repertoire, which is a collection of resources used in the quest to gain their joint enterprise. Community of practice also occurs concurrently over stages of development, which includes potential, coalescing, active, dispersed, and memorable. The theory emphasizes the social aspect of learning and interaction, (Nickols, 2003) in addition to advancement through knowledge, which all members possess (Freire, 1970). Wenger (1998a) posits that learning is essential to human identity, and those who actively participate within a social community and also construct an identity within that community (Wenger, 1998b).

Community of practice is identified by any of the four dualities: participationreification, local-global, identification-negotiability, and designed-emergent (Wenger, 1998a). These dualities are not in opposition, but rather work together within each set of dualities. The processes within each duality require and enable each other. Participationreification is finding the meaning of a complex practice through active involvement and participation for the purpose of succinct depiction to the community as a whole, also known as reification. Similarly, there are two groups involved in designed-emergent duality; however, the involvement is that of two CoPs. One CoP is at the local level and shares knowledge for their benefit, and for appropriate use within a global CoP. The duality is known as local-global. Identification-negotiability involves establishing applicable uses of the identified activity, perspective, or design for the sake of defining an individual, both personally and in the community. The design can be negotiated to adapt 
better to the need of community (Brown \& Duguid, 1991). Design is also utilized within the designed-emergent duality. Designed-emergent focuses on time and captures the conflict between deliberately designed and emergent activities in the community.

Wenger (1998a) extended the concept of legitimate peripheral participation, that is, the process that turns newcomers into seasoned participants in organizations. He believed social learning is fundamental to human identity (Lave et al., 1991). Those involved in CoP gradually become more engrossed in the domain and provide an incentive for other members to do the same. Constant interaction within a community constructs the identity of an individual participating in that community. The CoP supports problem-solving, involvement of experts, synergies across units, new strategies, knowledge sharing, reuse of resources, and networking (Wenger, 1998b).

\section{Significance of the Study}

The study of Black, NPHC members is a neglected area in the history of American higher education (Kimbrough, 2003; Parker, 2012). Literature specific to NPHC history fails to voice the issues of Black, sorority women. It is important to study this group of women because their focus is not like that of their counterparts, White sororities, which have more of a social aspect and intended to conclude at the undergraduate level, and have been heavily researched (McClure, 2006). The NPHC sororities by tradition, are lifelong memberships, organized to empower and contribute to the betterment of the Black community (Kimbrough, 2003). Study findings posit that White women are penalized for seemingly dominant behavior, where Black women are not (Livingston, Rosette \& Washington, 2012). The could be the basis for studies on 
NPHC sororities as leadership, mentoring, and engagement are indicators of civic engagement (Mathiasen, 2005), but the research is sparse. Empirical research on Black, NPHC sorority members' perspectives on academic achievement and civic engagement are scant and would serve as appropriate tools in networking and mentoring (Brown, Parks, \& Phillips, 2005; Kimbrough, 2003; Patton, Bridges, Flowers, 2011). Their experiences within Greek life are different than their male counterparts in NPHC and should be included in the body of literature (Kimbrough, 2003). A consequence of the shift in Black activism, from the corporate uplift in the early 1900s to a male-centered uplift by the 1960s, the focus became patriarchal, refocusing all aspects involving Black activism, including NPHC fraternities and sororities. Patriarchal thinking focused on the development of those things related to the Black male, including fraternities. The NPHC sororities did not receive the same focus and attention to development (Brown et al., 2005).

Greek advisors, who are tasked with assisting all Greek life on campus, have marginalized NPHC sororities, because of their organizational difference from mainstream Greeks and their lack of knowledge as it pertains to NPHC. Yet, NPHC sororities are expected to uphold the mission of their respective organizations, both academically and civically, within their communities (Patton, et al., 2011). Past research has revealed that the structure and history of NPHC serves a purpose distinct from that of mainstream Greeks (McClure, 2006). The NPHC sororities have unique characteristics that are often regarded as negative and lead to obstructive perspectives from untrained Greek life professionals and other student affairs practitioners (Kimbrough, 2009). For 
example, interested persons are expected to keep their sorority pursuit a secret. The secrecy can appear to the untrained professional as a means to participate in illicit activities, when it is actually tradition.

Black, NPHC sorority members are unique in that they are expected to excel without the same support received by mainstream Greeks and amid negative stereotypes (Fries-Britt et al., 2007). Obtaining Black, NPHC sorority members' perspectives on their lived experiences within the social context of Greek life and their communities will contextualize and advance the discourse of academic achievement and civic engagement beyond indolent labels, assumptions, and pontification (Johnson, Bradley, Bryant, Morton, \& Sawyer, 2008).

\section{Delimitations}

The study includes only sorority members in good standing with NPHC at HBCUs. The research will only include Black, female students, who are the focal population for the study.

\section{Definition of Terms}

This section of Chapter I includes terms contained in the following chapters that require clarification because of finite meanings that differ among disciplines.

\section{Academic Achievement}

Academic achievement is the act of consciously pursuing a degree (Bok, 2006).

\section{Aspirant}

An aspirant is an undergraduate, who has expressed interest in becoming a member of an NPHC sorority (Kimbrough, 2003). 


\section{Community of Practice}

The Community of Practice is a utilization of social learning by meeting regularly and exchanging ideas to improve something of common concern in a formal organization (Wenger, 1998b).

\section{Civic Engagement}

Civic engagement is defined as the involvement of students through discussion and action, about major social issues, both inside and outside the university (Dewey, 1916).

\section{Greek Advisor}

Greek advisor's role is to actively support those councils present on the college campus (NPC, \& NPHC) life through advising, advocacy and education efforts (Kimbrough, 2003; Ross, 2000).

\section{HBCU}

HBCU is an acronym for Historically Black College and University. The group of institutions was initially established for the education and betterment of Blacks in the United States (Jackson \& Nunn, 2003).

\section{Line-sister}

Undergraduate or graduate member women of the same pledge class (Kimbrough, 2003).

\section{MIP}

MIP is an acronym for membership intake process. It is the only legal process to educate the aspirants of an NPHC sorority (Ross, 2003). 


\section{Neophyte}

Neophyte (sometimes shortened to "neo") refers to the newest members of the sorority (Kimbrough, 2003).

\section{NPC}

NPC is an acronym for National Panhellenic Conference. It provides support and guidance for its 26, predominantly White, member sororities (Kimbrough, 2003).

\section{NPHC}

NPHC is an acronym for National Pan-Hellenic Council. It is also referred to as 'the Org,' 'the Pan' and 'Divine Nine.' The NPHC is the umbrella council, which houses Alpha Kappa Alpha Sorority, Inc., Alpha Phi Alpha Fraternity, Inc., Delta Sigma Theta Sorority, Inc., Zeta Phi Beta Sorority, Inc., Iota Phi Theta Fraternity, Inc., Kappa Alpha Psi Fraternity, Inc., Sigma Gamma Rho Sorority, Inc. Phi Beta Sigma Fraternity, Inc. and Omega Psi Phi Fraternity, Inc. (NPHC, 2012; Ross, 2003).

\section{Prophyte}

A prophyte is a seasoned member of a sorority (Kimbrough, 2003).

\section{PWI}

PWI is an acronym for Predominately White Institution (Kimbrough, 2003). The student body at a PWI is primarily White. National Pan-Hellenic Council has four organizations that were founded at PWIs, which are Alpha Phi Alpha Fraternity, Inc., Kappa Alpha Psi Fraternity, Inc., SGRho, and Iota Phi Theta Fraternity, Inc., (Ross, 2000). 


\section{Soror}

A Soror is a member of an NPHC sorority. The term is used as a title or greeting by fellow members (Kimbrough, 2003).

\section{Summary}

Chapter 1 included a discussion on the background of NPHC Greeks, in particular, NPHC sororities and the need for culturally competent Greek advisors. The goal of the study was to gain knowledge of Black, NPHC sorority members' understanding of the influence of membership on their academic achievement and civic engagement, and their community. Included in the discussion were academic achievement, civic engagement, research questions, theoretical framework of the study, and a section defining specific terms. Chapter 2 provides a literature review recounting empirical findings regarding Black students and college retention, NPHC background, NPHC sororities, academic achievement, and civic engagement. Chapter 3 is a discussion of the research methodology for the study, the target population, the data collection process and manner in which the resulting data were analyzed. 


\section{CHAPTER II}

\section{REVIEW OF THE LITERATURE}

In this chapter, a review of the relevant literature on Black students and college, history of college fraternities, NPHC background, academic achievement and civic engagement in higher education, as well as within the context of NPHC, Black sorority members is presented.

The section on notable Black students and college gives relevant statistical information on Black undergraduates. The section on the history of college fraternities presents the evolution of collegiate fraternities and sororities. The section on NPHC background provides insight on the history, and role played by these organizations and their members throughout history. The sections on academic achievement and civic engagement are described in the context of higher education, Black students, Greeks, and NPHC sororities.

\section{Black Students and College}

Admittedly, access to and involvement in higher education has improved over the last 40 years, but Blacks are still less prone to attend and finish college than their White counterparts (U.S. Department of Education, 1998). In the 1999-2000 academic year, four-year college enrollment among Whites was 46\%, but Blacks lagged behind at $40 \%$ (Harvey, 2003). In 2012-2013 academic years, of all undergraduates who matriculated at a four-year institution with the goal of a bachelor's degree completed it in six years, less than 7\% were earned by Black women (U.S. Department of Education, 
2013). Undergraduate recruitment is imperative, but retaining and assisting them in finishing their degree in 6 years is critical to the fiscal and societal health of the related communities; including Black communities (Education Commission of the States, 2004). In the same academic year, Black women lagged behind their White counterparts at 123,874. More recent data from National Center of Educational Statistics show a disparity of over 500,000 bachelor's degrees between White and Black women (U.S. Department of Education, 2013). The attainment of a bachelor's degree plays a significant role in the divide between the haves and have-nots with regards to family income, net worth, and credit use, which ultimately affects the quality of life for far more Black women than White (Bok, 2006; Maxfield, 2014).

\section{A Brief History of Collegiate Fraternal Organizations}

The first collegiate fraternity, Phi Beta Kappa (PBK) was established in Williamsburg, Virginia at William and Mary in 1776. The purpose of this organization was to address White, male issues of concern, and socializing away from the direct gaze of administrators (Thelin, 2004). To avoid external judgment, members emphasized secrecy. The stressed silence of PBK was different than any other student organization of the time (Johnson, 1972). Another distinction was chapter expansion beyond the mother institution and state. Women were included in the paradigm of fraternities. However, inclusions were an afterthought, once colleges became coeducational. Female presence entailed only auxiliary association but lacked full membership for which women were adamant. Since full membership was not granted, women established their own organizations (Johnson, 1972). The oldest of these organizations is Alpha Delta Pi 
Sorority (formerly Adelphean Society), founded at Wesleyan Female College in Macon, Georgia in 1851. Like their male predecessors, and other sororities, a veil of secrecy was maintained and the organization expanded (Baird, 1915).

\section{National Pan-Hellenic Council Background}

On May 10, 1930, on the campus of Howard University, in Washington DC, the National Pan Hellenic Council (NPHC) was formed as a permanent organization with the following charter members: Omega Psi Phi and Kappa Alpha Psi Fraternities, and Alpha Kappa Alpha, Delta Sigma Theta, and Zeta Phi Beta Sororities. In 1931, Alpha Phi Alpha and Phi Beta Sigma Fraternities joined the Council. Sigma Gamma Rho Sorority joined in 1937, and Iota Phi Theta Fraternity completed the list of member organizations in 1997. The NPHC was established, in part, because of the desire of Blacks to experience the Greek life they had been denied (Thelin, 2004) and to form a supportive community (Kimbrough, 2003; Ross, 2000). The oldest and most prevalent overarching Black Greek organization is the National Pan-Hellenic Council (Ross, 2000).

The stated purpose of NPHC is "unanimity of thought and action as far as possible in the conduct of Greek letter collegiate fraternities and sororities, and to consider problems of mutual interest to its member organizations" (Ross, 2000). The purpose has remained the same since 1930 . It intentionally casts a large net to allow its member organizations to address unforeseen issues of the future and take pride in the groundwork laid by founding members (Kimbrough, 2003; Ross, 2000). As collegiate and community pillars, NPHC sororities have maintained the mission of academic achievement (National Pan-Hellenic Council, 2014; Ross, 2000). Through collaborative 
efforts of knowledgeable university officials and member organizations, NPHC can positively impact cross sections of society (Strayhorn et al., 2012).

National Pan-Hellenic Council member sororities Alpha Kappa Alpha, Delta Sigma Theta, Zeta Phi Beta, and Sigma Gamma Rho were developed from an urgency to formally educate Blacks and address social injustice against the Black community (Berkowitz \& Pavadic, 1999). National Pan-Hellenic Council Sororities are structured and modeled to advance self-efficacy and enable individual success to better one's community (Kunjufu, 1997). Much like the CoP, NPHC uses social interaction to positively effect change in both academia and society (Kimbrough, 2003; Wenger, 1998b).

\section{National Pan-Hellenic Council Sororities}

Nine organizations fall under NPHC, four of which are sororities. All pursue scholarship as a founding principle and part of their mission statement is civic engagement. For those who are the first in their family to attend an institution of higher education or do not have any family members in NPHC sororities, choosing to join can be a decision to find a community where they are accepted and understood—a safe space, where Black women are free from the judgement of non-members and the biases of society, as well as interacting with like-minded women, candidly (Collins, 2000). A review of the literature revealed that Black women attend universities where they are socially and culturally comfortable (Harper et al., 2005). The appeal of joining an NPHC sorority is evident for many Black women because of the organizations' rich history in social activism, civic awareness, and emphasis on academics (Hughey \& Parks, 2011). 
Alpha Kappa Alpha was the first Black sorority founded on January 15, 1908, at Howard University in Washington, DC (Ross, 2000) during an overt time of racial injustice (Kimbrough, 2003). One example of the injustices that occurred in 1906 were the 62 documented lynchings inflicted on Black Americans (Chandler, 2013). Another example took place in August 1906, when Black soldiers revolted against segregation in the military and were consequently dishonorably discharged by President Roosevelt (Haynes, 1973). Also, in 1908, the Race Riot of Springfield, IL, was prompted by the transfer of two Black inmates, which left many Black-owned businesses and homes in ruin by White residents (Rasmussen, 2012).

Some social injustices have been addressed by legislation such as that of the Supreme Court ruling on segregation in public schools and President Lyndon Baines Johnson's signing of the Civil Rights Act of 1964, but injustices continued and continue (White, 1990). These injustices were particularly apparent at Predominantly White Institutions (PWI). Black people were not welcomed at the once exclusively White institutions, nor was it easy for them to achieve academic success in those institutions as a direct consequence of a prevailing racist climate. By 1964, however, Black Greek organizations grew in the number of chapters and colleges they sponsored, and eight of the (soon to be) nine Greek lettered organizations joined NPHC, to assist in resolving social issues (NPHC, 2012). Founders of these organizations are models of social and academic resilience. 
Black people were being excluded from the White Greek system (Thelin, 2004). National Pan-Hellenic Council sororities focus on academics, gender, and race. Since their inception, NPHC has supported their members through educational programming and personal student development opportunities (Ross, 2000). Similarly, CoP places emphasis on the social aspect of learning and interaction (Nickols, 2003), as well as networking to improve the circumstances affecting their community (Wenger, 1998b). The NPHC sorority community networks around academic achievement and civic engagement activities in order to consider problems of mutual interest to its member organizations (NPHC, 2012).

The literature on Black, NPHC sorority membership as it relates to academic achievement and civic engagement is scant (Patton et al., 2011). The relevant literature revealed an incomplete and imbalanced body of knowledge about Black, NPHC sorority membership and its effect on factors associated with academic achievement and civic engagement. The study provides a guide that institutions can use to facilitate the introduction of NPHC sororities at critical times during a student's undergraduate career, which can lead to lifelong civic engagements (Ross, 2000).

Notable NPHC Sorority Members: Achievement Academic and Civic Engagement

Civic engagement and academic achievement are integral parts of NPHC sorority membership. One of the first examples of a member academic achievement was Zora Neale Hurston, a twentieth-century author and member of ZPhiB. She earned an Associate degree from Howard University and a Bachelor of Arts degree from Barnard. During 1925 she matriculated at Barnard in New York City; she demonstrated 
leadership - a predictor of civic engagement (Wade, 2000) as she was the only Black student. Hurston consistently overcame societal limits placed upon Blacks, women, and Black artists. Charlayne Hunter-Gault, a member of DST, was the first Black woman to matriculate and graduate from the University of Georgia in 1963, and then went on to marry a White classmate, which the governor called a disgrace. As an unwelcomed student, she attributes her academic achievement to keep the oath of her Sorority at the forefront of her mind throughout her struggles and endeavors (Hunter-Gault, 1993). Her matriculation and marriage were the actions of a leader as well as predictors of civic engagement (Emler \& Fraser 1999). While Hunter-Gault relied on the words of her founders for encouragement, Yvonne Brathwaite-Burke, a member of AKA offered her own encouragement by breaking barriers. Brathwaite-Burke was the first Black woman from California to be elected to the U.S. House of Representatives in 1973. She also organized legal defense after the Watts riots (Sanchez, 2004). Her actions are examples of civic engagement (Mathiasen, 2005).

More recently, Hydeia Broadbent has become one of the youngest activists to speak out about the HIV/AIDS epidemic. As a member of SGRho, she has reached international levels to educate people of all ages. Ebony Magazine acknowledged Broadbent's civic engagement in both 2008 and 2011 when named as one of the Most Influential 150 African Americans. In 2014, Hydeia Broadbent was honored at PhRMA Research and Hope Awards for Excellence in Visibility and Progress (Broadbent, 2015). Academic achievement and civic engagement are the foundational fibers of all NPHC sororities. 
There is a litany of NPHC sorority members engaged in activities related to academic achievement and civic engagement (Kimbrough, 2003; Whipple \& Sullivan, 1998). Zora Neale Hurston once said, "Research is formalized curiosity. It is poking and prying with a purpose" (Taylor, 2013, para. 6). Research, as posited by Hurston, refers to the social aspect of learning and interacting with a community of practice. Essentially, these are collaborative efforts to determine strategies and to share solutions (Lave et al., 1991; Wenger, 1998b). Perhaps Hurston's statement, academic achievement, and civic engagement were impacted by her membership in her NPHC Sorority.

\section{Academic Achievement}

Most of the literature highlighted the importance of academic achievement as it pertains to the effort of both students and universities alike (Mbuva, 2011). It is essential that higher education professionals and students make the classroom experience as effective and fruitful as possible leading to program completion (Gentry, 2014). For the purpose of the study, academic achievement is the act of consciously pursuing a degree (Bok, 2006). The academic success of the students demonstrates the institution's achievement of its goal of educating and preparing its students for life after college (Prevatt et al., 2011).

The Academic Success Inventory for College Students (ASICS) is a self-reporting instrument aimed at evaluating academic success in college students. Students seeking to achieve academically can easily access ASICS. It is an internet-based survey that uses ten factors to measure academic success. The factors are general academic skills, career decidedness, internal motivation/confidence, external motivation/future, external 
motivation/future, anxiety, concentration, socializing, personal adjustment, and perceived efficacy of the instructor. The ASICS instrument was constructed after the pilot study of 315 university students, followed up by a sample of 930 students (Prevatt et al., 2011). Both sets of students were from a large public university in the southeastern United States. The demographic summary was 68\% White, 13\% Black, 11\% Latino, 3\% Asian and $6 \%$ unidentified. The survey was found to be useful for higher education advisors (Prevatt et al., 2011). It gave advisors a central location to access individualized student statistics related to academic success. Other effective intervention programs included items echoed by the 10 factors to measure academic success. These include: (1) nonthreatening learning environment, (2) committed staff, (3) culture encouraging staff selfgovernance and professional collegiality, and (4) school structure that provides for a low student-teacher ratio and a small class size (Gentry, 2014). While the information garnered can be used to evaluate academic success, the solutions need to be tailored to the needs of each student, and the evaluation fails to address the roles of sorority membership specifically.

Hartley (2011) posited that academic persistence depends on the student's ability to integrate academically and socially. A sample of 605 undergraduate students was recruited from two mid-western universities. Students who can motivate themselves to attend class and study, indicative of academic integration, and to fit into the school environment, which pertains to social integration, have a higher potential for retention. Involvement in on-campus activities and strong academic integration are linked to a higher GPA in the freshman year. Learning is effectively increased through classroom 
activities involving both academic and social integration such as discussion, dialogue, debate, and presentations (Gentry, 2014).

The second body of scholarship deals with self-efficacy. The belief one has in their ability to organize, complete tasks, reach goals, and manage future situations is selfefficacy (Bandura, 1995). Komarraju, Karau, Schmeck, and Avdic (2011) assessed personality traits and learning styles using the Five-Factor Inventory, the Inventory of Learning Processes, and the reported grade point average of 308 undergraduate participants. The personality traits assessed by Five Factory Inventory (Costa \& McCrae, 1992) consists of conscientiousness (being disciplined, organized, and achievementoriented), neuroticism (individuals who experience anxiety, self-doubt, and negative emotionality), extraversion (higher degree of sociability, assertiveness, and talkativeness), openness (a strong intellectual curiosity and a preference for novelty and variety), and agreeableness (cooperative, trusting, and helpful). Traits are associated with aspects of self-efficacy, as they all affect one's goals (Komarraju et al., 2011). The participants' ethnicity summary was $66.2 \%$ White, $22.7 \%$ Black, $2.6 \%$ Latino, 1.9\% Asian, and 1\% Native American. Openness, agreeableness, extraversion, and conscientiousness positively related to academic achievement, while neuroticism related negatively. Aspects of self-efficacy are relevant to academic achievement (Komarraju et al., 2011). Similarly, $80 \%$ of mothers ranging in ages 17 to 22 and the Steps to Success program, maintained enrollment or graduated from college in part because of their selfefficacy (Demeules \& Hamer, 2013). Steps to Success was piloted in Fall 2009, to focus on learning in the classroom, calculating grades, and arranging adequate study time while 
balancing various demands of their lives. Most of the mothers were ill-equipped for college-level work and needed guidance on how to map out time to complete assignments, study for tests, or approach their professors for help. Also, the women had to meet a leadership requirement that instilled confidence and self-advocacy skills, both of which enhanced their experiences inside and outside the classroom. The mothers displayed commitment and the ability to manage events that affected their lives, which are characteristics of self-efficacy (Bandura, 1995). Conceivably, life experience gained by the mothers supported their attitudes of self-efficacy (Martin, Wilson, Liem, \& Ginns, 2013).

The lack of student self-efficacy can lead to a mismatch of student and university pairing (Belasco \& Trivette, 2015). Mismatching occurs when students fail to enroll at a college or university that possesses a level of selectivity that matches their academic credentials. A sample size of 11, 720 students were examined for the purpose of identifying under-matching effects on academic achievement. White women had the highest level of matching at 0.560 in comparison to Black women at 0.163 . Research implies that additional focus be placed on the college admissions process and collegiate selectivity in order to pair students and institutions appropriately. Proper pairing can positively influence disadvantaged populations by overcoming cultural and attitudinal barriers that have typically distracted them from academic achievement. Low selfefficacy because of insufficient social and/or cultural capital may cause the student to self-select out of certain institutions because the student believes they are estranged from 
the individuals, activities, and norms that facilitate postsecondary access and success, subsequently experiencing mismatching.

The literature chronicles closing the achievement gap by actively engaging students. Student engagement has been defined as "participation in educationally effective practices, both inside and outside the classroom, which lead to a range of measurable outcomes" (Harper \& Quaye, 2009, p. 2). While the United States was facing a recession and universities nationwide were losing resources and making budget cuts, 20 institutions were able to engage their students (Kuh, Kinzie, Schuh, \& Whitt, 2011). The institutions moved beyond solely collecting and organizing data to zoning in on the empirical data relevant to changes that would yield increased student engagement, learning, and persistence. Between the years 2002 and 2009, 10 of the colleges improved their graduation rates by either $4 \%$ or $10 \%$. Other colleges experienced a $90-94 \%$ persistence rate within their first to the second-year student population. The 20 institutions had exemplary scores when using the National Survey of Student Engagement (NSSE) instrument. The NSSE constructed a survey instrument in 2000, which is used to collect information associated with student learning and development at the collegiate level (National Survey of Student Engagement, 2015). Four key components were identified as institutional best practices: (a) the courage to maintain positivity in all circumstances, (b) the use of data concerning student success to promote student, (c) both the Academic and Student Affairs department deliberately collaborate to encourage student success, and (d) leadership personnel commits to $\mathrm{CoP}$ in order to convey the importance of student success. Centralized efforts to acquire additional 
resources and participation in national initiatives to improve academic achievement aided the positive efforts of these institutions (Burkholder, 2014; Haak, HilleRisLambers, Pitre, \& Freeman, 2011; Rexeisen \& Garrison, 2013).

The STEM program at the University of Washington used a similar student engagement tactic by increasing levels of structure and practice, and the students performed significantly better (Haak et al., 2011). Conversely, they found that structure and active learning did not benefit academically ill-prepared students. In another study, the structure of curriculum was being changed and re-developed for the purpose of engaging students. There were 100 business schools surveyed using 17, 4-point Likert scales which measured sources of development and implementation of curricula changes designed to improve student learning. School respondents agreed that curricula changes were on the horizon and the schools are in the early stages of developing their practices and processes (Haak et al., 2011). However, responses relating to the different types of changes that schools can make in reaction to assessment results vary (Rexeisen et al., 2013). Student success by way of student engagement is in part dependent on the constant communication of university officials among themselves and with students, student self-efficacy, and relevant data collection, as well as the implementation of those pertinent programs (Gentry, 2014). 


\section{Black Students and Academic Achievement}

Pivotal research found that individual and institutional characteristics are a major predictor of academic achievement for Black undergraduates at both PWIs and HBCUs (Allen, 1992; Harper, 2012). Academic achievement is influenced by psychosocial variables such as college readiness, campus experiences, university practices and programs, and data-driven re-assessments.

Upon the inception of HBCUs, the mission called for the unwavering support of Black students as it relates to academic achievement (Jackson et al., 2003). The mission of the HBCU is to provide excellence in learning and education in addition to offering the chance of a college education to Black people who would not necessarily have that opportunity (Mbajekwe, 2006). From the porters to the professors, the student is monitored and supported. Non-cognitive variables are addressed on a daily basis through the family environment often associated with HBCUs. There are also several mentoring programs, social support groups, and student organizations intended to assist in academic achievement (Carter, 1999), some of which start before the student has even matriculated, such as pre-alumni programs (Tuskegee University, 2015). Depending on the state, the high school student is grouped with others who will be attending the same institution. Prior to arriving on the campus, high school students begin social integration, which contributes to academic achievement (Bean, 1980). 
Schwartz and Washington (1999) noted that African American women in particular face many hurdles to their academic success. Some of the hurdles include inadequate quantities of parental encouragement, restricted financial means to pay tuition and additional expenses associated with college, low confidence, and a lack of role models in their social setting. Faculty-student and peer-group programs including advising, counseling, and mentoring have positive effects on retention of African American female students, mainly when the faculty is symbolic of the indicated population (Flowers, 1998; Landry, 2002).

Predominantly White Institutions (PWIs) have developed and facilitated programs to support Blacks students in academic achievement including Educational Opportunity Programs (EOP), mentor programs, social support groups, and student organizations (including NPHC sororities) (Davis et al., 2004). Educational opportunity programs were established to improve retention of low-income and educationally disadvantaged students which are underrepresented minority students often — Black and Latinx students (SUNY, 2014). Upon being accepted into an EOP program, students benefit from free resources including counseling and advisement, which can improve motivation, self-appraisal, and self-efficacy, thus positively affect academic achievement. The EOP program also supports interactions with faculty and administrators and fosters building a connection to the institution, which also positively affects retention rates (Astin, 1984; Spady, 1971). National Pan-Hellenic Council sororities can have comparable effects on similar populations (Kimbrough, 2003) because seasoned members and neophytes engage in a constant knowledge transfer through academic engagement and civic engagement. 
There is literature focused on Black males and academic achievement. A study on a statewide consortium in Arkansas comprised of community colleges and four-year institutions found that some campus initiatives concentrated almost entirely on providing entertainment and opportunities for social interaction among Black students (Harper \& Kuykendall, 2012). While positive social interactions are pertinent in any college setting, priority should be placed on programs and services that will aid in the smooth adjustment to the academic rigor of college, resolve identity conflicts that detract from academic achievement, respond productively to racist stereotypes, and provide assistance before attrition. Later studies focused on the empowerment of undergraduate Black males and departed from the deficit-informed framework (Fries-Britt, 1997; Jenkins, 2006), which focused on failure, low-performance, and placed the onus solely on the Black male (Eunyoung \& Hargrove, 2013; Harper, 2012). However, the narrative was changed, by emphasizing campus administrators and faculty to cultivate learning environments that upheld institutional values (Adams, 2014; Harper 2012; Talley \& Scherer, 2013). Over the last four decades, the Department of Pan-African Studies (PAS) at the University of Louisville has effectively contributed to the academic achievement of both male and female Black students (Adams, 2014). Twenty-seven graduating seniors were interviewed, over a 3-year period, beginning when they were sophomores. The Black students in PAS maintained a slightly higher first-year retention rate as compared to their White counterparts at $78.5 \%$ and $76.4 \%$, respectively. Twenty-six of the 27 graduating PAS seniors felt supported both in and out of the classroom by PAS administrators. All but three students mentioned the opportunity for discussion within courses and the 
willingness of faculty to promote learning, yet it is not clear if their findings relate to the experience of Black women.

The voices of Black, NPHC sorority women might relate to the experiences expressed but, because of the gaps in the literature, it is not certain and can only be surmised.

\section{Greeks and Academic Achievement}

The term "Greek" is used by researchers as though their findings encompass all Greek students when in actuality, that is not true. McClure (2006) asserted

Previous research on Greek organizations typically ignores the different history and structure of BGOs, as compared to their predominately White counterparts. This takes the form of writing about White Greeks but using the term Greek without a racial modifier, so that race (in this case as in most, Whiteness) is made invisible. (p. 1052).

Black students came to PWIs in high numbers during the 1970s (Bok, 2006). One of the few organizations to assist in college adjustment was the NPHC. The Council promoted hiring more Black faculty and staff, developing courses that discussed African American history and creating a welcoming environment for Black students (Bok, 2006). The literature on NPHC and the impact on member's development and retention in college is sparse. Kimbrough (1995) studied 61 African Americans from three campus organizations: NPHC, the Black Student Association, and the Gospel Choir. Of the sample, 27 were NPHC members, 25 women, and two men. They answered a two-part questionnaire. The first part assessed their leadership skills and participation in their respective organization, while the second part used a Likert scale to investigate three separate areas: leadership and leadership experiences, the ability of different 
organizations to provide these opportunities, and their overall attitudes about NPHC and their members. Kimbrough (1995) found that both Greeks and non-Greeks saw value in Black organizations at a PWI.

Alvarez, Cabacungan, Jobson, and Kudera (1998) sought to examine the effects of peer environments on fraternity members. The study was conducted at a large public institution with a sample size of 85 men from two predominately White fraternities, fraternity A and B. Interviews were held with the president and scholarship chairpersons of each fraternity after researchers reviewed the data from surveys, distributed to the sample size. Fraternity A had a significantly higher GPA than Fraternity B. A significant portion of Fraternity A (98\%) attributed their academic success to the fraternity and credited the fraternity with honing their study skills, utilizing peer tutoring, implementing mandatory study hours, and engaging in various academically related activities. Fraternity A also indicated, that $16 \%$, found the fraternity house to be a distraction to achieving academic success. According to the t-test analysis, Fraternity A respondents perceived a major emphasis on academic achievement, resulting in higher individual GPAs. While $42 \%$ of Fraternity B, attributed their negative academic achievement to the fraternity. Fraternity A also offered incentives such as a number of scholarships for academic achievement in addition to preferred housing, whereas Fraternity B only offered preferred housing. The results supported the researchers' hypothesis if a fraternity places a higher emphasis on academic achievement they will have higher individual and/or collective GPA(s). Conversely, a fraternity that does not emphasize academic achievement will have lower GPAs. Though the study was on 
predominantly White fraternities, it employs CoP. Fraternity A used a social setting to emphasize academic achievement, causing members to achieve academic success; NPHC sororities do the same (Kimbrough, 2003). Additionally, NPHC sororities do not have designated houses which Fraternity A found to be a distraction (Ross, 2000).

The larger body of literature focuses on Greek life as a whole and is qualitative. With a total target sample of 3,910 students from eighteen institutions selected from the National Center on Educational Statistics Integrated Postsecondary Education Data System. Pascarella et al., (1996) sought to study the cognitive effects of Greek life using a pretest-posttest quasi-experimental design. Participants completed the Collegiate Assessment of Academic Proficiency (CAAP, 2010), which assesses general cognitive skills typically acquired during the first two years after matriculation. Analysis showed that sorority members who joined a sorority during the first year of college had a negative effect on overall academic achievement as compared to their non-Greek counterparts. However, the researchers did not collect council affiliation from the participants. Pascarella et al., (1996) noted that Greek students of color seem to form a subculture that upholds the academic achievement desired by institutions. Moreover, they posited, further study needed to be done on students of color, to determine what can be learned from them that might be useful in altering the dominant students' Greek culture. A follow-up study sought to estimate the cognitive impact of Greek affiliation on students beyond the first year of college (Pascarella, Flowers, \& Whitt, 2009). The study analyzed data on Greeks through their third-year experiences. Sorority membership had a statistically significant, total positive effect in science, writing, and thinking skills as 
compared to their non-Greek counterparts. It was unclear whether the sorority women were members of NPHC. The researchers noted that subsequent years in college showed fewer negative effects on sorority members as compared to their non-Greek counterparts. Pascarella et al., (2009) suggested that new members should not be inducted into sororities until after the first year of college. National Pan-Hellenic Council sororities have already implemented this practice (Kimbrough, 2003).

Hayek, Carini, O'Day, and Kuh (2002) examined levels of engagement among sorority and fraternity members, with a specific interest in comparing the engagement of non-members. Forty-two thousand one hundred and eighty-two undergraduate students of 192 institutions participated. Of the 42,182 undergraduates, 6,560 self-identified as Greek students (62\% women, 38\% men) and 35,622 other students (65\% women, $35 \%$ men). The NSSE instrument was used. The data analysis correlated Greek membership with higher levels of student engagement as compared to non-Greeks. Greeks were also found to implement educationally effective practices more often than their non-Greek counterparts. While the study offers a positive correlation with members, the data are not evaluated by race, nor is it separated by PWI/HBCU, or examined by council affiliation (NPHC, NPC, etc.). Also, some participants identified themselves as Greek members, but their institutions did not report any fraternities or sororities on their campus. 


\section{Sororities and Academic Achievement}

The first Black, collegiate Sorority, AKA, set the academic achievement

precedent by embodying the idea, education is a privilege and those that pursue as well as attain degrees are in "everlasting debt to raise [Black communities] up and to make them better" (Alpha Kappa Alpha Sorority, Inc., 2014, para. 3). Over the next 15 years, three more NPHC sororities were founded. While each had a slightly different objective, all placed academic achievement at the forefront of their endeavors (Kimbrough, 2003). National Pan-Hellenic Council sororities promote academic proficiency and have a required GPA for entrance and maintenance of membership in the sorority (Ross, 2000). GPAs directly affect retention because of institutional regulations (Harrell, 2012). The minimum GPA a student must maintain to continue their academic endeavor is mandated at all universities (SUNY, 2014). Once grades below the minimum GPA, financial aid is often dropped leaving the student without a means to pay for further education. The lack of funding can be devastating and quickly lead to a negative effect on retention.

There are cognitive impacts of Greek affiliation beyond the first year of college, which would be pertinent to NPHC sororities and are qualitative in nature (Pascarella, et al., 2009). The study analyzed the data of Greeks through their third-year experiences. Sorority membership had a statistically significant, total positive effect in science, writing, and thinking skills as compared to their non-Greek counterparts. Researchers did not denote whether the sorority women were members of NPHC. It would have also been beneficial to my study, had the data of those students of color been analyzed to determine how they attain academic achievement (Pascarella et al., 1996). The 
researchers did, however, note that subsequent years in college showed fewer negative effects on sorority members if not complete elimination as compared to fraternity members. Moreover, the researchers posited in the implications section that, prior to eradicating institutional policies on Greek life, a delay should be considered in relation to the induction of new members into sororities; specifically, until after the first year of college. National Pan-Hellenic Council sororities have already implemented this practice. Upon a year of successful adjustment to the academic demands, NPHC interests can be considered for possible membership. Analysis of the data implies that affiliated sorority activities have minimal adverse effects academic success.

Pike (2000) investigated the relationship among Greek membership, college experiences, and cognitive development. Three years later a study emphasized additional differential effects of the Greek system on first-year and senior students, both male and female (Pike, 2003). The study included 6,782 undergraduates attending 15 American Association of Universities (AAU) public research universities. The researchers utilized the NSSE instrument. However, College Student Report (CSR) was employed. Only $4.3 \%$ of the participants were Black, yet, the study does not specify whether some of the participants were NPHC members or members of another council. The study found firstyear Greek and non-Greek students differed considerably in academic achievement.

Those who were Greek were more inclined to participate in active learning and improve their academic achievement. Greek seniors were more involved than seniors who were not. 
Unlike Pike (2000), Grubb (2006) did not find significant differences. The researcher found that sorority membership was statistically insignificant when compared with the GPAs of non-sorority members. The study included a mid-sized institution with 3,557 participants to evaluate the effects of Greek membership on academic performance. All participants were seniors. There were 1567 males, 374 were members of a fraternity. The sorority members were a bit larger in number compared to their counterparts at 451 and the remaining 1539, were non-members. Academic transcripts were used to compile the data. The data also showed that sorority size had no effect on GPA. However, Grubb (2006) noted that the smallest sorority was 50\% larger than the smallest fraternity. The sororities averaged 35 members per chapter. The study is beneficial because of the findings, but there are differences in my study that may change the results. For example, chapter size of NPHC sororities is often smaller than the stated average in the study, neither does the study state the council that each Greek participant is associated with. Also, Grubb (2006) utilized the data to expound on the freshmen cost for Greeks to pledge, NPHC typically does not take freshmen (Kimbrough, 2003).

\section{Civic Engagement}

For the study, civic engagement is defined as the involvement of students through discussion and action with major social issues, both inside and outside the university (Dewey, 1916). For undergraduate students to experience meaningful civic engagement experiences, some researchers deem diversity within the student population a necessary component (Bowman, 2011; Manikowske \& Sunderlin, 2013). A meta-analysis was used to explore the relationship among college diversity experiences and civic engagement 
(Bowman, 2011). In the college setting, there are mainly three types of diversity structural (diverse people within a larger group), classroom (diversity-related courses and multicultural campus events), and informal interactional (interactions beyond those of a formal curricular or co-curricular context with a diverse population) (Hurtado, Milem, Clayton-Pedersen, \& Allen, 1999). A total of 175,950 undergraduates were included in the study. The researcher utilized self-reports and longitudinal methods to analyze the relationship. Hurtado et al., (1999) found diversity in student populations lends itself to increases in civic attitudes. The strength of the relationship between civic engagement and diversity is dependent on the type of diversity. Data indicated that the strongest relationship between civic engagement and diversity were formed during informal interactional diversity experiences. Others found classroom diversity to be an indicator of civic engagement (Manikowske et al., 2013; Markus, Howard \& King, 1993). For example, two teachers integrated classroom instruction with a community program called Clothing and Connections, with the intended outcome of civic engagement. The program assists in making a successful transition into the workforce by providing apparel and student volunteers in fashion design courses. Clothing and Connections began in 1999 and had helped over 3,200 clients. Students reported that they often become immersed in their own lives, but the particular experience made them aware of hardships faced by others. In addition, students worked with classmates they had never interacted with prior to volunteering for the program. They effectively communicated to fulfill the needs of the program. 
The intentional engagement of university students within the community, for the purpose of undertaking community issues, is pertinent to civic engagement (American Psychological Association, 2015). Duke University developed DukeEngage to function in the aforementioned capacity, specifically the seamless incorporation of co-curricular and curricular aspects of civic engagement at Duke University (Mlyn, 2013).

"DukeEngage provides one-time funding for Duke undergraduates who wish to pursue an immersive (minimum of eight weeks) service experience by meeting a community need locally, domestically or internationally" (Duke University, 2015, para. 3). In 2006, endowment gifts totaling \$30 million allowed the program to begin with substantial financial backing. The program began with 90 undergraduates, by 2013 the student participation had more than quadrupled to 435 annually, and the goal set for 2017 is 600 annually. In addition, DukeEngage has established the annual goal of \$20 million in endowment support of which $\$ 10$ million was gifted during 2012. Duke University saw the chance to engage community issues and provide student solutions with the guidance of faculty, as an opportunity to display another valuable by-product of America's higher institutions (Bok, 2006; Mlyn, 2013). Participants described positive outcomes related to informal interactional diversity experiences (Hurtado et al., 1999). More explicitly, they reported growth in personal efficacy, cultural competence, and leadership. After the student chose and experienced one of the many local and international civic engagement activities available, a questionnaire was utilized to explore the perceptions and outcomes of a civic engagement project (Braunsberger \& Flamm, 2013). Data indicated that civic engagement enhances learning with any civic engagement project, therefore improving 
grades as these civic engagement projects were co-curricular, in addition to assisting nonprofit and public sector in reaching their goals. However, the described gains seem to vary and are complex, based on cultural and national differences (Kyriacou \& Kato, 2014).

Both national and international community-based civic engagement activities hold an importance in institutions of higher education (Innovations in Civic Participation, 2008). A study used a questionnaire to explore civic engagement attitudes (Kyriacou et al., 2014). A sample of 120 undergraduates in England and 137 undergraduate students in Japan were questioned about their motives and feelings on civic engagement. While both sets of undergraduates found civic engagement to be enjoyable and helpful in their respective communities, they varied in their responses concerning personal development and opportunities to socialize. Two-thirds of the Japanese participants as compared to one-third of the participants in England considered personal development paramount. Additionally, Japanese participants were over five times more likely to cite opportunities to socialize as a reason to participate in civic engagement activities than English participants at $51.1 \%$ and $10.0 \%$, respectively. These studies identified financial and cultural differences that may influence the proposed study; however, they are were recognized because of the scant research (Kimbrough, 2003).

Cultural differences include religious variances (Gardener, 2002). The correlation between civic engagement and religion was examined (Becker \& Dhingra, 2001; Chickering, 2006; Droege \& Ferrari, 2012). Universities encourage faith-based, selfexploration to support constructive attitudes towards civic engagement (Chickering, 
2006). Droege et al., (2012) study explored attitudes relevant and favorable regarding civic engagement by utilizing a sample size of 955 undergraduate students (339 men, 616 women) of three large, Roman Catholic universities. The sample size was less than $15 \%$ of the actual population, of 13,627. More than half of the participants self-reported as White at $68.3 \%, 82.6 \%$ of them were employed, $48 \%$ were Christian but rarely attended church. Utilizing a web-based survey, researchers collected data regarding student's backgrounds, civic and faith-oriented behaviors, and perceptions. Results identified five reliable and valid subscales two of which were civic engagement and influences regarding spiritual growth. The study noted a positive correlation between civic engagement and spirituality.

The study of a small, rural, Christian university researched undergraduate attitudes, personal values, religious commitment, and regularity, as it relates to civic engagement (Strawhun, Perry \& Lloyd, 2014). The sample consisted of 40 females and 21 males, of which $80 \%$ were White. The data supported the researcher's hypothesis that Christian students did not place civic engagement at the forefront of their activities. Furthermore, the students' religious commitment was not an indicator of those who were heavily involved in civic engagement as opposed to those who were not. The NPHC sororities have Afro-Christian practices such as initiation rituals, rhythmic movements and sounds of stepping, Afro-iconographic retention, and Christian lore (Brown, et al., 2005) and these practices may affect civic engagement outcomes. 


\section{Black Students and Civic Engagement}

The breadth of literature encompasses the financial hardships faced by Historically Black Colleges and Universities (HBCUs) and Black churches when trying to fulfill their missions, which includes civic engagement (Pew Research Center, 2010). The Association for the Study of Higher Education reported on the changes necessary to maintain the legacy that is HBCUs intense involvement in civic engagement (Introduction and Overview, 2010). Traditional HBCU and Black church civic engagement practices were pivotal in President Barack Obama's win in 2008. President Obama believes that HBCUs will only survive if they focus more on degree attainment and less on those actions that helped him get into office- civic engagement (Gasman, 2009).

With the understanding that civic engagement is part of the HBCU mission, it is purported that HBCUs need to consider modifications in the current curriculum and its effect on the students (Acauave \& Edmonds Crewe, 2012; Pew Research Center, 2010). Howard University examined the benefits in adjusting the curriculum to bolster their students' participation in civic engagement, even though the students faced financial constraints (Acauave et al., 2012). The Howard University School of Social Work International Service Learning (Howard ISL) was established to address financial constraints or levels of affluence, encouragement and support from faculty, attrition rates, choice of major, family and community support, education about opportunities, anxiety about the unfamiliar or lack of previous travel experience, and correlations between international competence and career objectives. Through Howard ISL's civic 
engagement opportunity, students were able to travel to Cape Town, South Africa. The cost was absorbed through grants, fundraising, and donations (Howard University School of Social Work, 2013). From 2009-2011, 67 Black students were served. A majority of the students indicated that they had an above average mastery of the core competencies for their major, while more than half of the participants stated that their overall experience was exceptional. However, the study does explore prior experiences of participants including that of NPHC membership, which are indicators of future civic engagements (Wade, 2000).

Funding and the need for HBCUs to continue their mission in educating underrepresented post-secondary populations while preparing students through civic engagement has decreased because of federal and state budget allowances and perceptions of a post-racial America (Patterson, Dunston, \& Daniels, 2013). The shift requires research to establish strategies that will increase academic engagement, thus increasing revenue through student retention, and ultimately upholding the mission to prepare students via civic engagement (Fear, Rosaen, Bawden, \& Foster-Fishman, 2006). One of the possible resolutions utilized the co-curricular approach of a service-learning pedagogy. Service learning pedagogy is a widely used approach because it integrates classroom teachings, strengthens communities, employs active learning that requires critical thinking, allows for student engagement, and subsequently civic engagement. The approach is cost-effective and empirically supported, as a result fulfilling the needs of HBCUs. While the strategy is pragmatic, the mission of NPHC sororities and their function has been left out of the dialogue. Because most NPHC sororities were founded 
at an HBCU, the overlap of civic engagement outcomes can be useful in upholding both missions.

Many HBCUs are facing financing issues as a result of the lack of state funding and endowments, which are valuable in building the communities around them (HBCU Digest, 2015). The under-developed communities where many HBCUs are located make it difficult to attract businesses and new students, both of which are subsequent revenue for these HBCUs. To offset years of neglecting these communities, HBCUs have welcomed public service professionals because they can assist in establishing community development corporations (CDCs; Lowe \& Shipp, 2014). Advocacy and social justice activism birthed CDCs in the 1960's civil rights movement. The civil rights movement brought a sudden increase in NPHC chapters (Kimbrough, 2003) because of issues in social justice. It appears that HBCUs, CDCs, and NPHC sororities would be ideal allies in pooling their resources for the purpose of civic engagement outcomes, yet it was not discussed.

\section{Greeks and Civic Engagement}

The majority of studies addressing the impact of Greek membership on college students' outcomes tend to focus on the experiences of White students, with varied results (Wilder \& McKeegan, 1999). The existing literature seldom discusses distinctions between NPHC and other Greek councils, which are predominantly White (McClure, 2006). For example, a study on the frequency of civic engagement of college students indicated $60 \%$ of undergraduates failed to join groups that provide civic engagement opportunities, while only $13 \%$ of college students are in Greek organizations offering the 
possibility to engage in a civic manner (Andolina, Jenkins, Zukin, \& Keeter, 2003). The researcher fails to delineate Greek organizations by council and frequency of civic engagement opportunities within the respective councils.

Research about Greeks and civic engagement is scant. The focus is on Greek organizations and philanthropic efforts. Philanthropy is the act of promoting the welfare of others, usually expressed through generous donations of money to good causes (Drezner, 2011). Philanthropy differs significantly from civic engagement, which is the involvement of students through discussion and action with major social issues, both inside and outside the university (Dewey, 1916). The principal connection between Greek organization and the community is through fundraising and then donating to a cause (Parker, 2012). Furthermore, the researcher's use of the word "Greek" does not acknowledge the distinct role and structure of NPHC from that of mainstream Greeks (McClure, 2006).

The examination of the relationship between Greeks in NPHC and civic engagement is often addressed in the popular press but is lacking in the academic literature. Most recently, civil rights leader and U.S. Representative for Georgia, John Lewis, who is also a member of the NPHC fraternity Phi Beta Sigma (PBS), was portrayed in the movie Selma (Lewis, 2012; 2015). The movie depicted civic engagements of the then student activists John Lewis and Martin Luther King Jr.'s (member of the NPHC fraternity, Alpha Phi Alpha (APhiA) in the 1965 March from Selma to Montgomery, also known as Bloody Sunday, for the purpose of equal voting rights) (Lewis, 2012; Eyewitness, 2017). 
In 2011, the hard work of the men of Alpha Phi Alpha an NPHC fraternity, became evident to the public when the Martin Luther King, Jr. monument located on the National Mall in Washington D.C. was scheduled to be dedicated on August 28, 2011 on the anniversary of the 1963 March on Washington (Blalock, 2011). The men of APhiA worked diligently to raise money to erect the monument in their fraternity brother's name. They established fiscal and fundraising plans, drafted drawings and blueprints and rallied public support. Alpha Phi Alpha persuaded Congress and essential participants of the executive branch, including the Department of the Interior and the White House, to greenlight the project. President Obama was scheduled to deliver a speech concerning civic engagement's place in modern-day America in addition to the orations of several civil rights leaders detailing their stories of struggle. However, because of Hurricane Irene, the dedication was postponed to October 16, 2011, that marked the16th anniversary of the 1995 Million Man March.

The Million Man March was supported by all organizations in NPHC. Phi Beta Sigma not only supported but also sponsored the March at its International Headquarters at 145 Kennedy St. NW in Washington, DC. Benjamin Chavis Muhummad, a member of PBS, coordinated the event (Phi Beta Sigma, Zeta Delta, 2015). The March was one of the most momentous events with the sole intent of organizing Black men of all creeds, in the United States. For ten hours these men, including NPHC members, stood while listening and sharing experiences with each other to better their communities. They demonstrated their willingness to shoulder the responsibility of improving themselves, by taking part in civic engagement, in their respective communities (Nation of Islam, 2015). 
On March 18, 2015, Martese Johnson, a member of Kappa Alpha Psi (KAPsi), an NPHC fraternity was assaulted by Virginia Department of Alcoholic Beverage Control agents in Charlottesville, Virginia (Kingkade, 2015b). The encounter left Johnson, a student at the University of Virginia (UVa), bloodied and needing ten stitches in his head. He was held on $\$ 1,500$ bond and charged with resisting arrest, obstructing justice without threats of force, and profane swearing or intoxication in public. He was released on an unsecured bond the following morning (Heskett, 2015). Martese Johnson was a thirdyear honors student, member of the Honor Committee, member of the UVa Black Student Alliance, and was initiated at the University of Virginia, on March 10, 2013, in the Eta Sigma Chapter of KAPsi (Bates, 2015). The brothers of KAPsi started a webbased crowdfunding campaign on March $21^{\text {st }}$ to help pay for Johnson's legal and medical expenses (Nordrum, 2015). The immediate demonstration of civic engagement as displayed by KAPsi is indicative of NPHC organizations (Ross, 2000).

Ironically and unrelated, shortly before Johnson's assault, he posted his thoughts on Facebook about a Sigma Alpha Epsilon fraternity's racially charged incident (Kingkade, 2015a), "This is why things like Black Greek organizations, Black mentorship programs, and Black professional networks still need to exist. If you were wondering..." (Kingkade, 2015a, para. 10). He understands the value of Black Greek organizations and the need for civic engagement though many believe they live in a postracial America, because of self-social segregation which allows Americans to turn a blind-eye to injustices outside of their immediate circle (Speri, 2014). 


\section{Sororities and Civic Engagement}

Present day reports of police brutality on Black Americans have been the catalyst to recent acts of civic engagement by NPHC Sororities and their members. After civil unrest because of murders in Ferguson, Missouri; Staten Island, New York; and Cleveland, Ohio by the hands of police officers, the International President of ZPhiB, Mary Wright, addressed her Sorors and called them to action (Wright, 2014). Wright recounted the words of $\mathrm{ZPhiB}$ member, Elisabeth Omilami, and daughter of civil rights leader Hosea Williams (member of PBS), "we must remain non-violent in our protesting, but we must continue to protest" (Omilami, 2014, p. 1). Mary Wright called for ZPhiB members with expertise in law, law enforcement, political engagement, and youth development to become and remain involved in civic engagement (Wright, 2014). She challenged members to get engaged via protest through social action. In response, through CoP, Get Engaged was established and then released on December 22, 2014 (Zeta Phi Beta, Inc., 2014b). Get Engaged was created to address the fundamental ills contributing to the senseless killing of Black Americans in the U.S. The civic engagement initiative has three objectives:

1) Drive individual and community engagement in the underlying issues that are destroying our communities and augment an understanding of the benefits and consequences of action or inaction

2) Empower citizens through knowledge sharing and fostering collective responsibility among community members

3) Cultivate a culture of mutual respect in our communities. (Zeta Phi Beta, Inc., 2014b, p 1) 
Since the establishment of Get Engaged, Krysta Jones has been appointed as the National Director of Social Action (Zeta Phi Beta Sorority, Inc., 2015a). Get Engaged gives each $\mathrm{ZPhiB}$ chapter the opportunity to address specific community issues through $\mathrm{CoP}$ and share best practices at conferences with other chapters.

Stephanie Rawlings-Blake, a member of AKA (an NPHC Sorority), was sworn in as Baltimore's 49th mayor on February 4, 2010 (Maryland State Archives, 2017). She won the election with an overwhelming $87 \%$ on the platform of strengthening Baltimore neighborhoods through improving civil servant interactions with the public and public education. She has received many awards because of her civic engagement. In 2007 and 2011 Rawlings-Blake was awarded the Shirley Chisholm (DST member) Memorial Award Trailblazer by the National Congress of Black Women. She is a member of the Alliance of Black Women Attorneys and has served civic engagement organizations including Baltimore Substance Abuse Systems, Inc., Living Classrooms Foundation, and Parks and People Foundation. Mayor Rawlings-Blake came under fire while civil unrest ravaged the city of Baltimore (Schleifer, 2015). The civil unrest was in response to the subsequent death of Freddie Gray on April 19, 2015, upon suffering spinal cord injuries while in police custody (Fantz \& Botelho, 2015). In attempts to protect the civic engagements of protesters, Blake-Rawlings refused to impose a curfew on Baltimore as well as activate the state's national guard during the first night of civil unrest (Schleifer, 2015). Some saw her decision as passive and blamed her for the continued civil unrest. However, Mayor Blake-Rawlings remained steadfast in her sentiment, "What I said very clearly was ... when you facilitate space for people to be heard, that space was exploited 
by those who meant to do harm to our city" (Schleifer, 2015, p. 10). Her ability to support civic engagement rights of citizens while being criticized by the media and politicians may have been a skill honed during her interactions as an AKA, however, empirical research to support that is scant.

On April 29, 2015, an emergency town hall meeting was held after the protest began on April 18, 2015, in Baltimore (Lenghi, 2015). During the protests, hundreds of people were arrested, and police officers were injured, still, the number in attendance during the town hall meeting was even greater. The diverse group acknowledged problems including systematic poverty, corruption, and police brutality and discussed the beginnings of solutions. Among those in attendance were the women of ZPhiB (Fox, 2015). They came out in large numbers, sporting their Sorority paraphernalia and colors, royal blue and white. As CNN reporter Erin Burnett covered the Baltimore town hall meeting live, she described the members of ZPhiB as gang members. Members of ZPhiB viewing $\mathrm{CNN}$ at the time as well as other NPHC sorority members were livid and made their sentiments known to $\mathrm{CNN}$ through social media and email. By taking action against the misrepresentation of an NPHC Sorority through civic engagement, they received a public correction on Erin Burnett's OutFront the following day. Burnett noted that she did not intend to imply ZPhiB was a gang and acknowledged the civic engagement activities they had participated in to assist Baltimore since the civil unrest (CNN, 2015).

Boggs et al., (1995) stated "Civic activity may come about naturally, given the combination of innate intelligence and exposure to the volunteer and educational opportunities in every community" (p.463). The participation of NPHC sororities, 
specifically individual members in civic engagement, is documented in popular press but lack the academic literature to posit about prospective engagements. The study aims to initiate discourse and reflection among key higher education student affairs practitioners and NPHC Headquarters.

\begin{abstract}
Summary
Chapter 2 examined the literature surrounding academic achievement and civic engagement in higher education and as it pertains to NPHC and their sororities, including an introduction and examination of scholarly perspectives of these groups. Chapter 3 discusses the research design and method used in the study.
\end{abstract}




\section{Chapter III}

\section{METHODS}

This chapter begins with the purpose of the study and the research questions. The phenomenological research design is discussed, followed by my autobiography and assumptions related to the study. Next, sampling criteria and procedures for data collection, data analysis, and data management are described. The chapter concludes with a discussion of integrity measures, and limitations of the study.

\section{Purpose of the Study}

The purpose of this study was to explore the experiences of Black, NPHC sorority members, as they relate to understanding their academic achievement and civic engagement. The study was conducted in an effort to foster discourse and reflection on the part of NPHC Headquarters, Greek life advisors, NPHC sorority members, and student affairs practitioners in order to create supportive environments for sorority members. The discourse among the aforementioned parties, combined with findings from the study can affect the way NPHC sororities are advised. These organizations are historically different than mainstream Greeks and require support, but are not understood because of the lack of empirical research within higher education (Fries-Britt et al., 2007). Empirical research can provide support to historically marginalized people in institutions of higher education —Black women (Davies et al., 1994; Strayhorn et al., 2012). 


\section{Research Questions}

The primary research question is, from the points of view of Black NPHC sorority members, how do they view academic achievement and civic engagement? The subsidiary research questions are:

1) What are the perceptions, attitudes, and lived experiences of Black NPHC sorority members regarding academic achievement?

2) What are the perceptions, attitudes, and lived experiences of Black NPHC sorority members regarding civic engagement?

3) How do Black NPHC sorority members understand the influence of membership on their academic achievement and civic engagement?

4) How does an NPHC sorority act as a community of practice to foster a spirit of academic achievement and civic engagement in members?

\section{Phenomenological Research Design}

The phenomenological research design was used to seek understanding as it pertains to the fundamental core of a phenomenon (Creswell, 1998; Patton, 2002). The understanding of the phenomenon is gained through extensive research of lived experiences. The essence of one's experience is the essential, invariant structure or central underlying meaning (Creswell, 1998). Understanding the meaning of the phenomenon as it relates to the involved individuals can uncover "background factors such as stirrings of pleasure, shaping of judgment or incipient wishes" (Patton, 2002, p. 484) which establish realities as perceived by those individuals. These meanings are socially constructed based on the environmental and historical contexts of individuals 
(Gibson \& Hanes, 2003). These contexts affect individuals' perceptions and, thus, their realities. Phenomenological research begins with an inquiry concerning the meaning of participants' experiences of a phenomenon (Gibson et al., 2003). The phenomenon of interest, was Black, NPHC sorority members' understanding of the influence of membership on their academic achievement and civic engagement.

\section{Researcher's Autobiography}

As a freshman in college, I saw many groups in "funny letters" floating around campus. The groups were seen at social events such as parties and pep rallies, dancing to the latest songs in lines of synchronized rhythmic movement. The type of movement had only been viewed on television shows such as A Different World and Family Matters, but never in real life. I also heard calls and saw hand signs specific to each of these groups. The more I saw these groups, the more they intrigued me. I noticed the exclusivity of these groups and later realized they were sororities in NPHC.

Sororities had a strong presence at my university as it related to academic achievement and civic engagement. I noticed that they conducted several workshops tailored to those ideas on campus for the benefit of the student body. However, I never bothered to learn more about them until my mother suggested that I do so. Upon getting the nudge from my mother, I began exploring the world of NPHC sororities. The exploration led to my understanding that these sororities not only maintained a strong presence on my campus but also had international platforms geared toward academic achievement and civic engagement. 
After much inquiry and observation of the four NPHC sororities, I became a member of Zeta Phi Beta Sorority, Incorporated on April 7, 2001. For the next year, I honed skills to assist in my academic achievement and civic engagement. Academic achievement was refined through programs such as the National Educational Foundation designed to engage members in activities that aid in the educational development of all women (Zeta Phi Beta Sorority, Inc., 2015b, para.1).

Civic engagement was enhanced by participation in activities such as Z-HOPE (Zeta- Helping Other People Excel) which is "an outreach service program that has six primary objectives, corresponding measures of success and a mechanism for chapter recognition one of which is to foster collaborative partnerships between community organizations" (Zeta Phi Beta Sorority, Inc., 2015b, para. 2). I received social prompts from both members of my Sorority and members of other NPHC sororities to maintain close ties in academic achievement and civic engagement arenas. The obligation continues today, as NPHC sorority membership is a lifelong commitment.

The expectation and duty I feel to contribute to academic achievement and civic engagement, both personally and within the community, is constant. I have continued to pursue both academic achievement and civic engagement, though doing so has sometimes been an arduous task; but I attribute this to the tenacity taught through the Sorority. As a graduating senior in college, I became aware of a flag on my academic file in March of 2002, which would hinder my graduating on May 12, 2002. I had heard of this happening to seniors in years past, where necessary courses were missed by the academic advisor and were not discovered until it was seemingly too late to take the 
course and graduate on time, but never thought it would be an issue of mine. I was completely devastated and sought the counsel of another Sorority member. The other member suggested that I take the course in Fall 2002. I knew this would not be an option as I wanted to graduate with my class and that would only happen once. After a week of inquiry, another Sorority member found a mini-session at a local college that would allow me to fulfill the academic void and graduate with my class.

More recently I faced many obstacles in my doctoral program. One of which was my grandmother falling ill in Brooklyn, New York while I was in Miami. My grades were negatively affected, and I was facing possible dismissal from the program. After seeking the counsel of a ZPhiB undergraduate member, I was made aware of the forgiveness policy. I worked diligently to take the necessary coursework and fulfill the academic requirements of my program. Other sorority members would check on me and offer whatever they could spare, whether it was words of encouragement, making meals when I had no time to do so, or housing, as I was homeless during part of my doctoral coursework. Had it not been for the advisement of a Sorority member, I may have never had the opportunity to continue my pursuit of a doctoral degree, which is evidence of academic achievement.

Like academic achievement, civic engagement is an expectation and a duty of NPHC sorority members. Most recently, when the murder of Black people at the hands of law enforcement personnel became a constant headline in the news, I took action. I organized a community meeting at my place of employment and participated in rallies and protests in support of the hashtag \#BlackLivesMatter. At one of the protests, I was 
nearly injured by a law enforcement officer on a motorcycle. Thanks to the quick thinking of another NPHC Sorority member, the law enforcement officer was alerted by his fellow officer and avoided hitting my leg. I did not know this other woman, but she saw my Sorority jacket and felt compelled to react. It did not matter that we are in two different NPHC sororities.

I developed an interest in the academic achievement and civic engagement of Black, NPHC sorority members as a result of being a member of a Sorority for over 15 years and finding strength amidst adversity in higher education through lessons taught by the Sorority through academic achievement and civic engagement. Through further investigation of the concept of $\mathrm{CoP}$ and how it operates in other NPHC sorority members, it became apparent that a significant gap in the literature existed. The gap exists in discussion regarding academic achievement and civic engagement within NPHC sororities. My responsibility, as a Black, NPHC woman studying other Black, NPHC women, is to identify the struggles and efforts toward academic achievement and civic engagement within the sorority and express them in a manner that sheds light on the phenomenon (Collins, 2000).

\section{Assumptions}

The following highlight my assumptions for the study:

1) Black students participating in the study will, to at least some degree, mirror the experiences of Black students in other NPHC sororities.

2) Students interviewed will provide insight based on their lived experiences and provide their perceptions. 
3) Individuals may exaggerate their positive experiences as not to bring reproach to their organizations.

4) Participants will be able to share, in words that qualitatively capture the essence of their experiences sans their regard for their respective organizations.

\section{Journaling Process}

A journal was maintained to document my reactions, thoughts, and feelings while conducting interviews as well as after listening to the recording of an interview, to curtail any assumptions or beliefs. The journal served as a "disciplined and systematic effort to set aside prejudgments regarding the phenomenon being investigated in order to launch the study as far as possible free of preconceptions, beliefs, and knowledge... from prior experience and professional studies" (Moustakas, 1994, p. 22). All journal entries were handwritten in a notebook solely for the purpose of recording observations and note taking, not for data.

\section{Sampling}

Communities of practice are informed by matters deemed pertinent to its members (Wenger, 1998b). The members were Black, HBCU undergraduate, NPHC sorority women because of their personal experience. The study solely reflects those CoP members - Black, NPHC sorority women, because it is their perception that adds to the breadth of literature (Creswell, 2003) and exposes voices which have been excluded (Kimbrough, 2003). Criterion, purposive, and snowball sampling were used to secure participants. Criterion sampling involves predetermined criteria, which offers an opportunity to identify those participants with desired characteristics, while purposive 
sampling focuses on information-rich cases with limited resources (Patton, 2002). The criteria for NPHC sorority members sample was (a) a current undergraduate member of an NPHC sorority at an HBCU, (b) self-identified as Black, and (c) identified as a prophyte. A prophyte is a person who has been a member long enough to see their chapter induct a new line of members as opposed to a neophyte, who does not have much time or experience in the organization. The time to be an undergraduate prophyte is very limited as induction into NPHC sororities is the earliest, during sophomore year. The study sample included 13 participants as suggested by Creswell (1998) for the purpose of providing rich data to offer the best insights in the phenomenon.

A characteristic of phenomenological research is that it understands the phenomenon through the rich data collected from participants' lived experiences (Creswell, 1998). Though participant numbers may vary from as few as 6 to 10 (Teddlie \& Tashakkori, 2009) to 12 (Guest, Bunce, \& Johnson, 2006), rich data typically includes less than 26 participants (Miller \& Salkind, 2002). Saturation is accomplished when no new perspectives on a topic are introduced. The study included 13 participants as suggested by Creswell (1998) for the purpose of achieving saturation.

I am employed at an HBCU institution of higher education in the South, which has all four NPHC Sororities. Also, as a member of an NPHC Sorority, my membership affords me the opportunity to work with members and gain trust but can lend itself to insider bias. To minimize insider bias, I recorded my personal reactions in a journal. A sign-up sheet was posted in the Student Activities department to solicit participants (See Appendix D). Because of NPHC sorority intake restrictions, snowballing was utilized. 
Identified participants referred persons who had experience with the phenomenon of interest (Vogt, 1999). A formal email request was sent to potential participants explaining the purpose of the study, the selection criteria (See Appendix C), and the process to gain the consent of the participants in the study, in accordance with Florida International University Institutional Review Board (FIU IRB).

The participants hailed from four different HBCUs, half private and the other public. There were 11 seniors, one junior, and one graduate student ranging in age from 21-25 years. While the graduate student already earned her bachelor degree, a decision was made to retain her because she met the remaining criteria. Their majors included architecture, criminal justice, biology, business, communicative sciences and disorders, English, communication, pharmacy, and psychology.

\section{Data Collection}

Data was gathered using 1- hour semi-structured interviews over the phone. The use of interviews is appropriate when studying and understanding lived experiences (Seidman, 2006). An interview guide of semi-structured interview questions was constructed. The questions asked were open-ended and based on an interview protocol (See Appendix A) to ensure consistency across all interviews (Patton, 2002). In addition to the interview protocol, a brief survey gathering demographic information was distributed to participants to complete prior to starting the interview (See Appendix B). Research questions were addressed via the interview questions, organized around the perceptions, attitudes, and lived experiences of NPHC sorority members, specifically regarding academic achievement and civic engagement. In addition, the theoretical 
framework, CoP (Wenger, 1998b) informed the interview questions. The CoP was also used to inform the subject group, to reflect the members' own understanding of what is important (Wenger, 1998b). For this reason, Black, NPHC sorority women were the subject group. Follow-up questions were used to understand concepts for the purpose of clarification (Rubin \& Rubin, 2005).

Participant and researcher agreed on a mutual time to conduct a phone interview. The researcher called each participant at the scheduled time. Interviews were audiorecorded, then transcribed. During each interview, notes of musings, hunches, and/or additional questions were written. Interviews were recorded using a digital recorder and backed-up on a smart phone. Follow-up questions were asked to illuminate meanings both during and after interviews. A professional transcribing service was utilized, and the researcher checked the transcription for accuracy in addition to member checking for veracity. Transcripts were read and re-read to gain familiarity with the content.

\section{Data Analysis}

Data analysis within qualitative research is a process that involves the identification of significant patterns and the fundamental nature of the data (Patton, 1990). Data were analyzed by searching for themes and patterns informed by the research questions and the theoretical framework (CoP, Wenger, 1998b), and then subsequently organized into categories to expose meaning (Yin, 2009). The purpose of data analysis is to develop an overall understanding of the data and reflect on its meaning (Creswell, 2003, 2005). Seidman (2006) indicated that the researcher need not analyze the data while collecting it because it will contaminate the garnered data, though it is 
believed an analysis of data inadvertently begins upon collection. ATLAS.ti 8 was utilized to code and then identify themes. The data was organized into categories developed from each participant as well as each interview question and answer. Similar participant answers to the interview questions were clustered and formed into columns and labeled. The participants' answers were placed on code sheets to identify patterns and to answer the research questions (Patton, 2002).

\section{Data Management}

Data management refers to the collection, protection, and manipulation of the data gathered for the study (Patton, 2002). All interviews and transcriptions were digitized and stored on Google Drive. The online storage service is secure because of the password requirement. All hard copies were stored in a locked file cabinet located in my apartment. All records were managed in accordance with guidelines put forth by FIU Institutional Review Board (IRB).

\section{Ethical Considerations}

The use of human subjects requires ethical considerations to be taken. The IRB, which oversees compliance with the ethical treatment of human subjects, made an independent determination to approve the study. The determination was based on adequate protection of the human subjects. Once approval of both the IRB and Florida International University were obtained, I contacted university leadership and the potential participants via e-mail. An informed consent form was provided to each participant in the study. An explanation of their voluntary participation, as well as the level of confidentiality was shared. By responding and denoting a willingness and consent to be 
interviewed, participants provided approval to participate in the study. Participants were given the option to withdraw from the study at any time or to refuse to answer any particular question. All interviews were conducted according to IRB guidelines. Asigned copy of the informed consent form and interview transcripts were kept under lock and key in a security lockbox in my apartment, where I am the only occupant.

\section{Integrity Measures}

Phenomenological research requires a lot of data interpretation. To promote the quality of the interpreted data, the following integrity measures were used: member checks, peer review, and controlling for insider bias.

\section{Member Checking}

Member checks were accomplished by having the participants review descriptions and/or themes for accuracy (Creswell, 2003; Patton, 2002). Once the interviews were transcribed, participants were asked to review transcripts for accuracy. New information was added as necessary.

\section{Peer Review}

Peer review entails the use of professional or research colleagues, to read and comment on findings "so that the account will resonate with people other than the researcher" (Creswell, 2003, p. 196). My dissertation peer group was asked for feedback on the clarity of the themes via track changes or video chat. Their feedback further validated my interpretation of the data. 


\section{Insider Bias}

Insider bias refers to unconsciously making assumptions about the research process based on the researcher's prior knowledge (DeLyser, 2001). In an attempt to minimize my biases, I viewed the research within the current social circumstance as opposed to a historical one. In addition, I enlisted the help of my dissertation group and committee, to review my research and offer feedback via track changes and video chat, to minimize the impact of bias on the study. Journaling also assisted in minimizing my biases. The process of writing daily during the interview process, and as I analyzed and interpreted the data collected I was able to identify reactions, thoughts, and feelings, which might lead to bias in the study if unchecked.

\section{Summary}

Chapter 3 presented the research methods for the phenomenological study on an NPHC sorority experience. The plan of action used to execute the study was introduced in the research design. The chapter includes a description of the sampling strategy that was used, data collection method employed, and interview protocol followed. The chapter concludes with the steps to be taken to promote the integrity of the findings. 


\section{CHAPTER IV}

\section{FINDINGS}

The study explored the experiences of Black, National Pan-Hellenic Council (NPHC) sorority members regarding their academic achievement and civic engagement. The data was collected from participant interviews. The findings that emerged from an inductive analysis will be presented. When quotes are presented to support a finding, participants' pseudonyms, and the line number from the transcripts (i.e., Isis, lines 150155) generated for the use of ATLAS.ti 8 software, are cited. Four themes emerged from the inductive analysis: (a) support, (b) academic intention, (c) service, and (d) social awareness.

\section{Support}

Support is encouraging members to keep going, reinforcing that their studies are worthwhile, and that completion is an attainable goal (Yates, 2007). As students come together in higher education, they form support groups, which act as both safe spaces and encourage the crucial role of group learning. Support is recognized and thus, observed in an individual's lived experiences and perceptions. Those lived experiences are reported by participants in three subthemes: (a) academic support, (b) financial support, and (c) engaging and influence. 


\section{Academic Support}

Academic support is the use of instructional methods, educational services, and school resources provided to students by professional educators, to help them accelerate learning, and meeting and/or surpassing set standards (Concepts, 2013). Participant experience of academic support is instead member's providing academic guidance and support, and peer-to-peer support.

Kenti believed that her Sorority supported academics through checking on her well-being. That is, tending to the most basic of physiological needs while addressing academics. She also eludes to a sense of obligation members have to one another as it pertains to academics. Kenti shared:

It is my Sorority, but especially my chapter members, making sure that we stayed on point with our grades, staying on point with your grades means you can produce more, you can do more, you can be more active. It's been a thing that we accounted for each other. It's been more so "are you going to class, you have to go to class," "you're sick? I'll take you to the doctor after that, but you're going to go to class right now." (Kenti, lines 29-33)

Olivia also experienced academic support through her chapter members, both

past, and present. Past chapter members were active because of their commitment to the sorority and desire to see current members maintain a level of activity, which requires upholding at least a minimum GPA. Olivia said:

She [past chapter member] would call and check up on us like "hey, what's going on with classes, is everything okay?" and then we also have our advisor, who's off campus but we have to send in our GPAs because you have to have a certain GPA to be in an organization in general and to even be an active member. I guess that's just motivation and then they're like "is there any way we can help," we have study sessions as a chapter with the campus. Knowing that you have a responsibility to do certain things, helps get things done. (Olivia, lines 42-48) 
Kenti and Olivia experienced academic support through chapter members.

Simone experienced academic support through a chapter member, more specifically, her line sister. Though they were different ages, they were in the same "pledge class." Being not only fellow chapter members but line sisters, Simone expressed a level of intimacy in their interactions. Simone narrated:

One of my line sisters is two years ahead of me university wise, so when I was a sophomore, she was a senior, so a lot of the classes I was taking, she had already taken. I was struggling through a class, I think it might have been finance, and she kind of sat down with me and taught me how to prepare for the tests because I understood the information but just how to study to make sure that I can apply it when it came time to. (Simone, lines 20-25)

While some participants experienced academic support solely within their respective sorority, others had support from the other three sororities housed in NPHC. Ashley said:

I have received academic assistance, but it was an English course, and I received help from a member of the Delta Sigma Theta Sorority. We were both in the same English courses, and she's crazy smart. She's really good; she's always super nice. I received feedback and just trying to understand one of our harder courses together. That was my sophomore year or junior year. (Ashley, lines 2832)

Academic support from members of other NPHC sororities was instrumental and significant regardless of when it was received. Kenti recalled an experience that was over ten years ago, in junior high school, but important nonetheless. Kenti narrated:

She was a member of Delta Sigma Theta. However, I've always known Spanish but not on a fluent level, so she was that person that really wanted you to go to high school excelling and Philippa Schuyler always offered you the opportunity to take your Regents exam before going to high school. She really dedicated that extra time to stay after school, making sure she reached out to our parents like 
"I'll be here to teach your kids, but this is an opportunity that if they can do this, it's going to set that bar for them." (Kenti, lines 18-25)

Kenti appreciates the academic support displayed by her teacher and member of NPHC.

Her experience will never be forgotten and has been a continuous source of intrinsic motivation (Montague \& Tan, 2016).

\section{Financial Support}

A barrier to college access and completion for minority students is a lack of financial support. Some of the participants faced a financial need, which could not be met with their income and resources alone. For the participants, financial support is the ability to persist academically because of the monetary contribution of members of their Sorority to their education. Kyndra shared "[We] donate the money or the proceeds that we get, to a charity that we feel is worthy or another [active] member of the Sorority in need, in the form of a scholarship." (Kendra, lines 132-133)

Kyndra understood the needs of her community, which included members of her Sorority. Unlike like Kyndra, Ashonti's experience was more personal. She was the recipient of financial support because of her apparent need. Her support came in the form of both financial literacy and monetary donations. Ashonti recalled:

There was a point in my education where I've been paying for my tuition myself since my sophomore year, and so financially as an undergrad, it's not easy. I was at a point in my life where I was working four jobs, in school, secretary of Zeta, step-master at the same time, and it was just overwhelming. Everyone knows me. I like to hold stuff in and try to figure out everything on my own, and everybody knows I won't reach out until the very last minute. But I had my line sisters there by me who watch me, they know me, even if they don't say nothing or I don't say nothing, they know what's going on. It's just a point where I was just really going through, and I still didn't say nothing, but three of them pretty much came to me, stopped me from what I was doing, came and got me, it was just like they sat me 
down, had a conversation and they also knew it was just tough for me. They all brought me together, gave me some advice, gave me some assistance personally as far as finances to help me, just different little things that I would need to help me get there, so I don't have to do it on my own. It was just that point in time for me it was just knowing that I have people that know me, understand me without even saying anything. I feel like that was assistance to me. (Ashonti, lines 38-51)

Similarly, Kenti experienced firsthand financial need, but she did not foresee the need until it was too late. She had to miss a semester because of funding. Though she was unable to attend classes, she knew there was hope. Kenti said:

In a sense with the financial aspect, if it was ever a time that I felt I could not financially produce for school [the Sorority has helped] - I've seen it done for others as well - we find a way to get it done to make sure the finances don't come in between our academics. (Kenti, lines 33-36)

Kenti's personal experience sheds light on the importance of various forms of support, particularly financial and how her sorority membership assisted her. Kenti noted "not being in college, absolutely [showed me]. I say that because being academically supported also means financial in a sense.” (Kenti, lines 28-29)

\section{Engaging and Influence}

The act of centralizing efforts to acquire additional resources for the purpose of engaging and participation in areas of concern describes the phrase, 'engage and influence.' Since the establishment of NPHC in 1930, the mission and purpose have been to engage and influence as it relates to matters that affect members and their communities (Ross, 2000). Participants are expected to engage and influence other members as well as support efforts of the members. One of the quickest ways to become engaged and influence others in 2017 is through social media. Ashley shared: 
We have a GroupMe but it's more about English people since everybody was an English major, but within that group of people, there's people of different sorority memberships. When the shooting [of Black people by police] started to become repetitive, and we're getting frustrated, then we were well able to voice how frustrated we were and just comparing because we all live in different regions. I was able to say, "this is what's going on where I am at, and this is what's going on where this person is at, this is what I'm seeing." We had that type of discussion. (Ashley, lines 88-93)

Another way participants engaged and influenced others was through becoming a prophyte. As a prophyte, they are expected to be an example through positive engagement and influence, especially in the area of academics. Asia indicated:

It's not always about the strolling and the stepping and the hooting and hollering, being in the mix but making sure that you get your work done first and then you can play. That's definitely my stronghold in there. And it's something I instill in the neophytes. (Asia, lines 35-39)

She further explains the support given to neophytes is like that of a mother to her child, one of the most engaging and influential relationships known to mankind, that of raising a child. Asia stated:

It all comes from experience as well as getting older. You have to do what you have to do now before it's too late. It's like a mother to a daughter. You see it coming, like "wait, stop, you need to just hold on for a second, do this first, and then you can worry about that later." It's just a learning process. (Asia, lines 4447)

Another participant explained a similar sentiment. The sentiment was, to support the expected academic achievement of neophytes, positive engagement and influence are necessary from prophytes. Simone noted:

I realized that there were people looking up to me as far as academic achievement in the same way that I was taught to make sure that my academics came first before anything. I tried to really instill that in the people that came up under me. If they see me studying or if they know that I'm really trying to excel in my 
classes, if they recognize the fact that just like I was told academics come first, everything comes secondly. (Simone, lines 51-56)

Olivia described a form of African communalism, where the individual is secondary to the role and function of the collective group (Etta, Esowe, \& Asukwo, 2016). The behavior is supported in NPHC (Ross, 2000) and causes an intentional interdependence with the new members and their prophytes. Olivia shared:

After becoming a prophyte, it changed a bit because it wasn't just my own academic achievement anymore or the people in my pledge class; now I have people who came after me, and I know that they look up to me in a certain way, and if I have a certain status of myself, I have to have that for them as well. If they're struggling, we can talk about why and how we can help them. I guess it became more "how's OUR GPA looking" because the chapter does have a GPA, and the NPHC had a GPA, and we all have to have a certain GPA to stay active as a whole, so it's like "what if that one affects everyone," so now it's like "how is OUR grade right now?" (Olivia, lines 51-58)

Olivia's use of the plural nouns, we, us, our, reflect a mutual experience and a greater relationship commitment to the Sorority than herself. In a slightly different manner, Miriam supports engagement and influence through a practical approach. Miriam noted:

Taking what you've learned and applying it practically. That goes not only for what you experience in your own situation as an individual but in teaching others and giving advice. These are things that you might want to look out for. This is how you might learn to balance your time, etc., (Miriam, lines 30-33)

\section{Academic Intention}

Academic intention is the willingness to continue to try academically in the face of challenge and contentment, as both can yield slothful behavior. It involves the ability to see defeat as a lesson learned, not a reason to forego academic goals. Academic 
intention requires a level of emotional intelligence, which regulates one's feeling, critical thinking, and cognitive skills; all of which are academic success predictors. An inability to display emotional intelligence in the face of adversity can cause academic intention to be derailed. Conversely, an academically sound student, devoid of emotional intelligence, can become complacent in their success, falling victim to indolence and short of academic intention. Utilization of emotional intelligence to maintain academic intention is best exhibited through two subthemes: (a) understanding academic achievement before sorority membership, and (b) understanding academic achievement after sorority membership.

\section{Understanding Academic Achievement Before Sorority Membership}

Understanding academic achievement prior to membership is necessary to understand those variables that change when one becomes a member of a sorority. Some participants believed maintaining good grades and being above average was academic achievement. Kenti said:

Academic achievement was doing more than what was expected, not the satisfactory level, but more so it was always above a 70 in my eyes. That's what was pursued. You see growing up especially in New York a passing grade was 65 ; at one point in time, it was 55 , so as long as you get above that, that was academic achievement. (Kenti, lines 12-15)

Other participants echoed the importance of good grades. Iris stated:

Basically, I guess I was just brought up to believe that getting A's and B's was the only option, so I guess as far as achievement, I would base achievement off of A's and B's, so good grades basically. (Iris, lines 12-14)

Similarly, Brittany shared: 
My understanding of academic achievement was always what my parents instilled in me was you're going to further your education, so you need to make good grades, try to stay as close to a 4.0 as possible. It was really important to me to keep my GPA up in order to get to where I wanted to be, and so I think that's what it was. (Brittany, lines 21-26)

Another participant agreed with being above average and its significance to academic achievement, in addition to striving for excellence. Qiana noted:

Striving to do the best that you can, going above and beyond. If you're given a certain standard, going above that standard, not just settling for just passing, but doing the best that you possibly can. (Qiana, lines 18-20)

While maintaining a GPA was named pertinent to some participants, being present during class lectures, understanding assignments, and planning for a successful future by avoiding procrastination, was specifically important to Olivia, she indicated:

Academic achievement to me is maintaining a great GPA, 3.0 or above, going to all your classes, being on top of your homework, not procrastinating, just not stressing yourself out by having the appropriate amount of time to do your work. (Olivia, lines 17-19)

Olivia mentioned class attendance because, to her, obtaining knowledge during lectures was fundamental to academic intention. Miriam also believed lecture was essential to excelling, moreover, essential to understanding and applying concepts for her future career. Miriam shared:

Academic achievement is doing your best - excelling where you have placed yourself whether that's in your school or specifically in your department, learning as much as you can in your field and taking the opportunity to apply what you have learned in practical situations. (Miriam, lines 12-15)

Future careers were a common reason for attaining academic achievement. Kyndra said: 
I would have to say not just doing well, not having C's or D's in my class, but high B's and A's and just understanding what's going on in class and how it's going to help me in the future with my career. (Kyndra, lines 13-15)

Likewise, Tiana noted:

My understanding would be that in order to make it in the world, I would have to get my degree. So, in order for me to get my degree, that means I have to be focused or I'm getting all A's and maybe a B but no lower than a B, and that it is important to further your education. Education and knowledge is the only thing that will help you in the world today. (Tiana, lines 12-15)

A's and B's were of significance to Asia too. In addition, she inadvertently addressed the importance of emotional intelligence when pursuing academic intention. Asia stated:

Academic achievement was to me doing all in your power to get your A or your $\mathrm{B}$, and even if you didn't get to that point, you make sure that the next time that came around, you did all you needed to get to that point. (Asia, lines 17-19)

The participants had various responses to the understanding of academic achievement prior to membership. Though their answers varied, they all echoed intentional efforts towards academic achievement.

\section{Understanding Academic Achievement After Sorority Membership}

Understanding academic achievement after membership allows for insight into growth and thoughts of the participant, after having become a prophyte. Prior to membership in the Sorority, Ashonti agreed that getting good grades demonstrated an 
understanding of academic achievement. Upon becoming a prophyte, she described a deeper, more comprehensive understanding of academic achievement. She said:

A lot of students think academic achievement is just about how well you do in school, but it's also about how well you do as a person, just growing and learning from your experience. A lot of people feel like as long as I just go my four years and get out and graduate that's all I need, but you need other stuff to build you as a person. I had to learn that personally. (Ashonti, lines 183-187)

Ashonti further disclosed her personal experiences and gave practical accounts of emotional intelligence, academic intention, and resilience. She stated:

I've had my set of ups and downs that tried to hinder me from pushing forward. I had a point where I was just like "this is crazy" but it's just finding that person in you and the people around you that's going to push you and motivate you just to keep going. You can't just give up just because you might get a bad grade one semester; it doesn't necessarily mean that when you get to try to apply to grad school or other opportunities it's going to fail. It's not because you have a story to back up what happened. People just think about the grades and the grade point average, and "I was involved in this, but what did you do outside of school that helped you?" That's important as well. (Ashonti, lines 191-198)

Participants also identified newfound academic focus as prophytes. While

academics were always within immediate purview, the time spent being a neophyte can

present a challenge, as it requires both socializing and academic adeptness. As a

prophyte, academics had a fundamental importance for Simone. She said:

I realized that there were people looking up to me as far as academic achievement in the same way that I was taught to make sure that my academics came first before anything. I tried to really instill that in the people that came up under me. (Simone, lines 51-56)

Overall academic focus was the experience of Kyndra. She stated:

You're more focused on what you need to do and what needs to get done. As a Neo, you're like trying to figure it out, but as a prophyte, it's like "I already had this year under my belt so now it's just me trying to figure out I already know 
what I need to do, so I'm just going to stay focused and keep on doing what I need to do." (Kyndra, lines 42-46)

Balance and boundaries, conscious strategies to manage and negotiate relationships, in addition to incorporating the duty of sorority membership within the overarching role of student, yields success (Lowe \& Gayle, 2007). Balance can be achieved in an array of life's circumstances, particularly if the appropriate support is available. Tiana explained how she balanced and prioritized. She noted:

Balancing time is the only way that will help with that - balancing what comes first. It's your relationship with God and praying, and then school and then Sorority and helping members in other sororities. To me, all that is time management. (Tiana, lines 32-34)

Miriam also understood the importance of balance and time management as a prophyte.

She stated:

Taking what you've learned and applying it practically. That goes not only for what you experience in your own situation as an individual but in teaching others and giving advice. These are things that you might want to look out for. This is how you might learn to balance your time, etc., (Miriam, lines 30-33)

While Miriam expressed an easier transition from neophyte to prophyte, Gina described learning to balance as a painstaking yet necessary task. She shared:

After becoming a prophyte, it became very vital because we had to learn about time management and balancing and just making it day by day while having all this stuff in the background going on. It was difficult but I guess we just learned time management and how to organize your priorities and everything. (Gina, lines 46-49)

New expectations and responsibilities can be daunting as a neophyte, causing a loss of academic focus. However, as participants mature and grow personally, through 
experiences and gain insight, they transition to prophytes with a new understanding of academic achievement.

\section{Service}

Service is the commitment to serving one's community, through the labor of body or of body and mind, for the benefit of another. A service leader aids intrinsically, to positively affect the community in need (Grisaffe, VanMeter, \& Chonko, 2016). The participants were called to be service leaders, as the mission of all NPHC sororities is to the serve the communities they are in and represent. Three themes emerged concerning the participants' service: (a) civic engagement, (b) volunteering, and (c) filling a need.

\section{Civic Engagement}

The act of civic engagement is the involvement of students through discussion and action on major social issues, both inside and outside the university. Participants were often required to discuss and then take action as issues of social injustice arose. Miriam recalls a time where she spoke to her peers about rape culture at the collegiate level. She shared:

I've actually been on a couple of panels talking about the various injustices that was not only with my Sorority but with other organizations as well, talking about things that happened on campus such as rape culture and the importance of uplifting women and African American community, which also means changing the male perspective of the woman. (Miriam, lines 68-71).

Miriam was also moved to action and bringing others with her by using the Sorority as a means to receive and share information. She stated:

I can maybe act on my own and speak to one person or if I'm invited to speak to a group of people. There are more of us in the Sorority so I'm not only reaching out to my community but I can pass the idea along like "you guys are in another 
state, we could collaborate and do something much bigger." For example, when we have national meetings, bring something up then, and then it becomes a national situation where we are taking something and tackling the issue. (Miriam, lines 74-79)

Miriam was very passionate about not only discussing possible solutions but the actual work it would take to see change. She said:

Personally, you just never stop the conversation and the bill does not stop with your organization or with your chapter or with nationals. You are a continuing testament to what it is you say you believe in. If you're going to XYZ, then you should always be "hey, let me tell you about XYZ or let me show you how to do XYZ." (Miriam, lines 91-94)

Simone was just as passionate about civic engagement. She explained the importance of being a griot, as it relates to her chapter, as well speaking to the needs of the community.

The importance of passing down what you know or passing down what's important to you because civic engagement is one of those things that once I leave Hampton, that step still needs to get done - reaching out to the community is still important. As a prophyte, being able to really pass that down to the people that came up under me-- five or six years from now when I come back, the chapter is still flourishing, the chapter is still as involved in the community as it was when I left it. (Simone, lines 126-131)

After becoming a Sorority member, Simone, like Miriam, was very conscious of her personal footprint as it relates to civic engagement and service. Moreover, designating time to serve those communities properly through discussion and action.

Setting aside time and really valuing the importance because I think that civic engagement and service is really important to who I am as a person, so if it's important to who I am and it's a part of my foundation, then recognizing that it's important. If I can make time for everything else in my life, then that's something that I need to make time for as well. (Simone, lines 110-113)

Participants were deliberate in the execution of civic engagement. Tiana explained the process she went through to serve her community. She noted: 
One, we meet about it with them, and then we'll discuss how we want to do it.

It's basically footwork, word of mouth, talking to people in higher places at the school or just in general reaching out to the community and talking to them. I know for example that we're doing a mentor program with Orangeburg Wilkinson High School with the Junior and Senior females, and we're going to try to help them transition into getting ready for their college year, even if they go to Claflin or out of state because your freshman year basically is the foundation of the rest of your three years, and I feel like if we (as an organization) get them in high school, then it'll start them on the right path of how the prepare themselves as a Black woman. If you go to a PWI or an HBCU how to present yourself, how to stand out from your other peers. (Tiana, lines 94-102)

Participants described how they engage in service, more specifically, civic engagement. They are intentional in their actions, which begins and ends with discussion. The importance of maintaining continuous discussion assists in remaining relevant to the community and while working with fellow sorority members.

\section{Volunteering}

Another form of service is volunteering. Participants are called to assist established programs or events. Volunteering is a responsibility of the participant, to give selflessly for the good of others is an expectation of the Sorority. Kenti explained her experience when her Sorority partnered with an established program. Kenti shared:

Even when it comes down to our initiatives in Z-Hope, being able to do things such as March of Dimes and really getting in depth of what it is and babies being born prematurely - everyone is greatly affected by that, especially the African American women. (Kenti, lines 61-63)

Olivia also spoke of established national, sorority programs. Sorority members implemented national programs in the Baltimore City community such as Operation BigBookBag, to provide necessary supplies to school-age children and Project CRADLE 
Care, which assists at-risk women with prenatal care. Her volunteer experiences helped the high-risk community she served. Olivia narrated:

We have nine national programs that we do. So, we try to tackle as many as we can in each semester or each school year. And most of them, of course, can be service based, and thankfully we're in Baltimore City so there's lots of urban areas, youth around, homeless people, women, children, so we really just try to honestly get different places to go to each time, whether it's a soup kitchen or whether we're just passing out sandwiches to the homeless people in Baltimore, depending on the time of year - like when it gets colder, we'll make baskets of blankets and toiletries around Christmas time and stuff like that. It's easy because of the area that we are in to get those things done and we just have a checklist and just go through them all. (Olivia, lines 132-139)

Kyndra had a couple of experiences as a volunteer. Her chapter adopted a street to clean

regularly and volunteered to serve the homeless in a soup kitchen. She stated:

We adopted a street near Hampton so that we could clean that up and keep the city clean. We do that every two weeks out of the month, so I like that. And then, we also go to the soup kitchen, and we alternate between that and cleaning the street. One week, we'll clean streets and we'll go to the soup kitchen, then we'll clean the street again and we'll go to the soup kitchen. I like doing that. You actually get to talk to the people and just see where they're at and stuff like that. You don't have to go there and just give them, just to be there; you actually get to socialize with them. Talk about their past. You actually get to know them on a personal level. (Kyndra, lines 107-113)

Kyndra was moved by her experience as a volunteer. The opportunity to serve as a volunteer allowed her to get to know her community, by having one-on-one conversations with those she served. Iris had similar experiences as a volunteer through her Sorority's established auxiliary groups, as well as other volunteer experiences in service. Iris said:

We have a lot of different community initiatives. A couple of my favorites, we do [Adopt-A-Spot] every third Sunday of the month and we also go to a neighborhood school, one of the neighborhood schools that we go to, it's an elementary school, Aberdeen Elementary in Hampton, and we read to the kids for 
about an hour to an hour and a half every third Friday. That's pretty much the type of things that we do, but those are just my favorite. We also have different initiatives through auxiliary groups. We have four and they range from as young as 6 to about 18. We have different auxiliaries for according to what age the girls are. Oh, we also have the Amicae. I guess you can call them our friends, but you can only be one if you didn't attain your degree or you didn't obtain enough credits or something like that; whatever happens, if you still want to do something, you can still feel like you're a part. You still want to help out or give in a name of Zeta but not actually through Zeta, that's something that you can do in Amicae. We also have a male network for males that want to help out and stuff like that too. (Iris, lines 118-131)

Volunteering is a way the participants give back to their respective communities. Through established programs and events, participants serve different populations with distinct demographic characteristics. While established programs do not generally speak to issues of social injustice, the participants answer the charge placed on them by their sororities.

\section{Filing a Need}

Filling a need is an act of service, created by the participant. It is speaking to a

necessity and acting on it. The focus is the innovation of the participant. She shared:

I was a student-athlete in high school, and there's four high schools in my hometown, but only two of them had athletic programs, so of all the high schools, you had to choose between the schools. I chose one school that didn't have transportation for athletes after practices and sometimes not even after games. What we did was, I was a part of the executive board I guess you could say. As a student-athlete, we just banded together, and we fundraised a lot at first on our own, but then the community started to be involved and try to help us out. Now they have transportation for all the student-athletes that come to high school. (Iris, lines 51-58)

Iris' understanding of service started prior to her Sorority membership. She established a program with the help of others around her, as there was a need felt by the 
athletes because of the lack of transportation. She also learned from her involvement, which enhanced her experience as a member of her Sorority. Iris realized there were needs in different populations. As a student-athlete, she was forgotten but made sure not to repeat the same mistake with other populations. Iris stated:

I understood that when I was doing everything that I was doing at home, I feel like I was doing it for people like me, and so when we did the whole bus and transportation thing and raised all the money for it, I wanted to do it because I was driven because it was something that was happening to me and affecting me. But when I became a Zeta, all of my sisters were from different backgrounds and stuff, so I realized it was more than just student-athletes who weren't getting buses; it was different things going on in different types of areas. I opened my mind a bit about other things that were happening so I started to care about the homeless more and the elderly more because I didn't really think about these types of things. (Iris, lines 167-174)

Gina also experienced filling a need before sorority membership. She said:

Prior to joining Delta, I was actually Miss Freshman and Miss Sophomore, so I was really involved in the community service projects and coming up with all that for our class. (Gina, lines 63-64)

As a pageant contestant, it is a requirement that you create and implement a service project that fills a need, within the local community. However, the need is not always a tangible deficiency. Creating platforms to address trepidations within their communities such as the ongoing generational gap made apparent in their differing approaches to social injustice. Kenti stated:

Earlier this year, during Black History Month, Hampton does an actual expo, so I was in charge of putting on State of the Black Greek. It was interesting enough because, from my perspective, we were just going to do an old school versus a new school, and even though I assumed [it would be interesting], it was intriguing to see the approach that the old school had - of course, genuine topics about organizations and what we should stand for came up - but how the older, more seasoned members of fraternities and sororities began to speak and express how we're in a time where they feel as if there's not any young leaders; this is how 
many women, and many people, in general, are living it, feeling that there isn't the next Martin Luther King, there isn't the next Malcolm X, there's isn't the next person who's going to get up and stand up. You have a duty to your organization and your Founders to get up and be that group of people to stand on the forefront and also educate each other. It's more so about educating each other as well and being that voice, so it came down to a topic of how we should speak to one another in terms of how to address the police, and if you see that someone doesn't have that example, you must be that example and you must teach them. (Kenti, lines 96-109)

Kenti answered the charge by constructing a space for members, regardless of their experiences, to engage in discussion. Her service filled a need within the NPHC community.

\section{Social Awareness}

Social awareness is the historical understanding that contextualizes communitybased experiences, such that past events provide a context and a foundation for present community-based problem solving (Saltmarsh, 2005). History shapes a community and its culture. Each community has a rich and distinctive history, which fundamentally shapes the present, and requires intentional understanding. Current politics are informed by social awareness. Participants reported three common subthemes: (a) personal service goals, (b) personal social responsibility, and (c) understanding civic engagement agents.

\section{Personal Service Goals}

Personal service goals are intended individual objectives, aimed to help the community, sometimes with the assistance of others. Olivia used her position in the Sorority and her knowledge of community members to increase the number of service activities. Her social awareness of community needs and the community employed to assist made connecting the two feasible. Olivia shared: 
Personally now, as the president of my chapter, I actually sent out an email saying we need to have a chapter meeting to pick which ones we're going to focus on this semester, personally in my goals to make sure that we can do as many as we can to help the area because again we are in such a great area for that, so that shouldn't be a reason why we can't get it done. (Olivia, lines 141-144)

Additionally, Olivia explained a specific personal service goal, involvement in discussion with other NPHC organizations to bring about change in the Black community. Her understanding of NPHC's history to help local communities led to her participation. She said:

I know that as an NPHC we actually have an event coming up tomorrow. It's called \#MSUnited2k16. It was actually brought up by a member of Alpha Phi Alpha at our school and he wanted to just have a demonstration where a whole bunch of Black people come together and we just talk about our issues and show that Morgan State University as a whole actually cares, so members of NPHC will be there and hopefully students and faculty members as well just to talk about the issues that are going on and what we can do. We talk about it amongst ourselves and our chapters and at NPHC meetings, but now we're trying to bring the whole campus into it. That's the next thing that we're doing now. (Olivia, lines 108115)

Asia's personal service goals are to continue to serve her home church and high school, though she attends college in a different state. She knows their needs as her social awareness was affirmed prior to membership. Asia shared:

Even if I'm away from my chapter, being back home, I make sure I link up with the sorors here if I can. If I can't, I do things with my church and I'll go back to the things that I had before the sorority. Sorority wasn't always my life, so I go back to what I used to do before I had that. Just a few weeks ago, we filled 42 book-bags at my church for the kids. We have a high school across from our church, so we filled that for them, for kids around the neighborhood, from the block, and that was just nice to me. I was going back to the sorority without being in the sorority, if that makes sense. We also had a food giveaway so I went to that. We always have that every year, but certain times of the year, I'm at 
school so I can't go, but whenever I'm home and it's available, I make sure I'm there, and we hand out food to the community for free. (Asia, lines 134-143)

Qiana echoed the home-service sentiment. She mirrored the local graduate chapter of her sorority and undergraduate chapter at college. Her social awareness comes from living in the neighborhood as well as talking to those in the community. She shared:

The goals that we achieve at school, I bring them back home. My mom is a part of a grad chapter here so I work with her grad chapter. The majority of the grad chapter is older but there are a few younger Sorors. Us younger Sorors, even though we're not part of the grad chapter, we still go out and we do the same thing, so we'll go to the elementary schools while they're still in and we'll go read, or we'll go to the daycares and read to them, or the older kids in daycares because they go up to age 13. We'll talk to them and speak to the young ladies about etiquette, and how to carry yourself and respect, and things like that. Just bringing it back home. (Qiana, lines 120-126)

\section{Personal Social Responsibility}

Personal social responsibility is the act of keeping community needs at the

forefront. Miriam used the power of influence through alliance, that is, the ability to

motivate and inspire others, to galvanize her personal social responsibility. She narrated:

I think it pushes it more because I know there are people who think like me, who find the same matters just as urgent, and when you have large numbers of people, you can do more things than you can do on your own. As they say, strength in numbers. (Miriam, lines 50-52)

Ashley agreed that there was strength in numbers. She stated:

I think we became more responsible in saying that I now have another platform to speak out on things that might affect me or I might have an issue with or things that I just want to speak out about, because now I have more people behind me. My voice can just be a lot louder than if I was just standing here and I was just saying "I don't like that" but I have nationally, a bunch of people saying, "WE don't like that" internationally. (Ashley, lines 71-76) 
Simone used her social responsibility as a vehicle to address social injustice. She recognized the strength in numbers and association. Simone also acknowledged the obligation that comes with association and expressed apprehension when inadvertently representing the whole - the Sorority. She noted:

It influences my personal actions by recognizing again that I'm not just Simone, that I represent something bigger. In the ways that I may be addressed or go about addressing social actions or how I go about doing things, I recognize that it's also important in how I do it. I think one thing that sororities definitely encourage is you can go out and you can protest or you can start anything you want. You can take a stand for social activities, but it also reflects back on what the sorority does as a whole. (Simone, lines 92-97)

A few participants held a related outlook. Iris stated:

I had the letters Zeta Phi Beta, the Greek letters, on my sweatshirt. Basically, I wasn't just Iris; I was Iris the Zeta at that specific time. I didn't want to drink a whole lot of alcohol and what not like my friends were doing because I may have given the impression "those Zeta, they like to drink alcohol and get drunk," and stuff like that. You never know what someone may think, so I had to be conscious of that. I didn't even want to just drink period. I was old enough to drink, I was over 21, I was able to drink, but I didn't even want to do it because of the impression it might have given somebody about my entire organization, let alone my chapter, so I had to be responsible as far as that. (Iris, Lines 84-91)

Iris' social responsibility stemmed from a social awareness rooted in stereotypes of other councils, such as binge drinking (Peralta, Steele, Nofziger, \& Rickles, 2010; Weiss, 2013). Gina too carried the weight of social responsibility. Her awareness of sorority image, as a member, yielded a positive self-awareness. She shared:

I think it kind of makes you have to hold yourself to a higher standard because everybody's always looking and watching you and paying attention, so I feel like 
it makes you have to make sure you're always on your P's and Q's and doing what you have to do, being a role model to those that are aspiring to be in your organization or anything. (Gina, lines 69-72)

Tiana expressed a dual social responsibility, both stemming from image. She was

cognizant of her image as well as the image of her as a sorority member. Tiana said:

It influenced me by, one, I'm representing my Sorority, also, I'm representing myself, so when it comes to something that bothers me, I will speak on it but it's a certain way you have to speak on things. You just can't really say what you want to say because you're representing yourself and your sorority, so I have to take caution in what I say, but I still get my point across in a respectable way. (Tiana, lines 85-89)

\section{Understanding Civic Engagement Agents}

Although civic engagement is the involvement of students through dialogue and execution regarding major social issues, participants' understanding varied from no change, to intrinsic understanding, as well as group dynamics and awareness. Gina's understanding did not change after becoming a sorority member. She said:

My understanding didn't really change; it just kind of solidified more that you're a public figure and you need to make sure that there's a point that you have to react to the situation, but you still can't be biased. In regard to the police shootings and that type of brutality, I know we can't just publically make a statement from the perspective of how Delta Sigma Theta Sorority, Incorporated feels that way, but you can make a personal statement for yourself if you feel a way about a situation, so I guess being a public figure in that aspect. (Gina, lines 127-132) 
Kyndra likened civic engagement to community service. She noted "my understanding of civic engagement, I would have to say not just doing it because you have to for community service; actually doing it because you want to." (Kyndra, lines 135-136) Ashonti's understanding was akin to the operational definition of the study, involvement of students through discussion and action (Dewey, 1916). She stated:

Before, I had no idea, but after, like I was saying, it [civic engagement] was just being able to come together and just seeing if you could do good with others, then you find yourself pretty much. That's the gist of it. (Ashonti, lines 177-179)

The explanation Ashonti communicated alluded to the gathering of the group or community for acts of service. Tiana also utilized the community. She said:

I would look at who I can call on and I know their strengths and weaknesses. So, if I know one person's strength is maybe either talking to somebody or organizing something or contacting people, I would lean on that person - I would give that person that particular job and then look at somebody else whose strength is not that - I would pair them with them so they can work based off that one person so they can learn from them, to help them. (Tiana, lines 125-129)

Tiana was strategic in selecting those in her community to assist. She looked at the talents each Sorority member had, and how those talents might be used to better the community in need. Tiana's awareness of the group's individual talents helped in the process of assisting the community. However, Kenti's understanding encompassed social awareness. She stated:

It's about making sure you're conscious and those who are after you, you need to be of substance to your organization and knowing what's going on, being woke, so they could produce that change that you want to see. (Kenti, lines 162-164)

Social awareness was also included in Iris' understanding of civic engagement. Iris' statement made her views, she said, "my understanding would be —it's being involved, 
finding a problem, being a solution, getting it done" (Iris, lines 58-59). Iris articulated her understanding of civic engagement, which echoed the operational definition. Other participants explained their understanding of civic engagement, which did not always mirror the stated definition but contained elements. It was the participants understanding of civic engagement.

\section{Summary}

Participants indicated their experiences regarding support were positive. They experienced support through various interactions. Those interactions include peer-to-peer support through examples set by seasoned sorority members, financial assistance from sorority members, in addition to assistance from other sororities in NPHC, not of their own. Support and encouragement from sorority members reinforced academic pursuits. The choice to continue initial pursuits in academia and the unwavering willingness to endure academically is the essence of academic intention. Participants' understanding of academic achievement both before and after NPHC sorority membership provides insight to member shift in perceptions, attitudes, and detail lived experiences. In addition, the transition from neophyte to prophyte, a pivotal point in membership, casts light on participant academic intention and service.

Participants spent time volunteering, filling a need, and engaging civically. They galvanized NPHC sorority efforts for the purpose of assisting surrounding communities and their members. Participants pooled resources when they identified an injustice. They maintained an environmental awareness, which informed their personal service goals and social responsibility. Participants also experienced a social awareness which 
was based on historical community comprehension, that is, an extensive and wideranging ability to problem solve knowing the context of past detrimental events.

Likewise, the understanding of civic engagement informed their acts of service, goals, and social responsibility.

This chapter presented the findings from the inductive data analysis. The four themes that emerged from the inductive analysis were: (a) support, (b) academic intention, (c) service, and (d) social awareness. These themes capture the experiences of Black, NPHC Sorority women as it pertains to their understanding of academic achievement and civic engagement. In Chapter 5, the discussion and implications are reviewed.

\section{CHAPTER V}

\section{DISCUSSION \& IMPLICATIONS}

Chapter 5 is divided into seven separate sections: (a) responses to the research questions, (b) relationship to the theoretical framework (c) implications for practice, (d) recommendations for future research, (e) limitations of the study, and (f) final summary.

\section{Response to the Research Questions}

In this section, answers to the research questions are provided. Answers to the four subsidiary questions are discussed first to gain a clear understanding of the 
participants full experience, followed by the primary question. Responses are provided below.

\section{Perceptions, attitudes, and lived experiences of NPHC sorority members regarding academic achievement}

Participants indicated their experiences regarding academic achievement were positive although their understanding of classroom material wavered. Some participants sought the assistance of seasoned members when there was a disconnect between classroom curricula and practical application. The necessity of class comprehension informed the perception of choice and security. They understood the importance of academic achievement as a means to future freedoms including career choice and career security. Additionally, participants denote supportiveness from sorority members, who created spaces for their optimum academic achievement. Their supportiveness included offering their living quarters as a temporary solace or providing sustenance - both eliminated distractions - allowing for the attainment of academic achievement. The principles of the respective sororities also helped to inform participants. Each NPHC sorority maintains scholarship as a principle or requirement for membership. Deviation from academic expectation yields limited participation in the sorority and members knowingly join with this precept. 


\section{Perceptions, attitudes, and lived experiences of NPHC sorority members regarding}

civic engagement

Participants also perceive the principle of service, as a functional and useful precept. They indicated service as an all-encompassing term which includes volunteering, giving back, community service as well as civic engagement. Participants viewed civic engagement as an alluring aspect in their joining of an NPHC sorority. Upon joining, they develop their academic calendar with the intent of utilizing off-days as a time to serve their communities through civic engagement. Civic engagement influenced participant schedules and has informed the behavior of participants.

\section{Black NPHC sorority members understand the effect of membership on their academic achievement and civic engagement}

Participants specifically attribute their academic achievement and civic engagement to membership in the sorority. As members of this community of practice, they are expected to mentor and pass on the mission of civic engagement. Participants attributed the expectation to their effortful actions. Black, NPHC sorority members maintain a level of academic achievement to remain active within the sorority. They expressed the desire to be fully-functional and experience all rights and privileges of membership in the sorority. Membership directly influenced academics, as sorority involvement is hinged on academics. While participants connote a level of extrinsic motivation, it serves them in the sorority and at the university.

Conversely, participants indicated an intrinsic viewpoint of civic engagement. They affirmed their commitment to civic engagement prior to sorority membership. The 
nuance, however, is in membership influence on both frequency and intentionality of civic engagement. Black, NPHC sorority members denote an increase in civic engagement activities because of membership. Each sorority has civically organized national and/or international initiatives. These initiatives have target communities and specified frequencies. Participants are cognizant of the role sorority membership plays on the application of civic engagement in the community.

\section{NPHC sorority acts as a CoP to foster a spirit of academic achievement and civic engagement in members.}

The NPHC is a community with the resources to enrich the sorority community and the community they serve. It functions as a $\mathrm{CoP}$ by centralizing efforts to acquire participation in areas of concern. Those areas of concern include academic achievement and civic engagement. Through sharing information via discussion, participants have witnessed the improvement of civic initiatives and academic prowess. The CoP fosters the spirit of academic achievement and civic engagement by making a safe space for Black, NPHC sorority members to have open discourse. They are able to create, share, organize, revise, and pass on knowledge amongst various members with a common interest, both academically and civically. Participants indicated seasoned members as conduits in attaining optimal academic achievement and civic engagement.

\section{Primary Research Question: From the point of view of Black NPHC sorority} members, how do they view academic achievement and civic engagement?

The participants acknowledged that while their experiences vary from sorority to sorority, and even chapter to chapter, academic achievement, and civic engagement are 
staples in the sorority, incorporating both intrinsic and extrinsic motivation. Academic achievement and civic engagement are reasons for joining the sorority, as indicated by participants. Additionally, participants view NPHC sororities as vehicle for improving themselves and the communities around them.

\section{Relationship to Theoretical Framework}

The study utilizes the Community of Practice $(\mathrm{CoP})$ as the theoretical framework (Wenger, 1998b). The stages of development within CoP are potential, coalescing, active, dispersed, and memorable. Potential is discovering shared interest within a group or community. The community then moves to coalescing, which gives insight to community members' potential. Members then engage in joint activities, adapting to changing circumstances or renewing interest, which describes active. Over time, members engage less frequently but still holding reunions and keeping lines of communication open, this defines dispersed. The last stage is memorable, where the community is no longer central but members still associate the memories with a significant part of their lives.

The CoP stages including potential, coalescing, and active are evident in the findings, as it relates to civic engagement and academic achievement. For example, some participants indicated they coalesced around the water crisis in Flint, Michigan. After galvanizing sorority members whom also had an interest in alleviating the issue of contamination in Flint, they shipped pallets of water to the area, allowing them to partake in civic engagement. Likewise, some participants indicated experiencing academic support through member monetary supplements, to eliminate tuition balance. 
Communities of practice gave a voice to Black, NPHC sorority women, which is rarely discussed in the academic literature. Using CoP to guide the study facilitated a greater understanding of how Black, NPHC sorority women shared knowledge as it pertains to a mutual interest or concern. The findings confirmed that participants discussed matters they regard as pertinent. They are building their network through the use and reuse of member resources. Participants indicated a presence of academic support and increased civic engagement occurred because of fellow sorority members. While most stages of CoP gave voice to a marginalized group — Black, NPHC sorority women - there is a critique. One major critique of $\mathrm{CoP}$ is the assumption of disbandment or termination, in the dispersed and memorable stages. The theory indicates members of the community no longer engage intensely or have concerns in the same matters (Wenger, 1998b). However, the four sororities have never disbanded. They have grown in number and continue to assist marginalized populations while persisting as pillars in their communities (Kimbrough, 2003). The NPHC sororities continue galvanizing rather than following the dispersed and memorable stages because the issue is to help Black people (more specifically Black women) achieve in a hostile world (Ross, 2000). Until the day-to-day when disenfranchisement and disregard of Black women cease, NPHC sororities will maintain a significant presence during both undergraduate and graduate chapter experiences.

The CoP is a perpetual cycle of problem solving by which members involve experts, utilize synergies across units, come up with new strategies, knowledge sharing, reuse of resources, and networking. 
Based on the findings of the study, NPHC sororities problem-solving ranged from academic assistance to opposing social injustice. The first step to problem-solving is brainstorming a plan of action to address the problem or concern. Then they involve experts who are also NPHC sorority members, to partake in CoP. It is important to acknowledge that an expert denotes someone who has experience in the area of concern, whether it is academic or injustice. The NPHC sororities will seek those in their community with expertise in the given area to illuminate additional plans of action that are underdeveloped or that they may have missed. Because of their previous experiences, experts have resources. However, they are not the only ones with available resources. The combining of experts' resources is synergistic across units. For instance, if the concern is academic, an example would be a sorority member in need of academic assistance, seeking another member to explain a concept and then bringing someone else in that can do the same, but in another way for increased understanding. As it relates to injustice, different sorority members can bring their expertise, including but not limited to knowledge of the law, politics, and organizing protests. After academic tutoring or publicly denouncing injustice, sorority members return to discuss developments as a $\mathrm{CoP}$, which entails discussing new strategies and knowledge sharing. Members ask, what could have been done differently for a more favorable outcome, and develop new strategies through the exchange of knowledge. The new strategies can be, timelier when asking for academic assistance and not waiting until it is nearly an overwhelming concern. Similarly, as a community, members think of those they did not call upon but have area expertise and regard them as an available network resource, for future use. 


\section{Implications for Student Affairs Practitioners}

The study has implications for student affairs practitioners who work with NPHC sororities at HBCUs. The role of student affairs is to provide students with services and support beyond the classroom. Student affairs facilitate learning outside of the classroom and are critical aspects of the higher education experience. They are also responsible for providing knowledgeable student affairs practitioners, including NPHC advisors. The job of an NPHC advisor is to uphold university policy, sorority procedures, in addition to possessing a comprehensive understanding of NPHC sororities. However, many student affairs practitioners do not understand their roles as advisor of NPHC sororities.

\section{University Policy}

Student affairs practitioners, specifically NPHC advisors, are expected to comply with university policy because it is intended to guide practitioners. Moreover, it guides and assists in the development of the students they are there to serve (NASPA, 2017). However, NPHC advisors are often ill-equipped in guiding and assisting these sororities because they do not understand the governing policies for NPHC (Kimbrough, 2003). Assuming to understand NPHC sororities by comparing them to Black fraternities or predominantly white Greek organizations, only further alienates the organizations and their members. Additionally, the comparison also weakens the ability of student affairs practitioners to adequately advise, engage and support members in their academic and civic pursuits, both on campus and in their communities. It is imperative to understanding the importance of NPHC sororities as it relates to their longevity and 
necessity by providing safe spaces for those in them and the surrounding community (Collins, 2000).

\section{Sorority Procedures}

The study revealed nuances in the way NPHC sororities operate. Participants indicated deference, that is, respect and esteem for a prophyte from a neophyte because they are seasoned. Deference guides sorority procedures from, who should be left to stand when there are a limited number of seats, to not allowing non-sorority members to break stroll lines and leaving younger members to handle disobliging individuals. The display of deference can appear to non-members, including student affairs practitioners, as intentional isolation and extremely standoffish. The perceived aloofness has led to a lack of support from student affairs practitioners (Kimbrough, 2003). Inadequate understanding of NPHC sororities also leads to perceived aloofness. The study findings demonstrate that while Black, NPHC sorority women advanced academically, their support most often came from members of the NPHC.

\section{Comprehensive Understanding}

Lacking a comprehensive understanding of NPHC sororities does not violate student affairs policy. However, the assumption that students in the sorority will support their members does not absolve the university of supporting the student and sorority member. When student affairs practitioners fail to provide opportunities for engagement and academic support with sorority members and non-sorority members, an opportunity to partake in informal interactional interactions, which will increase diversity experiences is wasted (Hurtado et al., 1999). Additionally, an objective of student affairs is to bring 
together sorority and non-sorority members (Kimbrough, 2003) to increase engagement among the two populations, which then increases academic achievement and civic engagement (Bowman, 2011). For ideal undergraduate interactions and experiences, student affairs practitioners should consider intentional programs such as service activities, study sessions, and educational forums with both members and non-members. National Pan-Hellenic Council members strive for academic achievement and can be a positive influence on members of other NPHC sororities and non-NPHC persons.

The findings may foster increased understanding of the perceptions, attitudes, and lived experiences of Black, sorority women resulting in changes to the policies and practices of student affairs practitioners. The findings may foster increased understanding of the perceptions, attitudes, and lived experiences of Black, sorority women.

Diversity within the undergraduate student population, no matter the sorority affiliation or lack thereof, yields meaningful civic engagement experiences by creating environments, opportunities, events, and situations that engage at different levels (Manikowske et al., 2013).

\section{Recommendations for Future Research}

Research studies that focus on perceptions, attitudes, and lived experiences of Black, NPHC sorority members relating to their understanding of academic achievement and civic engagement have not been found. The literature is skewed by Eurocentric standards and is focused on non-NPHC sororities. The findings from the study have begun to examine the experiences of Black, NPHC sorority members at an HBCU. As 
such, further research examining the experiences of Black, NPHC sorority women at HBCUs should conducted.

Further exploration of the experiences of Black, NPHC sorority members at other HBCUs and PWIs are necessary if Black sororities are to be successfully integrated into the global campus communities. These are not social organizations, but founded on rich history, provide socio-cultural support in hostile environments because of supremacist ideologies, whether rooted in patriarchy or race.

National Pan-Hellenic Council graduate chapters welcome both members initiated at the undergraduate level, and new members initiated in the graduate chapter. The women will have varying Chapter and life experiences, as graduate members assume advisory roles they can potentially expand the scope of academic achievement and civic engagement in relation to undergraduate members (Kimbrough, 2003). The expectation upon graduation is that undergraduate members join the local graduate chapter of their respective organization. Further qualitative research can expand understanding and potentially assist in adequate advising of undergraduate members.

The study discusses prophytes' understanding of academic achievement and civic engagement. However, there is value in seeking to understand neophytes in the same manner. The NPHC sororities do not accept members until they obtain at least sophomore credits. Thus, a survey, phenomenology, or a longitudinal study could be done of those interested in NPHC sororities. A better understanding of first year student motivation, level of civic engagement, and academic achievement, would offer insight about potential sorority members. The initial findings can then be compared to their 
progress as they continue their studies, comparing those that became members to those that did not. Further research will potentially assist sorority members at the undergraduate and graduate levels, student affairs practitioners, and advisors in selection of new members.

Findings of the study are not exhaustive, and reflect perceptions, attitudes, and lived experiences of 13 Black, NPHC sorority members at four different HBCUs. Future research that focuses on the experiences of Black, NPHC sorority members at HBCUs can build on the findings of the study.

\section{Limitations of the Study}

Findings of the study should be considered in the context of certain limitations. The Black, NPHC Sorority women in the study had different experiences within their sorority, as a result of their years of membership and prophyte status. Participants' variance in years of membership and prophyte status might yield different findings at HBCUs of varying sizes. Smaller HBCUs bring forth smaller chapters and intimate interactions. Conversely, larger HBCUs yield larger chapters with varying levels of intimacy. 
All the participants in the study attended different HBCUs. Historically Black Colleges and Universities are not monolithic or static, and can yield heterogeneous findings. Narrowing the focus to one specific HBCU may produce different findings from my study because of the use of participants, from four HBCUs.

\section{Summary}

Chapter 5 concludes the study with responses to the research questions, relationship to the theoretical framework, implications for practice, recommendations for future research, and limitations of the study. The thematic analysis study was to gather insight into perceptions, attitudes and lived experiences of Black, NPHC sorority members at HBCU about academic achievement and civic engagement.

Four themes emerged from the data collected through participant interviews. The themes were support, academic intention, service, and social awareness. The CoP theory provided insight into the lived experiences and understandings of Black, sorority women. For Black, sorority members seeking to find other like-minded women in NPHC, their experiences at HBCUs should be that of support and encouragement, specifically as it relates to academic and civic prowess.

The study provided implications for practitioners in higher education, such as the need to understand the historical significance, to advise these groups in a more comprehensive manner, and to identify sorority Interests prior to membership for optimal outcomes. The study findings have implications for future research such as examining the experiences of graduate chapter members caused by life occurrences. In addition, there are implications for support and resources, offered to help these women navigate 
both student life and sorority membership. It is recommended that future researchers

continue to examine the experiences of Black, NPHC sorority women, in order to inform

higher education practitioners to better assist with their growth and development.

\section{REFERENCES}

Acauave, L. A., \& Edmonds Crewe, S. (2012). International programs: Advancing human rights and social justice for African American students. Journal of Social Work Education, 48, 763-784. doi:10.5175/ JSWE.2012.20110013

Adams, T. A. (2014). The Pan-African studies effect and its impact on undergraduate students. Journal of Pan African Studies, 7, 23-37.

Andolina, M. W., Jenkins, K., Zukin, C., \& Keeter, S. (2003). Habits from home, lessons from school: Influences on youth civic engagement. Social Education, 67, 275280. Retrieved from http://journals.cambridge.org/download.php?file=/PSC/PSC36_02/S10490965030 0221Xa.pdf\&code $=$ df2c6b7eaa35eb235d1724b76fbc7feb

Allen, W. R. (1992). The color of success: African-American college student outcomes at predominantly White and historically Black colleges. Harvard Educational Review, 6(2), 26-44.

Alpha Kappa Alpha Sorority, Inc. (2014). History. Retrieved from http://www.aka1908.com/about/history

Alvarez, P. L., Cabacungan, E. C., Jobson, J. E., \& Kudera, D. L. (1998). The effects of fraternity involvement. Journal of the Indiana University Student Personnel Association, 1998, 14-23. Retrieved from http://portal.education.indiana.edu/Portals/32/The Effects.pdf

American Diabetes Association. (2014, October). Treatment and care for African Americans. Retrieved from http://www.diabetes.org/living-withdiabetes/treatment-and-care/high-risk-populations/treatment-africanamericans.html

American Psychological Association. (2015). Civic engagement. Retrieved from http://www.apa.org/education/undergrad/civic-engagement.aspx 
Armfield, F. L., Bradley, S. M., Clarke, K. I., Sr., \& Parks, G. S. (2011). Defining the "alpha" identity. In G.S. Parks \& S. M. Bradley (Eds.), Alpha phi alpha: A legacy of greatness, the demands oft transcendence (pp. 23-49). Lexington, KY: University Press of Kentucky.

Asel, A. M., Seifert, T. A., \& Pascarella, E. T. (2009). The effects of fraternity/sorority membership on college experiences and outcomes: A portrait of complexity. Oracle: The Research Journal of the Association of Fraternity/Sorority Advisors, 4, 1-15.

Astin, A. W. (1984). Student involvement: A developmental theory for higher education. Journal of College Student Personnel, 25, 297-308.

Baier, J., \& Whipple, E. (1990). Greek values and attitudes: A comparison with independents. NASPA Journal, 28, 43-53.

Baird, W.A. (1915). Baird's manual of American college fraternities. (Volume 8). California: G. Banta Company.

Bandura, A. (1995). Exercise of personal and collective efficacy in changing societies. In A. Bandura (Ed.), Self-efficacy in changing societies (pp. 1-45). New York, NY: Cambridge University Press.

Bates, W. (2015). Grand polemarch's special message: Incident at UVA. Retrieved from http://www.kappaalphapsi1911.com/?page=GPM_UVA\&hhSearchTerms="marte se and johnson"

Bean, J. P. (1980). Dropouts and turnover: The synthesis and test of a causal model of student attrition. Research in Higher Education, 12, 155-187.

Becker, P., \& Dhingra, P. (2001). Religious involvement and volunteering: Implications for civil society. Sociology of Religion, 62, 315-355.

Belasco, A. S., \& Trivette, M. J. (2015). Aiming low: Estimating the scope and predictors of postsecondary undermatch. Journal of Higher Education, 86, 233-263.

Berkowitz, A., \& Padavic, I. (1999). Getting a man or getting ahead: A comparison of white and black sororities . Journal of contemporary ethnography, 27, 530557. Retrieved from http://www.coss.fsu.edu/sociology/sites/coss.fsu.edu.sociology/files/1999_Berko witz_Padavic_Getting_A_Man.pdf

Bernard, M. (2013). Despite the tremendous risk, African American women marched for suffrage, too. Washington Post. Retrieved 1 October 2017, from 
https://www.washingtonpost.com/blogs/she-the-people/wp/2013/03/03/despitethe-tremendous-risk-african-american-women-marched-for-suffragetoo/?utm_term=.15d7f0d $3 \mathrm{f} 882$

Blalock, R. (2011, October 16). Fraternity brothers helped make king monument a reality. CNN: US edition. Retrieved from http://www.cnn.com/2011/10/14/opinion/blalock-king-monument-history/

Boggs, D. L., Rocco, T., \& Spangler, S. (1995). A framework for understanding older adults' civic behavior. Educational Gerontology, 21(5), 449-465. Retrieved from http://content.ebscohost.com.ezproxy.fiu.edu/ContentServer.asp?T=P\&P=AN\&K $=9508090094 \& S=R \& D=a 9 h \& E b s c o C o n t e n t=d G J y M N H r 7 E S e p q 84 y 9 f w O L C m r$ 02ep7RSrqy4SbWWxWXS\&ContentCustomer=dGJyMPGutk6wp7BNuePfgeyx 44Dt6fIA

Bok, D. (2006). Our underachieving colleges. Princeton, NJ: Princeton University Press.

Bonner, F. A. (2006). The historically black greek letter organization: Finding a place and making a way. Black History Bulletin, 69(1), 17-21. Retrieved from http://drfredbonner.com/wp-content/uploads/2012/09/Black_History.pdf

Bowman, N. A. (2011). Promoting participation in a diverse democracy: A meta-analysis of college diversity experiences and civic engagement. Review of Educational Research, 81(1), 29-68. doi:10.3102/0034654310383047

Boyer, E. L. (1994). Creating the new American college. The Chronicle of Higher Education, 40(27), A48.

Brandt, J., \& Bohnel, S. (2015, April 15). Protest after racial slur at Greek event. The Temple News. Retrieved from http://temple-news.com/news/protest-after-racialslur-at-greek-event/

Braunsberger, K., \& Flamm, R. (2013). A mission of civic engagement: Undergraduate students working with nonprofit organizations and public sector agencies to enhance societal wellbeing. Voluntas: International Journal of Voluntary \& Nonprofit Organizations, 24(1), 1-31. doi:10.1007/s11266-012-9289-6

Bringle, R. G., Hatcher, J. A., \& Holland, B. (2007). Conceptualizing civic engagement: Orchestrating change at a metropolitan university. Metropolitan Universities, 18(3), 57-74. 
Bringle, R., \& Steinberg, K. (2010). Educating for informed community involvement. American Journal and Community Psychology, 46, 428-441. doi:10.1.7/s10464010-9340-y

Broadbent. H. (2015, October). About. Retrieved from http://www.hydeiabroadbent.com/p/about.html

Brown J.S., \& Duguid, P. (1991). Organizational learning and communities-of-practice: Toward a unified view of working, learning, and innovation. Organization Science. 1991(2), 40-57. doi: 10.1287/orsc.2.1.40.

Brown, T. L., Parks, G. S., \& Phillips, C. M. (2005). African American fraternities and sororities: The legacy and the vision. Lexington, KY: The University Press of Kentucky.

Burkholder, P. (2014). A content means to a critical thinking end: Group quizzing in history surveys. History Teacher, 47, 551-578.

CAAP student guide. (2010). American College Testing. Retrieved from http://www.nccu.edu/formsdocs/proxy.cfm?file_id=1668

Carter, D. F. (1999). The impact of institutional choice and environment on AfricanAmerican and White student's degree expectations. Research in Higher Education, 40, 17-41.

Carter, J. (2015, January 13). Canceled 'sorority sisters' shows where bglo power, influence is needed most. HBCU Digest. Retrieved from http://www.hbcudigest.com/articles/0115/canceled-sorority-sisters-shows-wherebglo-power-influence-is-needed-most.html

Center for the Study of the College Fraternity. (2010). Publications. Retrieved from http://www.indiana.edu/ cscf/publications.htm

Chandler, D. L. (2013, November 7). Record number of lynchings reported on this day in 1888 \& 1906. News One. Retrieved from http://newsone.com/2760834/recordnumber-of-lynchings-reported-on-this-day-in-1888-1906/

Chickering, A. W. (2006). Strengthening spirituality and civic engagement in higher education. Journal of College \& Character, 8(1), 1-5.

Chong, D., \& R. Rogers. (2005). Racial solidarity and political participation. Political Behavior 27, 347-374. 
CNN. (Producer). (2015, May 5). Burnett didn't intend to imply sorority was a gang [Video file]. Retrieved from https://www.youtube.com/watch?v=XGvYyX9al9g

Collins, P.H. (2000). Black feminist thought: Knowledge, consciousness, and the politics of empowerment. ( $2^{\text {nd }}$ ed.). New York: Routledge.

Concepts, L. (2013). Academic support definition. The glossary of education reform. Retrieved from http://edglossary.org/academic-support/

Costa, P. T., \& McCrae, R. R. (1992). NEO PI-R: Professional manual: Revised NEO PI$R$ and NEO-FFI. Florida: Psychological Assessment Resources, Inc.

Creswell, J. W. (1998). Qualitative inquiry and research design: Choosing among five designs. Thousand Oaks, CA: Sage.

Creswell, J. W. (2003). Research design: Qualitative, quantitative, and mixed methods approaches. ( $2^{\text {nd }}$ ed.). Thousand Oaks, CA: Sage Publications.

Creswell, J. W. (2005). Educational research planning, conducting and evaluating quantitative and qualitative research ( $2^{\text {nd }}$ ed.). Upper Saddle River, NJ: Pearson Prentice Hall.

Crow, L.D., \& Crow, A. 1969). Adolescent development and adjustment. United States: Mc Grow-Hill Book Company.

Davies, S., Lubelska, C., \& Quinn, J. (1994). Changing the subject: Women in higher education. Bristol, PA: Taylor and Francis.

Davis, M., Dias-Bowie, Y., Greenberg, K., Klukken, G., Pollio, H. R., Thomas, S. P., \& Thompson, C. L. (2004). A fly in the buttermilk: Descriptions of university life by successful Black undergraduate students at a predominately White southeastern university. The Journal of Higher Education, 420-445.

Delta Sigma Theta Sorority, Inc. (2015). Program expansion: 1931-1955. Retrieved from http://highbanktexashistory.com/Delta-Sigma-Theta.html

DeLyser, D. (2001). “Do you really live here?” Thoughts on insider research. Geographical Review, 91(1), 441-453.

Demeules, J., \& Hamer, B. (2013). Retaining young student parents: A growing challenge. About Campus, 18(4), 22-25. doi:10.1002/abc.21127 
Dewey, J. (1916). Democracy and education: An introduction to the philosophy of education. New York, NY: The Macmillan company.

Droege, J. R., \& Ferrari, J. R. (2012). Toward a new measure for faith and civic engagement: Exploring the structure of the FACE Scale. Christian Higher Education, 11(3), 146-157. doi:10.1080/15363751003780852

Drezner, N.D. (2011). The influence of philanthropy on American higher education. ASHE Higher Education Report, 37(2), 17-26.

Duke University. (2015). Duke engage: About. Retrieved from http://dukeengage.duke.edu/about-dukeengage

Education Commission of the States. (2004). Completion. Retrieved from http://www.ecs.org/html/issue.asp.

Emler, N., \& Fraser, E. (1999). Politics: the education effect. Oxford Review of Education, 25(1\&2), 251- 272.

Etta, E., Esowe, D., \& Asukwo, O. (2016). African communalism and globalization. African Research Review, 10(3), 302-316. Retrieved from https://www.ajol.info/index.php/afrrev/article/view/137045/126539

Eunyoung, K., \& Hargrove, D. T. (2013). Deficient or resilient: A critical review of Black male academic success and persistence in higher education. Journal of Negro Education, 82(3), 300-311.

Eyewitness. (2017). Confrontations for justice. Retrieved from https://www.archives.gov/exhibits/eyewitness/html.php?section=2

Fantz, A., \& Botelho, G. (2015, April 29). What we know, don't know about Freddie Gray's death. CNN U.S. Retrieved from http://www.cnn.com/2015/04/22/us/baltimore-freddie-gray-what-we-know/

Fear, F. A., Rosaen, C. L., Bawden, R. J., \& Foster-Fishman, P. G. (2006). Coming to critical engagement: An autoethnographic exploration. Lanham, MD: University Press of America.

Flowers, J. (1998). Improving female enrollment in tech Ed. The Technology Teacher, $58(2), 21-25$. 
Fox, L. R. D. (2015, April 29). Cnn reporter mistakes zeta phi beta sorority members for the crips. Madamenoire. Retrieved from http://madamenoire.com/529842/zetaphi-beta/

Freire, P. (1970). Pedagogy of the oppressed. New York: Herder and Herder.

Fries-Britt, S. (1997). Identifying and supporting gifted African American men. New Directions for Student Services, 8, 65-80.

Fries-Britt, S., \& Griffin, K. (2007). The Black box: How high-achieving blacks resist stereotypes about Black Americans. Journal of College Student Development, $48,509-524$.

Gardner, G. (2002). Invoking the spirit: Religion and spirituality in the quest for a sustainable world (Worldwatch Paper No.164). Washington DC: Worldwatch Institute.

Gasman, M. (2009, August 25). Obama's agenda for black colleges. Retrieved from https://www.insidehighered.com/views/2009/08/25/gasman

Gentry, R. (2014). Sustaining college students' persistence and achievement through exemplary instructional strategies. Research in Higher Education Journal, 24, 1 $-14$.

Gibson, S., \& Hanes, L. (2003). The contribution of phenomenology to HRD research. Human Resource Development Review, 2, 181-205.

Ginsberg, A. E., Shapiro, J. P., \& Brown, S. P. (2004). Gender in urban education: Strategies for student achievement. New York, NY: Pearson Education.

Grisaffe, B., VanMeter, R., \& Chonko, B. (2016). Serving first for the benefit of others: Preliminary evidence for a hierarchical conceptualization of servant leadership. Journal of Personal Selling \& Sales Management, 36(1), 40-58. https://doi.org/10.1080/08853134.2016.1151303

Grubb, F. (2006), Does going greek impair undergraduate academic performance? American Journal of Economics and Sociology, 65, 1085-1110. doi:10.1111/j.1536-7150.2006.00457.x

Guest, G., Bunce, A., \& Johnson, L. (2006). How many interviews are enough? An experiment with data saturation and variability. Field studies, 18(2), 59-82. doi: $10.1177 / 1525822 \times 05279903$ 
Haak, D. C., HilleRisLambers, J., Pitre, E., \& Freeman, S. (2011). Increased structure and active learning reduce the achievement gap in biology. Science, 332, 1213-1216.

Harper, S. R. (2012). Black male student success in higher education: A report from the National Black Male College Achievement Study. Philadelphia: University of Pennsylvania, Center for the Study of Race and Equity in Education.

Harper, S. R., Byars, L. F., \& Jelke, T. B. (Ed.). (2005). How Black Greek-letter organization membership affects college adjustment and undergraduate outcomes. Lexington, KY: The University Press of Kentucky.

Harper, S. R., \& Kuykendall, J. A. (Eds.). (2012). Institutional efforts to improve Black male student achievement: A standards-based approach. Change, 44(2), 23-29. doi:10.1080/00091383.2012.655234

Harper, S., \& Quaye, S. (2009). Student engagement in higher education: Theoretical perspectives and practical approaches for diverse populations. New York: Routledge.

Harrell, A. (2012). Nphc awards packet (Unpublished raw data). Student Affairs, Hampton University, Hampton, VA.

Hartley, M.T. (2011). Examining the relationships between resilience, mental health, and academic persistence in undergraduate college students. Journal of American College Health, 59, 596-604.

Harvey, W. B. (2003). Minorities in higher education: 2002-2003 annual status report. Washington, DC: American Council on Education.

Hayek, J. C., Carini, R. M., O’Day, P. T., \& Kuh, G. D. (2002). Triumph or tragedy: Comparing student engagement levels of members of Greek-letter organizations and other students. Journal of College Student Development, 43, 643-63.

Haynes, R. V. (1973). The Houston mutiny and riot of 1917. The Southwestern historical quarterly, 76, 418-439). Retrieved from http://www.studythepast.com/civilrightsundergraduate/materials/houston_riot_of_ 1917.pdf

HBCU Digest. (2015, May 12). Prairie view voters to decide in historical town-gown divide. $H B C U$ Digest. Retrieved from http://hbcudigest.com/post/118832835971/developing-hbcu-communities 
Hernandez, D. (2002, September 24). Suit alleges hazing in death. Los Angeles Times. Retrieved from http://articles.latimes.com/2002/sep/24/local/me-high24

Heskett, C. (2015, March 18). University student, honor committee member Martese Johnson arrested. The cavalier daily. Retrieved from http://www.cavalierdaily.com/article/2015/03/university-student-honorcommittee-member-martese-johnson-arrested

Hill, M. L. (Producer). (2012). Do Black fraternities \& sororities still matter? [Web series episode]. Huffpost Live. Retrieved from http://live.huffingtonpost.com/r/segment/do-blackfraternities/50341198fe34445ba20006a4

Ho, R. (2015, January 14). Vh1 buries rest of 'sorority sisters' episodes Friday, January 16 [Web log message]. Retrieved from http://radiotvtalk.blog.ajc.com/2015/01/13/vh1-buries-rest-of-sorority-sistersepisodes-friday-january-16/

Howard University School of Social Work. (2013). The urgency of now: Social work and social justice. Retrieved from http://www.howard.edu/schoolsocialwork/docs/Newsletter2013Fall.pdf

Hughey, M. W., \& Parks, G. S. (2011). Black greek-letter organizations 2.0: New directions in the study of African American fraternities and sororities. Jackson, MS: University Press of Mississippi.

Hunter-Gault, C. (1993). In My Place. New York: First Vintage Books Edition.

Hurtado, S., Milem, J. F., Clayton-Pedersen, A. R., \& Allen, W. R. (1999). Enhancing diverse learning environments: Improving the climate for racial/ethnic diversity in higher education (ASHE-ERIC Higher Education Report 26-8). Washington, DC: George Washington University.

Jacoby, B. (2009). Civic Engagement in Higher Education. San Francisco, CA: JosseyBass.

Jackson, C. L., \& Nunn, E. F. (2003). Historically Black colleges and universities. Santa Barbara, CA: ABC-CLIO, Inc.

Jenkins, T. S. (2006). Mr. nigger: The challenges of educating Black males within American society. Journal of Black Studies, 37, 127-155. 
Johnson, C.S. (1972). Fraternities in our colleges. New York: National Interfraternity Foundation.

Johnson, G. H. (2014). African American sororities: Learning to give. Retrieved from http://learningtogive.org/papers/paper172.html

Johnson, T. D. (2006). APHA working with black sororities to prevent diabetes. Nation's Health, 36(9), 5.

Johnson, T. R. (2015, April 26). The political power of the black sorority. The Atlantic. Retrieved from http://www.theatlantic.com/politics/archive/2015/04/loretta-lynchand-the-political-power-of-the-black-sorority/391385/

Johnson, R., Bradley, D., Bryant, L., Morton, D. M., \& Sawyer, D. C., III. (2008). Advising Black Greek-letter organizations: A student development approach. In G. S. Parks (Ed.), Black Greek-letter organizations in the twenty-first century: Our fight has just begun (pp. 437-458). Lexington, KY: University Press of Kentucky.

Kingkade, T. (2015a, March 8). Oklahoma frat boys caught singing 'there will never be a $\mathrm{n} * * * * *$ in sae'. Huff Post College. Retrieved from http://www.huffingtonpost.com/2015/03/08/frat-racist-saeoklahoma_n_6828212.html

Kingkade, T. (2015b, March 18). Black uva student Martese Johnson bloodied during arrest by state liquor agents. Huff Post College. Retrieved from http://www.huffingtonpost.com/2015/03/18/martese-johnson-uvaarrest_n_6896756.html

Kimbrough, W. M. (1995). Self-assessment, participation, and value of leadership skills, activities, and experiences for Black students relative to their membership in historically Black fraternities and sororities. Journal of Negro Education, 64(1), 63-74.

Kimbrough, W. M. (2003). Black Greek 101: The culture, customs, and challenges of black fraternities and sororities. Cranbury, NJ: Associated University Presses.

Kimbrough, W. M. (2005). Should black fraternities and sororities abolish undergraduate chapters? About Campus: Enriching the student learning experience, 10(4), 2729. Retrieved from http://www.readcube.com/articles/10.1002/abc.140?locale=en. 
Kimbrough, W.M. (2009). The membership intake movement of historically Black Greek-letter organizations. NASPA Journal, 46(4), 603-613.

Komarraju, M., Karau, S. J., Schmeck, R. R., \& Avdic, A. (2011). The big five personality traits, learning styles, and academic achievement. Personality and Individual Differences, 51(4), 472-477. doi: 10.1016/j.paid.2011.04.019

Kuh, G. D., Kinzie, J., Schuh, J. H., \& Whitt, E. J. (2011). Fostering student success in hard times. Change, 43(4), 12-19. doi:10.1080/00091383.2011.585311

Kunjufu, J. (1997). Black college student's survival guide. Chicago, IL: African American Images.

Kyriacou, C., \& Kato, Y. (2014). Original Article: Undergraduate students' motives towards volunteer civic engagement in England and Japan. Psychology of Education Review, 38(1), 33-39.

Landry, C. C. (2002). Retention of women and people of color: Unique challenges and institutional responses. Journal of College Student Retention: Research, Theory \& Practice, 4(1), 1-14.

Lave, J., \& Wenger, E. (1991). Situated learning: Legitimate peripheral participation. New York, NY: Cambridge University Press.

Lei, P., Bassiri, D., \& Schultz, E. M. (2001). Alternatives to the grade point average as a measure of academic achievement. Retrieved from http://files.eric.ed.gov/fulltext/ED462407.pdf

Lenghi, M. (2015, April 29). Hundreds attend Baltimore town hall meeting to curb violence. WUSA9. Retrieved from http://www.wusa9.com/story/news/local/maryland/2015/04/29/baltimore-townhall-meeting-protests-riots/26557419/

Lewis, J. (2012, March 8). Congressmen John Lewis. Retrieved from http://johnlewis.house.gov/

Lewis, J. (2015, January 16). Op-ed john lewis tells his truth about 'selma'. La Times. Retrieved from http://www.latimes.com/opinion/op-ed/la-oe-lewis-selma-movie20150119-story.html

Livingston, R. W., Rosette, A. S., \& Washington, E. F. (2012). Can an agentic black woman get ahead? The impact of race and interpersonal dominance on perceptions of female leaders. Psychological Science, 23, 354-58. 
Lowe, J., \& Gayle, V. (2007). Exploring the work/life/study balance: The experience of higher education students in a Scottish further education college. Journal of Further and Higher Education, 31, 225-238.

doi.org/10.1080/03098770701424942

Lowe, J. S., \& Shipp, S. C. (2014). Black church and Black college community development corporations: Enhancing the public sector discourse. Western Journal of Black Studies, 38, 244-259.

Lucas, R. (1988, March 01). It's greek to them how five fraternity brothers viewed 'school daze'. [Daily News]. Retrieved from http://articles.philly.com/1988-0301/news/26275146_1_black-greek-letter-alpha-phi-alpha-fraternity-black-greekorganizations nphchq.org

Manikowske, L., \& Sunderlin, S. R. (2013). Clothing and Connections: A partnership for civic engagement and service learning. Delta Kappa Gamma Bulletin, 79(3), 4649.

Markus, G., Howard, J., \& King, D. (1993). Integrating community service and classroom instruction enhances learning: Results from an experiment. Educational Evaluation and Policy Analysis, 15: 410-419.

Martin, A. J., Wilson, R., Liem, G. D., \& Ginns, P. (2013). Academic momentum at university/college: Exploring the roles of prior learning, life experience, and ongoing performance in academic achievement across time. Journal of Higher Education, 84, 640-674.

Maryland State Archives. (2017). Baltimore City, Maryland: Executive branch. Stephanie C. Rawlings-Blake. Retrieved from http://msa.maryland.gov/msa/mdmanual/36loc/bcity/former/html/msa14500.html

Maslin, J. (1988, February 12). School daze (1988). The New York Times. Retrieved from http://www.nytimes.com/movie/review?res=940DE5DD1639F931A25751C0A96 E948260

Mathiasen, R. E. (2005). Moral development in fraternity members: A case study. College Student Journal, 39, 242-253.

Maxfield, J. (2014, September 14). Why going to college is important. USAToday. Retrieved from 
http://www.usatoday.com/story/money/personalfinance/2014/09/14/why-goingto-college-is-important/15525805/

Mbajekwe, W. (2006). The future of historically black colleges and universities: Ten presidents speak out. Jefferson, NC: McFarland \& Company, Inc. Publishers.

Mbuva, J. M. (2011). An examination of student retention and student success in high school, college, and university. Journal of Higher Education Theory and Practice, 11(4), 92-101.

McClure, S. M. (2006). Voluntary association membership: Black Greek men on a predominantly White campus. Journal of Higher Education, 77, 1036-1057.

McGrath, M., \& Braunstein, A. (1997). The prediction of freshmen attrition: An examination of the importance of certain demographic, academic, financial, and social factors. College Student Journal, 31, 396-408.

Miller, D.C., \& Salkind, N.J. (2002). Handbook of research design and social measurement. ( $6^{\text {th }}$ ed.). USA: SAGE Publications, Inc.

Mlyn, E. (2013). Higher education and civic engagement: The example of DukeEngage. Change, 45(5), 36-42. doi:10.1080/00091383.2013.824349

Montague, M. J., \& Tan, L. M. (2016). Applied psychology: 2015 Asian Congress of Applied Psychology (ACAP 2015). Singapore: World Scientific.

Moustakas, C. (1994). Phenomenological research methods. London: Sage

NAEP. (2017). Are the nation's twelfth-graders making progress in mathematics and reading? Retrieved from http://www.nationsreportcard.gov/reading_math_g12_2013/.

NASP. (2017). Aiding student affairs professionals in higher education. Retrieved from from https://www.naspa.org/about

Nation of Islam. (2015). About the million man march. Retrieved from http://www.noi.org/about-million-man-march/

National Pan-Hellenic Council, Inc. (2014). Standards. Washington, DC: National association of student personnel administrators. Retrieved from http://www.naspa.org/constituent-groups/kcs/fraternity-and-sorority/resources 
National Survey of Student Engagement. (2015). Survey instrument. Retrieved from http://nsse.iub.edu/html/survey_instruments.cfm

Nickols, F. (2003). Communities of practice: What's it like inside? Retrieved from http://waterwiki.net/images/temp/4/49/20060411222400!CoPInside.pdf

Nordrum, A. (2015, March 23). Martese Johnson uva arrest crowdfunding: Money raised for university of Virginia student's medical, legal expenses. International Business Times. Retrieved from http://www.ibtimes.com/martese-johnson-uvaarrest-crowdfunding-money-raised-university-virginia-students- 1856620

NPHC. (2012). Member organizations. Decatur, GA: NPHC Headquarters.

NPHC. (2014). Statement against sorority sisters. Retrieved from http://www.nphchq.org/nphc-statement-against-sorority-sisters/

Office on Women's Health Department of Health and Human Services. (2010, May 18). Minority women's health. Retrieved from http://www.womenshealth.gov/minority-health/african-americans/diabetes.html.

Omilami, E. (2014). This is not a post racist era. Retrieved from https://civilrightsagenda.wordpress.com/2014/11/26/this-is-not-a-post-racist-eraby-elisabeth-omilami-hosea-feed-the-hungry-homeless/

Parker, P. (2012). Greek life \& philanthropy. Retrieved from http://www.npcatalyst.com/wpcontent/uploads/2012/02/GreekLifeandPhilanthropy-study.pdf

Parks, G. (2014, April 2). The end of bglos [Web log message]. Retrieved from http://gregoryparks.net/wordpress/?p=63

Parks, G., \& Spencer, D. (2013). Student affairs professionals, black “greek” hazing, and university civil liability. College Student Affairs Journal, 31(2), 125-138. Retrieved from http://gregoryparks.net/articles/1391833524004-Parks\&Spencer (1).pdf

Pascarella, E., Edison, M., Whitt, E., Nora, A., Hagedorn, L., \& Terenzini, P. (1996). Cognitive effects of Greek affiliation during the first year of college. NASPA Journal, 33(4), 242- 259.

Pascarella, E. T., Flowers, L., \& Whitt, E. J. (2009). Cognitive effects of greek affiliation in college: Additional evidence. NASPA Journal, 46(3), 447-468. Retrieved from 
http://www.education.uiowa.edu/docs/default-source/cruepublications/NASPAJournal09vol46-3.pdf?sfvrsn=0

Pascarella, E. T., \& Terenzini, P. T. (1991). How college affects students: Findings and insights from twenty years of research. San Francisco, CA: Jossey-Bass, Inc.

Patterson, G., Dunston, Y., \& Daniels, K. (2013). Extreme Makeover: Preserving the HBCU Mission Through Service Learning Pedagogy. Journal of African American Studies, 17, 154-161. doi:10.1007/s12111-011-9192-z

Patton, M.Q. (1990). Qualitative evaluation and research methods. (2nd ed.). Newbury Park, CA: Sage

Patton, M.Q. (2002). Qualitative research and evaluation methods. California: Sage Publications.

Patton, L.D., Bridges, B.K., Flowers, L.A. (2011). Effects of Greek affiliation on African American students' engagement: Differences by college racial composition. College Student Affairs Journal, 29(2), 113-123

Peralta, R. L., Steele, J. L., Nofziger, S., \& Rickles, M. (2010). The impact of gender on binge drinking behavior among US college students attending a Midwestern university: An analysis of two gender measures. Feminist criminology, 5(4), 355379.

Pew Research Center. (2010). Religion among the millennials: Introduction and overview. Retrieved from http://www.pewforum.org/2010/02/17/religion-amongthe-millennials/

Pharr, S. (1996). In the time of the right: Reflections on liberation. Berkeley, CA: Chardon Press.

Pharr, S. (1997). Homophobia: A weapon of sexism. Berkeley, CA: Chardon Press.

Phi Beta Sigma, Zeta Delta. (2015). The fraternity of firsts. Retrieved from http://www.rso.wmich.edu/phibetasigma/first.htm

Pike, G. (2000). The influence of fraternity or sorority membership on students' college experiences and cognitive development. Research in Higher Education, 41, 117139. 
Pike, G. (2003). Membership in a fraternity or sorority, student engagement, and educational outcomes at AAU public research universities. Journal of College Student Development, 44, 369-382.

Porter, S. C. \& Parks, G.S. (2011). The realities and consequences of unconscious antiBlack bias among BGLO members. In M. W. Hughey and G. S. Parks. Jackson (Eds.), Black Greek-letter Organizations 2.0: New Directions in the Study of African American Fraternities and Sororities (pp. 49-66). Jackson, MS: University Press of Mississippi.

Prevatt, F., Huijun, L., Welles, T., Festa-Dreher, D., Yelland, S., \& Jiyoon, L. (2011). The Academic Success Inventory for college students: Scale development and practical implications for use with students. Journal of College Admission, 211, 26-31.

Rasmussen, F. N. (2012, February 11). 1908 Illinois race riot was impetus behind founding of the NAACP. The Baltimore Sun. Retrieved from http://articles.baltimoresun.com/2012-02-11/news/bs-md-backstory-naacp20120212_1_civil-rights-race-riot-william-english-walling

Rexeisen, R. J., \& Garrison, M. J. (2013). Closing the Loop in Assurance of Learning Programs: Current Practices and Future Challenges. Journal of Education for Business, 88, 280-285. doi:10.1080/08832323.2012.697929

Rhodan, M. (2015, April 27). Loretta lynch sworn in as 83rd attorney general. TIME. Retrieved from http://time.com/3836789/loretta-lynch-swearing-in/

Ross, L. C. (2000). The divine nine: the history of African American fraternities and sororities. New York, NY: Kensington Publishing Corp.

Ross, M. J. (Ed.). (2003). Success factors of young African American women at a historically Black college. Westport, CT: Praeger Publishers.

Rubin H., \& Rubin, I. (2005) Qualitative interviewing the art of hearing data. Thousand Oaks, CA: Sage.

Saltmarsh, J. (2005). The civic promise of service learning. Liberal Education, 91(2), 5055. Retrieved from https://eric.ed.gov/?id=EJ697354

Sanchez, Brenna. (2004). Burke, Yvonne Braithwaite 1932 -. Retrieved from http://www.encyclopedia.com/doc/1G2-3430800015.html 
Sax, L. J. (2004). Citizenship development and the American college student. New Directions for Institutional Research, 122, 65-80. doi:10.1002/ir.110

Schleifer, T. (2015, April 28). Baltimore mayor struggles in response to riots. $C N N$ Politics. Retrieved from http://www.cnn.com/2015/04/23/politics/stephanierawlings-blake-freddie-gray-baltimore/

Schwartz, R. A., \& Washington, C. M. (1999). Predicting academic success and retention for African American women in college. Journal of College Student Retention, 1(2), 177-190.

Scott, L. D. (2003). Cultural Orientation and coping with perceived discrimination among African American youth. Journal of Black Psychology, 29, 235-256.

Seidman, I. (2006). Interviewing as qualitative research: A guide for researchers in education and the social sciences. (3rd ed.). New York: Teachers College Press.

Sigma Gamma Rho Sorority National Education Fund, Inc. (2015). Region nef. Retrieved from http://sigmaswregion.com/region-nef

Spady, W. (1971). Dropouts from higher education: Toward an empirical model. Interchange, 2(3), 38- 62.

Speri, A. (2004). Half of America thinks we live in a post-racial society - The other half, not so much. VICE News. Retrieved from https://news.vice.com/article/half-ofamerica-thinks-we-live-in-a-post-racial-society-the-other-half-not-so-much

Strawhun, A.L., Perry, J.L., \& Lloyd, C.A. (2014). Civic engagement among university students. Journal of Youth Ministry, 12(2), 26-31.

Strayhorn, T.L., \& McCall, F.C. (2012). Cultural competency of Black Greek-letter organization advisors. Journal of African American Studies, 16, 700-715. doi:10.1007/s12111-011-9169-y

SUNY. (2014, October). Suny fast facts. Retrieved from http://www.suny.edu/media/suny/content-assets/documents/FastFacts2014.pdf

Talley, C. P., \& Scherer, S. (2013). The enhanced flipped classroom: Increasing academic Performance with student-recorded lectures and practice testing in a "Flipped" STEM course. Journal of Negro Education, 82, 339-347. 
Taylor, A. (2013, October). Poking and prying with a purpose. Retrieved from https://www.artsjournal.com/artfulmanager/main/poking-and-prying-with-apurpose.php

Teddlie, C., \& Tashakkori, A. (2009). Foundations of mixed methods research: Integrating quantitative and qualitative approaches in the social and behavioral sciences. Thousand Oaks CA: Sage.

Thelin, J. R. (ed.). (2004). A history of American higher education. Baltimore, MD: The Johns Hopkins University Press.

Tross, S.A., Harper, J.P., Osher, L.W., \& Kneodinger, L.M. (2000). Not just the usual cast of characteristics: Using personality to predict college performance and retention. Journal of College Student Development, 41, 323-334.

Trotter, J. (2004). African American fraternal organizations in American history: An introduction. Social Science History, 28(3), 355-366. Retrieved from https://muse.jhu.edu/article/172788/summary

Tuskegee University. (2015). UNCF pre-alumni council. Retrieved from http://www.tuskegee.edu/alumni_friends/uncf_pre-alumni_council.aspx

Innovations in Civic Participation. (2008). Young people's civic engagement in East Asia and the Pacific. Retrieved from UNICEF:

https://www.unicef.org/adolescence/cypguide/files/EAPRO_study_by_Innovation s_in_Civic_Participation.pdf

University of North Carolina at Charlotte. (2011). National pan-hellenic council. Retrieved from http://unccdso.orgsync.com/org/ofsl/NPHC

U.S. Department of Education, (1998). National Center for Education Statistics. Washington, DC: U.S. Department of Education.

U.S. Department of Education. (2013). National Center for Education Statistics. Washington, DC: U.S. Department of Education.

Vogt, W. P. (1999). Dictionary of Statistics and Methodology: A Nontechnical Guide for the Social Sciences. London: Sage.

Wade, R. C. (2000). Beyond charity: Service-learning for social justice. Social Studies and the Young Learner, 12(4), 6-9.

Ward, A., Stoker, H. W., \& Murray-Ward, M. (1996). Educational measurement: Theories and applications. Lanham, MD: University Press of America. 
Weiss, K. G. (2013). Party school: Crime, campus, and community. Boston: Northeastern University Press.

Wenger, E. (1998a). Communities of practice: Learning, meaning, and identity. United Kingdom: Cambridge University Press.

Wenger, E. (1998b). Communities of practice: Learning as a social system. Systems Thinker, 9(5), 2-3.

Wenger, E., McDermott, R., \& Snyder, W. M. (2002). Cultivating communities of practice. Boston: Harvard Business School Press.

Whipple, E. G. (Ed.). (1998). New challenges for Greek letter organizations: Transforming fraternities and sororities into learning communities. San Francisco: Jossey-Bass.

Whipple, E. G. and Sullivan, E. G. (1998), Greek Letter Organizations: Communities of Learners? New Directions for Student Services, 1998, 7-17. doi: 10.1002/ss.8101

White, J. (1990). Black leadership in America . (2 $2^{\text {nd }}$ ed.). Harlow, England: Longman Group UK Limited.

Wilder, D. H., \& McKeegan, H. F. (1999). Greek-letter social organizations in higher education: A review of research. In J. C. Smart (Ed.), Higher education: Handbook of theory and research (pp. 317-366). New York: Agathon.

Wilson, J. (2000). Volunteering. Annual Review of Sociology, 26, 215-240.

Wright, M. B. (2014). Zeta phi beta sorority, incorporated calls for protest through social action. Retrieved from http://www.zphib1920.org/zeta-phi-beta-sororityincorporated-calls-for-protest-through-social-action/

Yates, B. (2007). Integrating doctoral candidates into research teams. In C. Denholm, \& T. Evans (Eds.), Supervising doctorates downunder (pp. 105-

112). Camberwell: ACER Press.

Yin, R. K. (2009). Case study research: Design and methods. $\left(4^{\text {th }}\right.$ ed.). Thousand Oaks, CA: Sage.

Zeta National Educational Foundation, Inc. (2014). Z-NEF. Retrieved from http://www.zpbnef1975.org 
Zeta Phi Beta Sorority, Inc. (2014b). Get engaged. Retrieved from http://www.zphib1920.org/wpcontent/uploads/2014/12/GetEngaged_Overview_Final.pdf

Zeta Phi Beta Sorority, Inc. (2015a). Get engaged. Retrieved from http://www.zphib1920.org/getengaged/

Zeta Phi Beta Sorority, Inc. (2015b). Z-hope. Retrieved from http://www.zphib1920.org/national-programs/z-hope/ 
APPENDICES

APPENDIX A

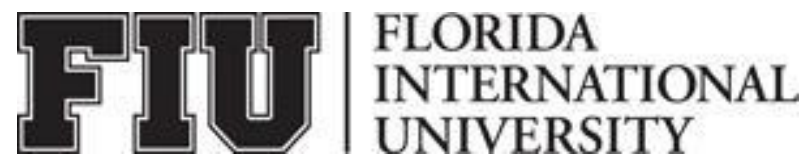

Interview Protocol

Semi- structured Interview Guide

1) Why did you decide to join a sorority?

2) After matriculating into college but prior to your joining an NPHC sorority, what was your understanding of academic achievement?

3) Tell me about a time you received academic assistance from a sorority member.

4) Explain a situation where you felt academically supported by sorority members.

5) After becoming a prophyte, what was your understanding of academic achievement?

6) Prior to your joining an NPHC sorority what was your understanding of civic engagement?

7) How has your sorority membership influenced your sense of social responsibility?

8) How has the sorority made you aware of issues faced by Black people in America?

9) Tell me about a time you engaged in a discussion among sorority members about social injustice.

10) How does your sorority membership influence your actions as it pertains to social injustice?

11) How does your chapter actively seek to achieve their service-oriented goals?

12) How do you personally achieve these service-oriented goals?

13) What leadership roles have you considered since becoming a sorority member?

14) After becoming a prophyte, what was your understanding of civic engagement?

15) What question(s) would you ask if you were doing the interview? 


\section{APPENDIX B}

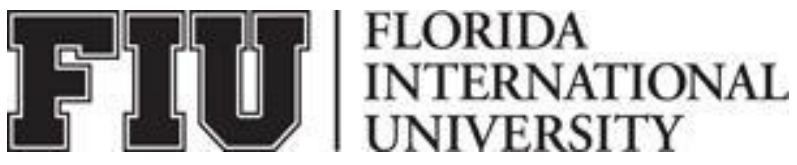

Demographic Survey

Please complete the following:

1. How old are you?

2. What is your major?

3. Do you currently attend an HBCU?

4. Are you a member of an NPHC sorority?

5. Are you a prophyte?

6. Please provide the best email for contact. 


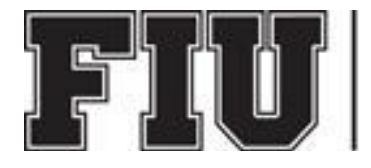

\title{
FLORIDA
}

INTERNATIONAL

UNIVERSITY

\author{
ADULT CONSENT TO PARTICIPATE IN A RESEARCH STUDY \\ An Exploration of Black NPHC Sorority membership as it Relates to Academic \\ Achievement and Civic Engagement
}

\section{PURPOSE OF THE STUDY}

You are being asked to be in a research study. The purpose of this study is to understand the lived experiences of Black NPHC Sorority membership, academic achievement, and civic engagement.

\section{NUMBER OF STUDY PARTICIPANTS}

If you decide to be in this study, you will be one of 12 people in this research study.

\section{DURATION OF THE STUDY}

Your participation will require 1 hour.

\section{PROCEDURES}

If you agree to be in the study, we will ask you to do the following things:

1. You will be asked 16 interview questions. The interview will be audio taped for the purpose of transcribing.

2. You will only be interviewed once. However, you will be contacted after the transcripts are produced to ensure they capture the essence of your experience.

\section{RISKS AND/OR DISCOMFORTS}

There are no known risks involved in this study.

\section{BENEFITS}

While there are no direct benefits to the participants of this study, they data gained can help better the future experience of NPHC sorority members at the collegiate level.

\section{ALTERNATIVES}

There are no known alternatives available to you other than not taking part in this study. However, any significant new findings developed during the course of the research, which may relate to your willingness to continue participation will be provided to you. CONFIDENTIALITY 
The records of this study will be kept private and will be protected to the fullest extent provided by law. In any sort of report we might publish, we will not include any information that will make it possible to identify a subject. Research records will be stored securely and only the researcher team will have access to the records. However, your records may be reviewed for audit purposes by authorized University or other agents who will be bound by the same provisions of confidentiality.

\section{COMPENSATION \& COSTS}

There will be no compensation for participating in this study. In addition, you will not be responsible for any costs to participate in this study.

\section{RIGHT TO DECLINE OR WITHDRAW}

Your participation in this study is voluntary. You are free to participate in the study or withdraw your consent at any time during the study. Your withdrawal or lack of participation will not affect any benefits to which you are otherwise entitled. The investigator reserves the right to remove you without your consent at such time that they feel it is in the best interest.

\section{RESEARCHER CONTACT INFORMATION}

If you have any questions about the purpose, procedures, or any other issues relating to this research study you may contact Canela Eatman at Florida International University 757.328.7270, Ceatm001@ fiu.edu.

\section{IRB CONTACT INFORMATION}

If you would like to talk with someone about your rights of being a subject in this research study or about ethical issues with this research study, you may contact the FIU Office of Research Integrity by phone at 305-348-2494 or by email at ori@ fiu.edu.

\section{PARTICIPANT AGREEMENT}

I have read the information in this consent form and agree to participate in this study. I have had a chance to ask any questions I have about this study, and they have been answered for me. I understand that I will be given a copy of this form for my records.

Signature of Participant

$$
\text { Date }
$$

Printed Name of Participant

Date

Signature of Person Obtaining Consent

Date 


\section{APPENDIX D}

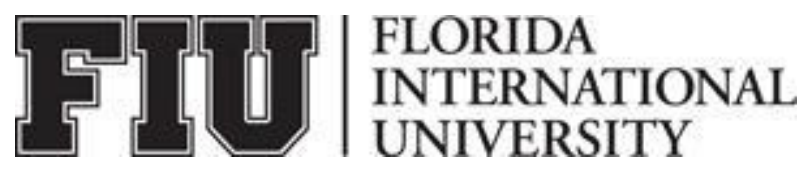

\section{VOLUNTEERS NEEDED FOR}

\section{RESEARCH SURVEY ON}

\section{NPHC Sorority Women}

We are looking for volunteers to participate in an interview about their experience as an NPHC sorority member. As a participant in this study, you will be asked to: recall and explain some memories from your experience as an NPHC sorority member.

If you are interested, please inquire here.

Thank you!

This study has been reviewed and approved by the

Institutional Review Board 
VITA

\section{CANELA UNA ACOSTA EATMAN}

Born, Brooklyn, New York

2002

2005

$2005-2006$

$2006-2008$

$2007-2008$

$2008-2010$

$2010-2015$

$2015-2016$

2016 - Present
Bachelor of Science in Psychology

Hampton University, Hampton, Virginia

Master of Arts in Urban Education: Counseling Pre K- 12

Norfolk State University, Norfolk, Virginia

Hampton University, Hampton, Virginia

Residence Director, Dean of Women

Florida International University, Miami, FL

PEACE Coordinator

Miami Dade College, Miami, FL

College Prep Writing Instructor

College Summit, Washington, DC

Writing Coach

Hampton University, Hampton, VA

Resident Director

Captain Kidd's Learning Center, Hampton, VA

Lead Teacher

Emagination Computer Camps, Salem, NH

Assistant Director

GEAR UP, Waterbury, MD

Teacher/Mentor

Morgan State University, Baltimore, MD

Resident Director 